Uma rede Ethernet on chip parametrizável para aplicações DSP em FPGA

Hélio Fernandes da Cunha Junior 



\title{
Uma rede Ethernet on chip parametrizável para aplicações DSP em FPGA
}

\author{
Hélio Fernandes da Cunha Junior
}

Orientador: Prof. Dr. Vanderlei Bonato

Dissertação apresentada ao Instituto de Ciências Matemáticas e de Computação - ICMC-USP, como parte dos requisitos para obtenção do título de Mestre em Ciências - Ciências de Computação e Matemática Computacional. EXEMPLAR DE DEFESA 
Ficha catalográfica elaborada pela Biblioteca Prof. Achille Bassi e Seção Técnica de Informática, ICMC/USP, com os dados fornecidos pelo(a) autor(a)

\begin{tabular}{|c|c|}
\hline \multirow[t]{3}{*}{ C972r } & $\begin{array}{l}\text { Cunha Junior, Hélio Fernandes da } \\
\text { Uma rede Ethernet on chip parametrizável para } \\
\text { aplicações DSP em FPGA / Hélio Fernandes da Cunha } \\
\text { Junior; orientador Vanderlei Bonato. -- São Carlos, } \\
2015 \text {. } \\
\quad 91 \text { p. }\end{array}$ \\
\hline & $\begin{array}{l}\text { Dissertação (Mestrado - Programa de Pós-Graduação } \\
\text { em Ciências de Computação e Matemática } \\
\text { Computacional) -- Instituto de Ciências Matemáticas } \\
\text { e de Computação, Universidade de São Paulo, } 2015 .\end{array}$ \\
\hline & $\begin{array}{l}\text { 1. Network-on-chip. 2. Ethernet. 3. FPGA. } 4 . \\
\text { DSP. I. Bonato, Vanderlei, orient. II. Título. }\end{array}$ \\
\hline
\end{tabular}


Com o crescimento acelerado da complexidade das aplicações e softwares que exigem alto desempenho, o hardware e sua arquitetura passou por algumas mudanças para que pudesse atender essa necessidade. Uma das abordagens propostas e desenvolvidas para suportar essas aplicações, foi a integração de mais de um core de processamento em um único circuito integrado. Inicialmente, a comunicação utilizando barramento foi escolhida, pela sua vantagem de reuso comparado a ponto a ponto. No entanto, com o aumento acelerado da quantidade de cores nos Systems-on-Chip (SoC), essa abordagem passou a apresentar problemas para suportar a comunicação interna. Uma alternativa que vem sendo explorada é a Network-on-Chip (NoC), uma abordagem que propõe utilizar o conhecimento de redes comuns em projetos de comunicação interna de SoC. Esse trabalho fornece uma arquitetura de NoC completa, configurável, parametrizável e no padrão Ethernet. Os três módulos básicos da NoC, Network Adapter (NA), Link e Switch, são implementados e disponibilizados. Os resultados foram obtidos utilizando o FPGA Stratix IV da Altera. As métricas de desempenho utilizadas para validação da NoC são a área no FPGA e o atraso na comunicação. Os parâmetros disponibilizados são referentes as configurações dos módulos desenvolvidos, considerando características apresentadas de aplicações DSP (Digital Signal Processing). O experimento utilizando dois NAs, dois cores e um Switch precisou de 7310 ALUTs do FPGA EP4SGX230KF40C2ES o que corresponde a $4 \%$ dos seus recursos lógicos. O tempo gasto para a transmissão de um quadro ethernet de 64 Bytes foi de 422 ciclos de clock a uma frequência de $50 \mathrm{MHz}$. 
With the accelerated growth of the complexity of the software and applications that require high performance, hardware and its architecture has undergone a few changes so it could meet that need. One of the proposals and approaches developed to support these applications, was the integration of more than one core processing in a single integrated circuit. Initially, the bus communication architecture was chosen, using for its reuse benefit compared to point-to-point. However, with the cores number increase in Systems-on-Chip (SoC), this approach began to present problems to support internal communication. An alternative that has been explored is the Network-on-Chip (NoC), an approach that proposes to use knowledge of common networks on internal communication projects of SOC. This dissertation focuses is to provide a complete NoC architecture, configurable, customizable and on standard Ethernet. The three NoC basic modules, Network Adapter (NA), Link and Switch, are implemented. The results were obtained using the Stratix IV FPGA. The performance metrics used for NoC validation are silicon area and latency. The available parameters are related to developed modules settings, considering features presented of DSP applications. The experiment using two NA, two cores and one Switch needed 7310 FPGA ALUTs which corresponds to $4 \%$ of their logical resources. The time for the transmission of an ethernet frame of 64 Bytes was 422 clock cycles at $50 \mathrm{MHz}$. 
Abstract $\quad$ iv

Lista de Abreviaturas e Siglas $\quad$ ix

1 Introdução 12

1.1 Contextualização . . . . . . . . . . . . . . . . . . . . . . . . 12

1.2 Objetivo . . . . . . . . . . . . . . . . . . . . . 14

1.3 Justificativa . . . . . . . . . . . . . . . . . . . . . . . . . . . 14

1.4 Organização . . . . . . . . . . . . . . . . . . . . 16

2 Conceitos e implementações de Network on chip 17

2.1 Arquitetura $\mathrm{NoC} \ldots \ldots \ldots \ldots \ldots$

2.1.1 Tipos de arquiteturas $\mathrm{NoC} \ldots \ldots \ldots . \ldots . . \ldots 18$

2.1.2 Módulos básicos da arquitetura NoC . . . . . . . . . . . . . . . 19

2.1.2.1 Link . . . . . . . . . . . . . . . . . . . . . . 19

2.1.2.2 Network Adapter . . . . . . . . . . . . . . . . . 19

2.1.2.3 Switch . . . . . . . . . . . . . . 21

2.1.3 Modo de operação e QoS . . . . . . . . . . . . . . . . . 23

2.1.4 Camadas funcionais de $\mathrm{NoC}$. . . . . . . . . . . . . . . 24

2.2 Estado da arte . . . . . . . . . . . . . . . . . . . . 25

3 Padrão Ethernet IEEE 802.3 28

3.1 Modelo dos serviços providos pelo MAC . . . . . . . . . . . . . . . 29

3.1 .1 Requisição . . . . . . . . . . . . . . . . . . 29

3.1 .2 Indicação . . . . . . . . . . . . . . . . . . . . . . . . 29

3.2 Frame Ethernet . . . . . . . . . . . . . . . . . . . . . . . . 30

3.3 Protocolo MAC . . . . . . . . . . . . . . . . . . . . . . . . 32

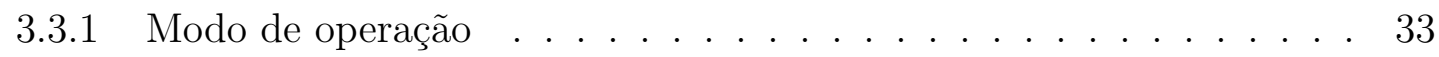

3.3 .2 Procedimento de transmissão e recepção . . . . . . . . . . . . . . . 34

3.4 Media independent interface - MII . . . . . . . . . . . . . . . 36

4 Aplicações e Arquiteturas DSPs $\quad 38$

4.1 Processamento digital de sinais . . . . . . . . . . . . . . . . . 38

4.2 Aplicações DSPs . . . . . . . . . . . . . . . . . . . . . . . . . . . . 39

4.2.1 Características das aplicações DSP . . . . . . . . . . . . . . 40 
4.2 .2 Classes de aplicações DSP . . . . . . . . . . . . . . . . . . . . . . . . . . . . . . . 42

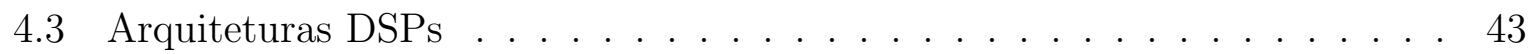

4.3.1 Arquiteturas DSP multicore . . . . . . . . . . . . . 46

4.4 Considerações Finais . . . . . . . . . . . . . . . . . . . . . . . . . 48

5 Implementação, Operação e Resultados da NoC em FPGA 49

5.1 Materiais e métodos . . . . . . . . . . . . . . . . 50

5.1 .1 OpenCore ethernet MAC . . . . . . . . . . . . . 50

5.1 .2 OpenCore MAC layer switch . . . . . . . . . . . . . . 52

5.1 .3 FPGA Altera Stratix IV e Ferramentas . . . . . . . . . . . . . . 52

5.2 Implementação . . . . . . . . . . . . . . . . . . . . . . . . 53

5.2 .1 NA . . . . . . . . . . . . . . . . 53

5.2.1.1 Registradores de configuração . . . . . . . . . . . . . 53

5.2 .1 .2 Buffer Descriptor . . . . . . . . . . . . . . 55

5.2.1.3 Procedimento de transmissão e recepção . . . . . . . . . 56

5.2 .2 Elemento de controle . . . . . . . . . . . . . . . . 57

5.2 .3 Link . . . . . . . . . . . . . . . . . . . . 59

5.2 .4 Switch . . . . . . . . . . . . . . . . 60

$5.2 .4 \quad \mathrm{PLU} \ldots \ldots \ldots \ldots \ldots \ldots$

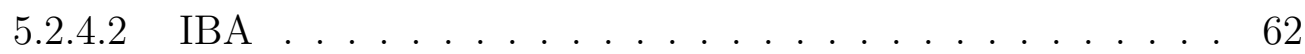

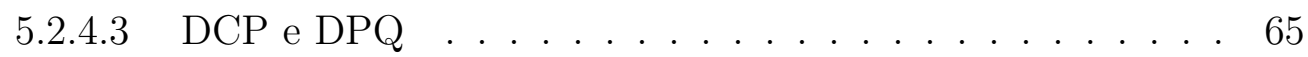

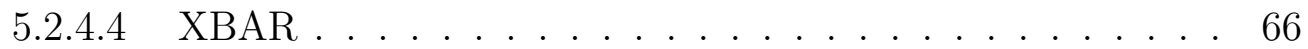

5.2 .5 Arquivo de configuração . . . . . . . . . . . . . . 67

5.3 Rede ethernet on chip parametrizável: características e parâmetros . . . . 69

5.4 Resultados . . . . . . . . . . . . . . . . . . . 71

5.4.1 Métricas de desempenho . . . . . . . . . . . . . . . 71

5.4 Experimentos . . . . . . . . . . . . . . . . 72

5.4 .3 Análise dos resultados . . . . . . . . . . . . . . . 75

6 Conclusões $\quad 77$

6.1 Trabalhos futuros . . . . . . . . . . . . . . . 78

$\begin{array}{lr}\text { Referências } & 83\end{array}$

$\begin{array}{lr}\text { A Protocolo Wishbone } & \mathbf{8 4}\end{array}$

A.1 Protocolo Wishbone . . . . . . . . . . . . . . . . . 84

A.1.1 Sinais do protocolo Wishbone . . . . . . . . . . . . . . . . . 84

A.1.1.1 Sinais do modulo SYSCON . . . . . . . . . . . . 85

A.1.1.2 Sinais comuns das interfaces master e slave . . . . . . . 85

A.1.1.3 Sinais do master . . . . . . . . . . . . . . . . . 86

A.1.1.4 Sinais do slave . . . . . . . . . . . . . . . . . . . 87

A.1.2 Ciclos do Wishbone . . . . . . . . . . . . . . . . . . . . 88

A.1.2.1 Ciclo clássico: leitura . . . . . . . . . . . . . . . . . . 88

A.1.2.2 Ciclo clássico: escrita . . . . . . . . . . . . . . 89

A.1.2.3 Ciclo Rajada incremental: leitura e escrita . . . . . . . . 89 
1.1 Exemplo de comunicações em MPSoC.

1.2 Gráfico de crescimento dos recursos lógicos dos FPGAs nos últimos anos. Fonte: (The Dini Group, 2014) ～. . . . . . . . . . . . . . . . . 15

2.1 Network Adapter. Adaptado de Bjerregaard e Mahadevan (2006) . . . . . 20

2.2 Arquitetura básica de um switch . . . . . . . . . . . . . . . . . 21

2.3 Topologias de NoC . . . . . . . . . . . . . . . . . . . . . . 22

2.4 Fluxo de dado através dos componentes de uma NoC. (Bjerregaard e Mahadevan, 2006) . . . . . . . . . . . . . . . . . . . 24

3.1 Relação do padrão IEEE 802.3 com as camadas do modelo OSI. . . . . . . 28

3.2 Pacote Ethernet. Adaptado de The Institute of Electrical and Electronics Engineers (2012) . . . . . . . . . . . . . . . . . . . . . . . . . . . . . . . 30

3.3 Modelo genérico de um MAC Ethernet . . . . . . . . . . . . . . . . . . 34

3.4 Entrada e saída da sub camada RS. Adaptado de The Institute of Electrical and Electronics Engineers (2012) . . . . . . . . . . . . . 36

4.1 Evolução da demanda de processamento das aplicações, de acordo com o número de instruções por período de amostragem. Adaptado de Karam et al. (2009). . . . . . . . . . . . . . . . . . . . . 41

4.2 Arquitetura do processador DSP multicore TNETV3020 da TI (Karam et

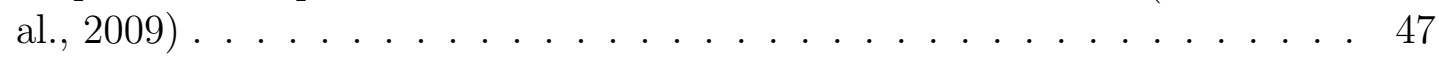

5.1 Diagrama de blocos da $N o C$ ethernet parametrizável . . . . . . . . . . . 49

5.2 Estrutura interna do ethmac . . . . . . . . . . . . . . . 51

5.3 Passos para realizar uma transmissão utilizando o CE . . . . . . . . . . 57

5.4 Máquina de estado de controle da comunicação do CE . . . . . . . . . . 58

5.5 Máquina de estado de controle da comunicação do MEM . . . . . . . . . . 59

5.6 Sinais de interconexão entre uma NA e um switch . . . . . . . . . . . . . . 60

5.7 Estrutura interna do módulo PLU . . . . . . . . . . . . . . . . . . . . . . . . . . . . . 61

5.8 Estrutura interna do módulo IBA . . . . . . . . . . . . . . . . . . 62

5.9 Sinal de dados com atraso, corrigido pelo complete_on_write . . . . . . . 63

5.10 Os principais pontos da implementação dos parâmetros flow-control e buffer

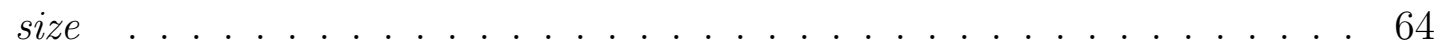

5.11 Estrutura interna dos módulos DCP e DPQ . . . . . . . . . . . 65 
5.12 Trecho de código do direcionamento das informações da porta de entrada 1 para todas as portas de saída . . . . . . . . . . . . 66

5.13 Exemplo do arquivo de configuração da NoC . . . . . . . . . . . . . . 67

5.14 Exemplo do caminho da configuração buffer offset de uma NA $\ldots$. . . . . . 69

5.15 Componentes da NoC implementados (verde), modificados (azul) e não implementados (amarelo) . . . . . . . . . . . . . . 70

5.16 Formas de onda capturadas no SinalTap da execução do experimento 1 . . 72

5.17 Configuração dos experimentos 3,4 e 5 . . . . . . . . . . . . . . 74

A.1 Sinais básicos dos módulos master e slave interconectados ponto a ponto . 85

A.2 Sinais de um ciclo clássico de leitura (Herveille, 2002) . . . . . . . . . 88

A.3 Sinais de um ciclo clássico de escrita (Herveille, 2002) . . . . . . . . . . . . 90

A.4 Sinais de um módulo master realizando uma operação de leitura com ciclo de rajada incremental (Herveille, 2002) . . . . . . . . . . . . . . 91 


\section{Lista de Tabelas}

3.1 Características das sub camadas . . . . . . . . . . . . . . . . . 32

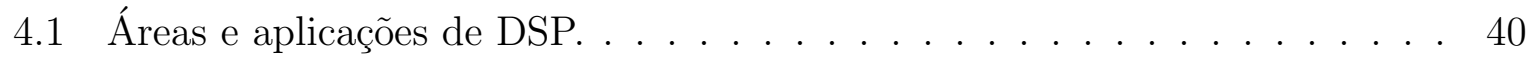

4.2 Aplicações e suas taxa de amostragem . . . . . . . . . . . . . . . . . . . . . . 42

4.3 Processadores DSP e seus fabricantes . . . . . . . . . . . . . . . 45

4.4 Processadores DSP multicores, seus fornecedores e suas características . . . . . 46

5.1 Principais configurações do registrador MODER . . . . . . . . . . . . . . 54

5.2 Representação do endereço de origem nos registradores MAC_ADDR0 e

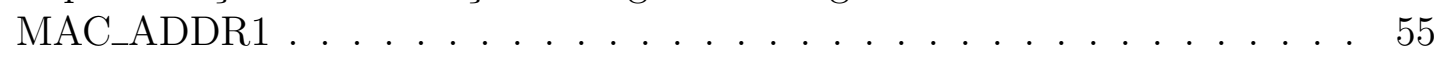

5.3 Parâmetros da NoC . . . . . . . . . . . . . . . . . . . . . . . 71

5.4 Recursos lógicos utilizados nos experimentos $1,2,3,4$ e $5 \ldots \ldots$. . . . 75

5.5 Resultados dos experimentos 3 , 4 e $5 \ldots \ldots \ldots$

A.1 Tipos de ciclo do Wishbone . . . . . . . . . . . . . . . . . . 86 


\section{Lista de Abreviaturas e Siglas}

AMI American Microsystem Inc

ASIC Application-specific Integrated Circuit

ASIP Applicattion Specific Instruction-set Processor

BE Best Effort

CDMA Code-Division Multiple Access

CFB Cochlear Filter Banks

CI Core Interface

CODEC Coder-decoder

CMP Chip Scale Multiprocessors

CRC Cyclic Redundancy Check

CSMA/CD Carrier Sense Multiple Access / Collision Detect

DFT Discrete Fourier Transform

DSP Digital Signal Processing

FCS Frame Check Sequence

FFT Fast Fourier Transform

FIT Finite Impulse Response

FPGA Field-programmable Gate Array

GALS Globally-asynchronous Locally-synchronous

GMII Gigabit Media Independent Interface

GS Globally-synchronous

GS Guaranteed-service

GT Guaranteed Throughput

HD High Definition

IDE Integrated Development Environment

IEEE The Institute of Electrical and Electronics Engineers

IP Intellectual Property

LLC Logical Link Control

LSB Least Significant Bit

MAC Media Access Control

MDC Management Data Clock

MDIO Management Data Input/Output

MFB Mel Filter Banks

MFCC Mel Frequency Cepstrum Coefficients

MII Media Independent Interface 
MIPS Microprocessor without Interlocked Pipeline Stages

MPSoC Multi Processor Systems on Chip

MSB Most Significant Bit

NA Network Adapter

NI Network Interface

NoC Network-on-Chip

OCP Open core Protocol

OSI Open Systems Interconnection

PAD Packet Assembler/Disassembler

PDSPs Programmable Digital Signal Processor

PLS Physical layer signaling

QoS Quality-of-Service

RIB Router Information Bit

RS Reconciliation sublayer

SD Standart Definition

SDF Start Frame Delimiter

SPARC Scalable Processor Architecture

SoC Systems-on-Chip

TDM Time-division Multiplexing

TI Texas Instruments

VCI Virtual component interfaces

VLSI Very-large-scale Integration

VOIP Voice over IP

XGMII 10 Gigabit Media Independent Interface 


\subsection{Contextualização}

O aumento da complexidade das aplicações e da exigência por alto desempenho fez com que o hardware e sua arquitetura passasse por mudanças para poder atender a necessidade de processamento. Durante muitos anos confiou-se na diminuição da dimensão dos transistores como meio de projetar processadores mais rápidos. A abordagem tradicional de aumentar a frequência de clock com o objetivo de obter uma maior performance atingiu um limite devido a problemas de aquecimento e o consumo de energia excessivo. Uma das alternativas estudada e implementada é a exploração do paralelismo a nível de instruções. Esse tipo de paralelismo é explorado pelos processadores superescalares e permite a execução de mais do que uma instrução simultaneamente. Os processadores superescalares são complexos e o ganho de performance nem sempre compensa a complexidade adicional (Asanovic et al., 2006).

Uma outra solução consiste nos chamados sistemas de multiprocessamento. Sistemas de multiprocessamento são sistemas com mais de um elemento de processamento que permitem a execução de vários processos ou tarefas simultaneamente. Os sistemas de multiprocessamento apareceram primeiramente como múltiplos chips conectados. Com o avançar da tecnologia, começaram a aparecer também sistemas de multiprocessamento completos integrados num único chip. Estes tipos de sistemas são designados por sistemas de multiprocessamento em chip, MPSoC (Multi Processor Systems-on-Chip). O aparecimento dos MPSoCs ou também chamados CMP (Chip Scale Multiprocessors) per- 
mitiram reduzir a latência de comunicação entre os elementos do sistema, pois os atrasos de comunicação dentro de um chip são menores (Asanovic et al., 2006).

Para interligar os cores desses MPSoCs são utilizadas diferentes arquiteturas de comunicação. As mais tradicionais são as de canais ponto-a-ponto ((a) da Figura 1.1) e barramento ((b), (c) e (d) da Figura 1.1). A arquitetura ponto-a-ponto consiste em canais dedicados de comunicação entre os cores, o que oferece um melhor desempenho. $\mathrm{Na}$ arquitetura de barramento, os cores são conectados a um mesmo canal de comunicação, ou seja, eles compartilham a mesma estrutura para troca de dados, o que causa uma redução no desempenho do sistema devido a concorrência pelo meio compartilhado. Além disso, com maior número de cores conectados aos canais do barramento, a carga capacitiva dos canais é incrementada, resultando em um aumento do tempo e da energia necessários à propagação dos sinais pelos fios do barramento.

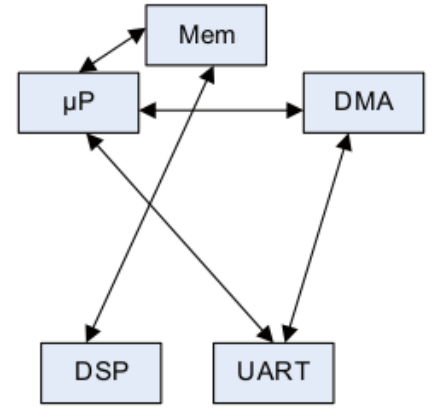

(a) Ponto a ponto

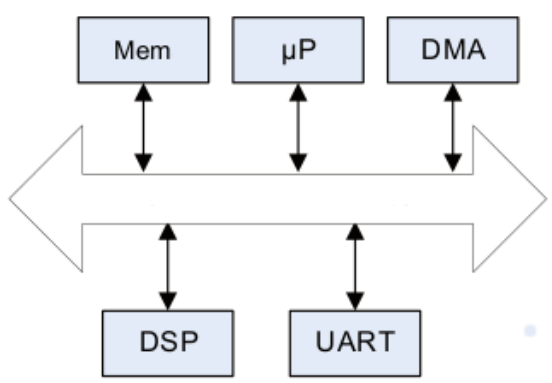

(b) Barramento compartilhado

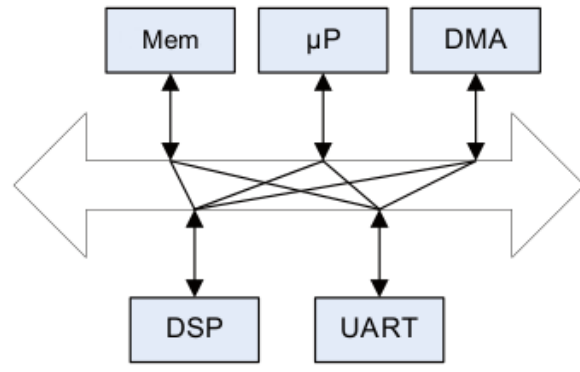

(c) Crossbar

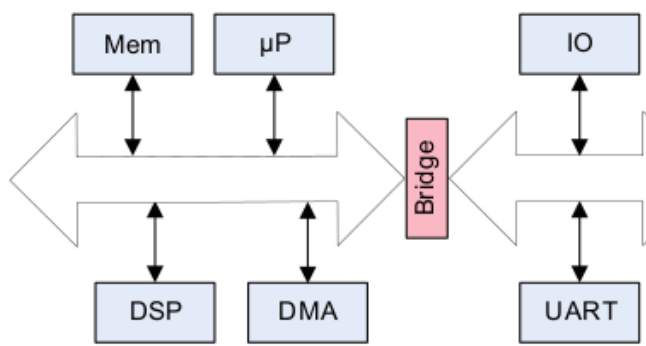

(d) Barramento hierárquico

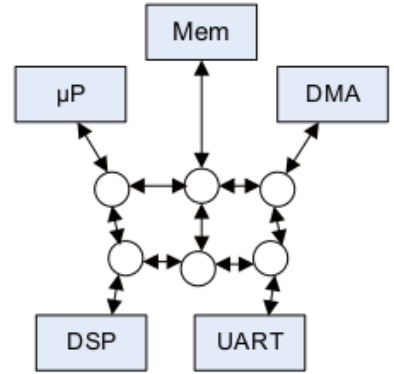

(e) Rede on chip

Figura 1.1: Exemplo de comunicações em MPSoC.

A arquitetura ponto-a-ponto possui baixa flexibilidade de comunicação e de expansão. Ela pode adotar um padrão para facilitar sua reutilização, porém, para tirar proveito dessa arquitetura sua implementação normalmente é customizada em cada interconexão. Contudo, isso torna sua reusabilidade limitada, enquanto no barramento a mesma estrutura pode ser reutilizada em diferentes sistemas, reduzindo o tempo de projeto. Devido a isso, e ao baixo custo em silício, o barramento tornou-se a arquitetura de comunicação mais utilizada (da Silva Cardozo, 2005).

Alguns trabalhos relatam, de forma distinta, a mesma tendência do aumento do número de cores em um único chip para possibilitar o ganho de desempenho (Intel, 2005), 
(da Silva Cardozo, 2005). Portanto, um novo paradigma para implementar a comunicação entre os cores foi desenvolvido e proposto, a Network-on-Chip (NoC) (Benini e De Micheli, 2002). Esse paradigma, ilustrado pelo exemplo (e) da Figura 1.1, tem como principal característica a descentralização da comunicação, possibilitando a redução dos gargalos de comunicação e aumentando a escalabilidade dos sistemas. A comunidade científica tem apresentado diversas formas de se construir uma NoC, tendo a maioria dos trabalhos voltados para a customização a fim de reduzir o uso de recursos lógicos e a latência de comunicação sem se preocupar com a adoção de padrões universais. No entanto, com a constante expansão da quantidade de recursos lógicos dos circuitos integrados, a adoção de um padrão pode trazer diversas vantagens em relação a esses trabalhos.

O estado da arte mostra a NoC como a mais promissora arquitetura de comunicação paralela on-chip para SoCs com um número grande de componentes integrados (Truong et al., 2009). Além das suas vantagens sobre as outras arquiteturas de comunicação em MPSoC, como a reusabilidade e o desempenho, a NoC também pode ser uma boa ferramenta para testes, monitoramento e reconfigurabilidade em tempo real.

\subsection{Objetivo}

O objetivo desse trabalho é desenvolver uma NoC que atenda o padrão ethernet e tenha configurações parametrizadas. Essas configurações devem ser desenvolvidas considerando as características das aplicações DSP. O desenvolvimento envolve a implementação dos três módulos básicos de uma NoC, Network Adapter, Link e Switch.

Os objetivos secundários desse trabalho são: (i) implementar um arquivo de configuração para facilitar a usabilidade das configurações dos componentes da NoC; (ii) fornecer uma arquitetura de comunicação para projetos de MPSoCs; (iii) divulgar os componentes desenvolvidos no site do grupo OpenCores; (iv) disponibilizar uma biblioteca de componentes de NoC para serem utilizados em trabalhos desenvolvidos no LCR e (v) prover um meio de comunicação plug-and-play de componentes internos do FPGA com componentes externos.

\subsection{Justificativa}

O ethernet é o padrão mais utilizado em redes Local Area Networks (LANs). Esse padrão vem sendo utilizado ao longo dos anos, testando, validando e verificando o seu funcionamento inúmeras vezes em vários ambientes de comunicação. Por esse motivo, pode-se considerar um padrão seguro e confiável. Além dessas características, outra vantagem de uso do padrão ethernet é a sua diversidade de aplicações, garantido o seu conhecimento para vários profissionais da área de computação. Isso torna mais fácil a manutenção e adição de novas características que adotam um padrão difundido como o ethernet. No 
entanto, existe um custo por essas vantagens, que é o overhead intrínseco da comunicação por conta do controle adicionado na mesma. Porém, essa desvantagem pode ser desconsiderada quando se tem recursos suficientes para uso de um padrão.

O desenvolvimento de NoC sem o uso de padrões para sua operação interna faz com que a adição de novas características possua uma difícil curva de aprendizado. Mesmo em propostas de NoC com muitas configurações já implementadas, seu entendimento e sua manutenção não são triviais. As principais justificativas apresentadas por alguns autores, como Benini e Bertozzi (2005); Benini e De Micheli (2002); Tsai et al. (2012); Xu et al. (2006) de não implementar um padrão é a customização da NoC para uma determinada aplicação e o custo em termos de área ocupada no silício. Porém, para a primeira justificativa, se a rede não for customizada, mas possuir boa configurabilidade em termos de parâmetros, os benefícios da customização pode ser alcançados. No caso do custo por área ocupada, os chips para comportar SoC possuem cada vez mais capacidade, permitindo projetos mais complexos e onerosos em termos de recursos de hardware. Para ilustrar essa capacidade, o gráfico da Figura 1.2 apresenta dados atuais dos novos FPGAs, comparando com o FPGA utilizado no projeto proposto. Por isso, esse projeto propõe o uso do padrão ethernet para o desenvolvimento de uma NoC parametrizável.

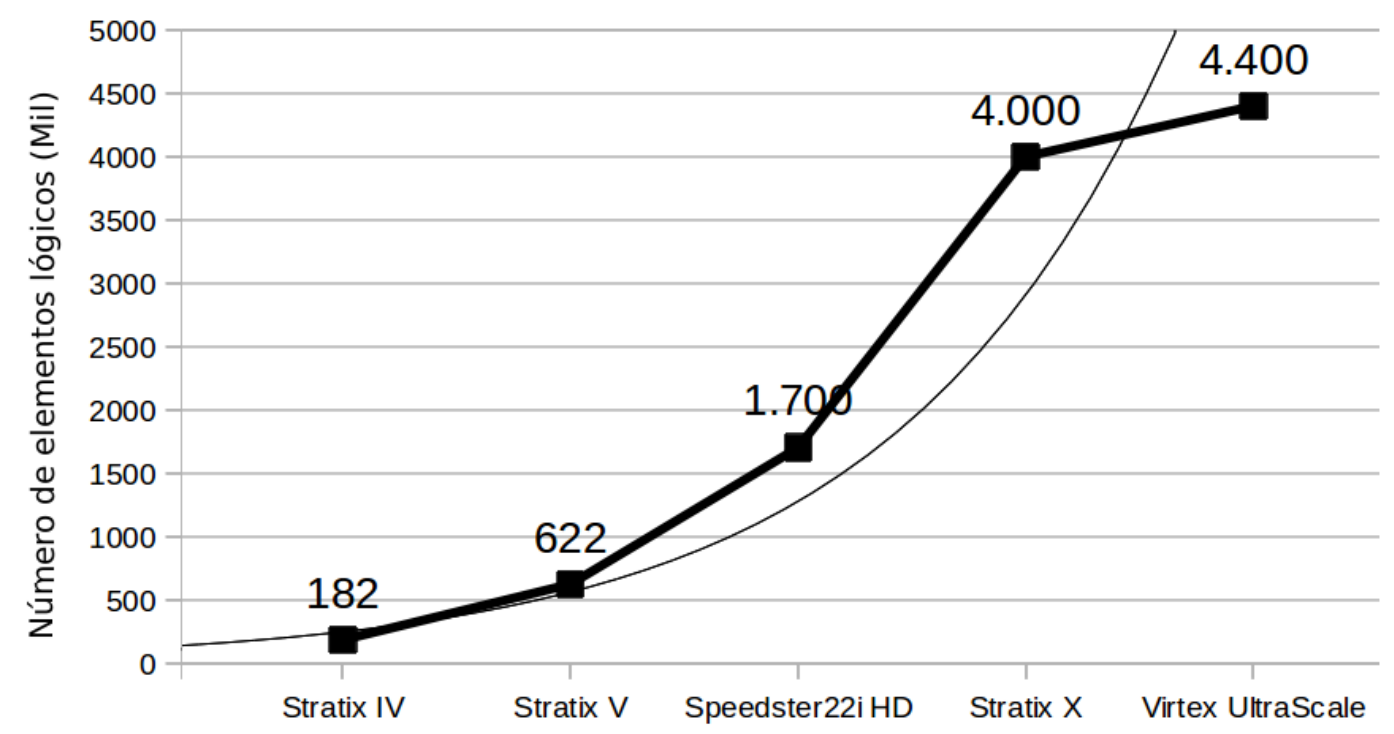

Figura 1.2: Gráfico de crescimento dos recursos lógicos dos FPGAs nos últimos anos. Fonte: (The Dini Group, 2014)

O padrão é importante para difundir a abordagem NoC em SoC complexos. Como ilustrado pelo gráfico da Figura 1.2, o crescimento dos recursos lógicos tem sido constante e torna cada vez mais notável a adoção de um padrão, que neste trabalho é o ethernet. 


\subsection{Organização}

O capítulo 2 abrange os principais conceitos de NoC detalhando as características de arquitetura, os principais módulos e o modo de operação. Além disso, apresenta o estado da arte de NoC e trabalhos similares com o proposto.

O capítulo 3 detalha as principais funcionalidades e características do padrão IEEE 802.3. Além disso, demonstra as funções do protocolo MAC e da interface MII.

O capítulo 4 apresenta o que é um DSP com uma breve evolução histórica, seguido das aplicações e suas principais características. Por fim, são apresentadas arquiteturas de DSP atuais, dentre elas, algumas multicores que têm sua comunicação interna baseada em NoC.

No capítulo 5 é detalhado a implementação do projeto proposto, com a definição dos parâmetros de configuração e a apresentação dos resultados finais.

O capítulo 6 contém as considerações finais do trabalho e sugestões para trabalhos futuros.

O Apêndice A contêm informações de funcionamento e características do protocolo Wishbone. 


\section{2}

\section{Conceitos e implementações de \\ Network on chip}

Uma Network on Chip (NoC) consiste em aplicar o conhecimento de redes de comunicação comum aos sistemas em chip (SoC). Quando existem muitos núcleos de processamento em um único chip NoC é uma solução que possibilita que o meio de comunicação também seja escalável para atender as demandas de conexão entre esses núcleos. A ideia é utilizar pequenos routers dentro do chip que permitam a comunicação entre os vários nós do sistema com uma baixa latência (Dorta et al., 2009). As NoCs são redes de interconexão, switched, multihop, integradas em um único chip. O acesso aos cores da rede é feito por interfaces ponto a ponto e seus pacotes são encaminhados ao destino pela rede considerando um número de hops. As NoCs se diferenciam de redes comuns principalmente pela sua proximidade local. No entanto, algumas características são distintas, por exemplo, o requisito de consumo de energia e o tempo necessário para especialização de projeto (aprendizado da tecnologia), que normalmente só existem em NoC. Um exemplo de redução de consumo de energia em NoCs é a diminuição da frequência do clock e da tensão dos nós de acordo com a banda de transmissão atual (Benini e De Micheli, 2002).

Os projetos de redes comuns e de $\mathrm{NoC}$ devem conter requisitos de desempenho e de limites no consumo de energia, que são bem diferentes para NoC. Nas redes tradicionais, como LAN ou WAN, os projetos estão sob restrições de largura de banda e latência de reposta, que também são comuns em projetos de NoC. 


\subsection{Arquitetura NoC}

A arquitetura de uma NoC define a topologia de interconexão da rede e a organização física dos componentes, enquanto os protocolos definem como os recursos de rede são utilizados na operação do sistema. Os protocolos são apresentados como fluxo de controle, ainda nesse capítulo.

\subsubsection{Tipos de arquiteturas NoC}

Os tipos de arquiteturas NoC apresentadas por Benini são redes de compartilhamento de meio, redes diretas e indiretas e redes híbridas (Benini e De Micheli, 2002).

- Arquitetura de compartilhamento de meio: possui estruturas de interconexão simplificadas, todos os dispositivos de comunicação compartilham o meio de transmissão, apenas um dispositivo pode transmitir por vez e suporta broadcast. Uma das suas vantagens é uma intercomunicação de baixo overhead, quando o sistema possui fluxo de informação com poucos transmissores e muitos receptores. Em função de utilizar um meio compartilhado, faz-se necessário um mecanismo de arbitragem que pode tornar a comunicação lenta. Esse mecanismo deve ser rápido e, se possível, evitado. Com isso, o sistema fica com elocidade de comunicação dependente dos receptores e com escalabilidade limitada.

- Arquitetura direta: cada nó conecta diretamente a um número limitado de vizinhos. As unidades computacionais internas do chip contém um bloco de interface de rede que são comumente chamados de router, que lida com a comunicação e conecta diretamente com os outros nós vizinhos. Essa arquitetura tem sido aplicada em desenvolvimento de sistemas de larga escala devido a sua largura de banda de comunicação total, que aumenta conforme a quantidade de nós no sistema. No entanto, essa arquitetura possui o mesmo problema de escalabilidade da arquitetura de compartilhamento de meio.

- Arquitetura indireta: a conexão entre os nós é feita através de um conjunto de switches. O adaptador de rede associa cada conexão de um determinado nó a uma porta do switch. Os switches por si só não fazem processamento de dados, eles apenas provêem uma conexão programável entre suas portas, configurando um caminho de comunicação que pode mudar com o tempo. A diferença entre redes diretas e indiretas são basicamente o uso de routers para as arquiteturas de rede direta e o uso de switches para arquiteturas indiretas. Uma vantagem desta arquitetura é sua escalabilidade que pode ser uma alternativa para o problema apresentado pelas arquteturas de meio compartilhado ou direto. 
- Arquitetura híbrida: essa arquitetura é o uso combinado das arquiteturas anteriores, que introduz um quantidade controlada de não uniformidade em um projeto de rede de comunicação, o que pode prover certos benefícios como, o aumento da largura de banda e da eficiência energética (Benini e De Micheli, 2002).

\subsubsection{Módulos básicos da arquitetura NoC}

Uma arquitetura NoC pode ser dividida em três módulos básicos, Link, Network Adapter e Router/Switch.

\subsubsection{Link}

O link pode ser comparado com os fios de uma rede comum, só que no caso de NoC, são as ligações físicas dentro do chip responsáveis por interconectar os módulos uns aos outros. Dependendo da topologia escolhida e do tamanho do sistema, os caminhos de interconexão podem ficar muito longos podendo gerar atraso na transmissão dos pacotes e dos sinais de sincronização. Esses problemas são discutidos por Benini, que apresenta algumas soluções, por exemplo, o uso de pipeline nas interconexões (Benini e Bertozzi, 2005). Algumas propostas, como Xpipes NoC (Dall'Osso et al., 2012), adotam o uso de sinais de ACK/NACK para confirmação de recebimento dos pacotes. Porém, esses sinais são opcionais e podem ser utilizados quando o projeto possui restrições de garantia de entrega da mensagem, de QoS e de confiabilidade.

No trabalho de Murillo (2009), as mensagens de confirmação são relacionadas com o sincronismo entre os switches da rede. Esse sincronismo é relatado de duas formas possíveis, credit-based e a handshake. Na credit-based o controle dos buffers do switch é realizado através de contadores. Quando o switch recebe um flit, um contador é decrementado e quando um flit é transmitido esse contador é incrementado. Caso esse contador chegue a zero, isso indica que o buffer está cheio. Já na abordagem handshake, utiliza-se as mensagens de confirmação para realizar esse controle, que são o ACK, para informar que o pacote foi transmitido com sucesso, e o NACK, para informar que houve problema na transmissão.

\subsubsection{Network Adapter}

O modulo Network Adapter (NA) é responsável por traduzir a mensagem do core em pacotes endereçados ao seu destino, além de repassar mensagens de pacotes para o core. Essas responsabilidades podem ser divididas em três tarefas para prove: (i) um conjunto padronizado de transações ponto a ponto para os nós; (ii) um mapeamento eficiente das transações ponto a ponto da rede; e (iii) uma interface com a rede para montar, entregar e desmontar pacotes. 


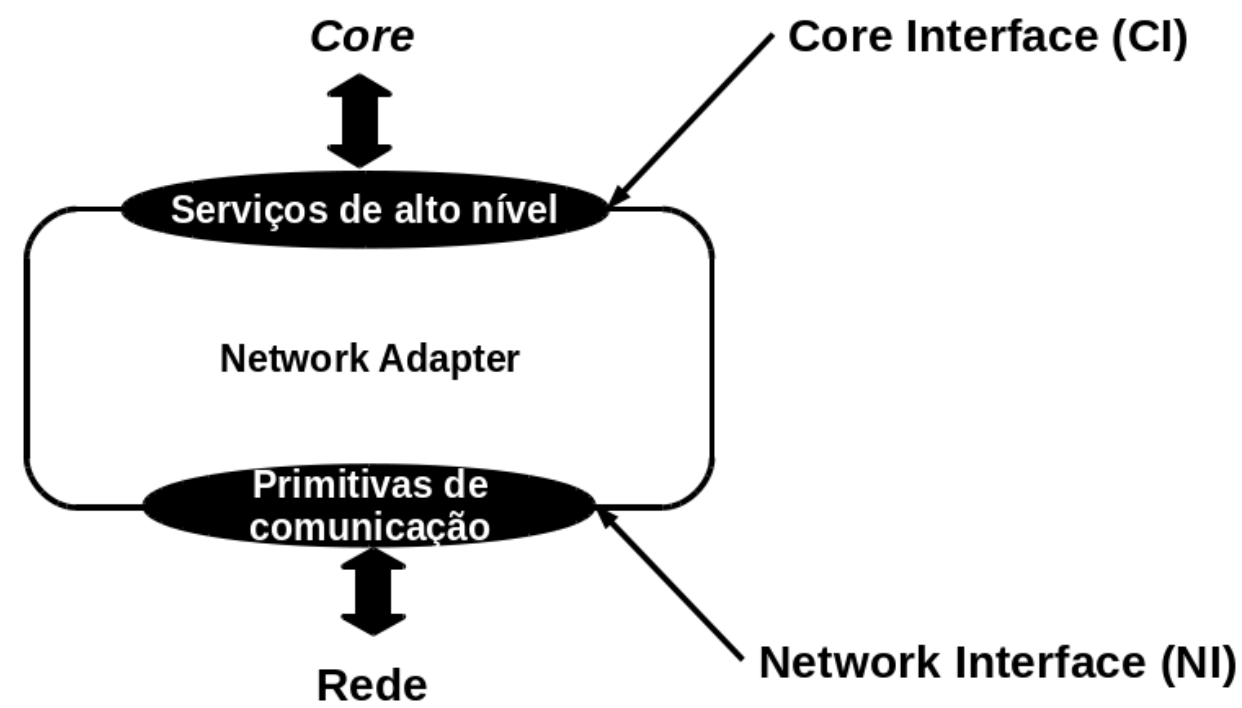

Figura 2.1: Network Adapter. Adaptado de Bjerregaard e Mahadevan (2006)

A primeira tarefa especifica um padrão que deve ser adotado pelos cores para se comunicar com o módulos NA. Esse padrão pode ser implementado no Core Interface (CI), ilustrado pela Figura 2.1, que é o nome definido por Bjerregaard e Mahadevan (2006) para a interface entre o core e a sua NA. A segunda tarefa disponibiliza um conjunto de funções para serem utilizadas pelo core, com o intuito de comunicar com outros nós através da rede, que na Figura 2.1 pode ser identificado por serviços de alto nível. E por fim, a terceira combina as atividades de recepção de uma entrada e a interface com a rede, representadas na figura pela Primitivas de Comunicação e pela Network Interface.

No modulo NA deve ser definido como o pacote deve ser montado e que formato de pacote se espera receber. Os pacotes em NoC normalmente possuem cabeçalho, payload e tail. O cabeçalho contém informações de roteamento do pacote pela rede, por exemplo, o endereço do destino e o tamanho do pacote. O payload contém os dados do core a serem transmitidos. O tail pode conter informações para checagem do pacote, uma sequência de bits calculada para verificar a integridade do pacote. O tamanho do pacote influência no máximo de buffer necessário para suportar o tráfego e consequentemente no QoS (Peyravi, 1999). Os pacotes são frequentemente quebrados em unidades de controle de fluxo de mensagem chamadas flits (Benini e Bertozzi, 2005; Xu et al., 2006). Um phit é a unidade de informação que pode ser transferido através de um canal físico em um único ciclo de clock. Os flits representam unidades lógicas de informação, ao contrário do phits que corresponde a quantias físicas. Normalmente, um flit é configurado para ser igual ao phit.

Como exemplo de alguns desses conceitos apresentados, o trabalho de Xu et al. (2006) propõe uma NoC com circuito assíncrono baseado em comutação de pacotes, com foco na implementação do roteamento. Nesse trabalho, os routers possuem duas entradas e duas saídas, com divisão de responsabilidade em dois blocos: bloco de controle e caminho de 
dados. Para essa proposta, o flit foi igualado ao phit e seu tamanho foi de 32-bits. Isto significa que a cada ciclo de clock, a NoC consegue transferir 32-bits em cada link da rede. O pacote é divido em duas partes, cabeçalho de 32-bits e payload de dados. O tamanho do pacote é fixo, previamente determinado. O roteamento é decidido pelo router information bit (RIB), no caso representado pelo least significant bit (LSB) do cabeçalho, que possui a informação de qual porta das duas possíveis do router o pacote deveria ser encaminhado. Os resultados da simulação sugerem que as redes assíncronas podem superar as redes síncronas, considerando que as redes assíncronas dependem do tamanho do pacote (Xu et al., 2006).

\subsubsection{Switch}

O switch é o modulo que interliga as NAs umas as outras. Sua tarefa é carregar os pacotes injetados na rede até seu destino final, seguindo um caminho de rota estática ou dinâmica. Ele transfere pacotes de uma de suas portas de entrada para uma ou mais de suas portas de saída. A Figura 2.2 ilustra uma arquitetura básica de um switch que contém 4 portas de entrada e 4 de saída, buffers de entrada e saída, bloco de controle e um crossbar $^{1}$. Nota que essa arquitetura possui dois canais do buffer de entrada que ligam ao crossbar, sendo que um deles passa pelo bloco de controle onde é realizada a tomada de decisão do roteamento, e o outro conecta direto. No canal que passa pelo controle, trafegam apenas os flits relacionados com o cabeçalho. Já no outro canal, passam apenas os flits referentes ao payload (dados), que são encaminhados diretamente do buffer de entrada para o crossbar, para depois serem encaminhados ao buffer da porta de saída.

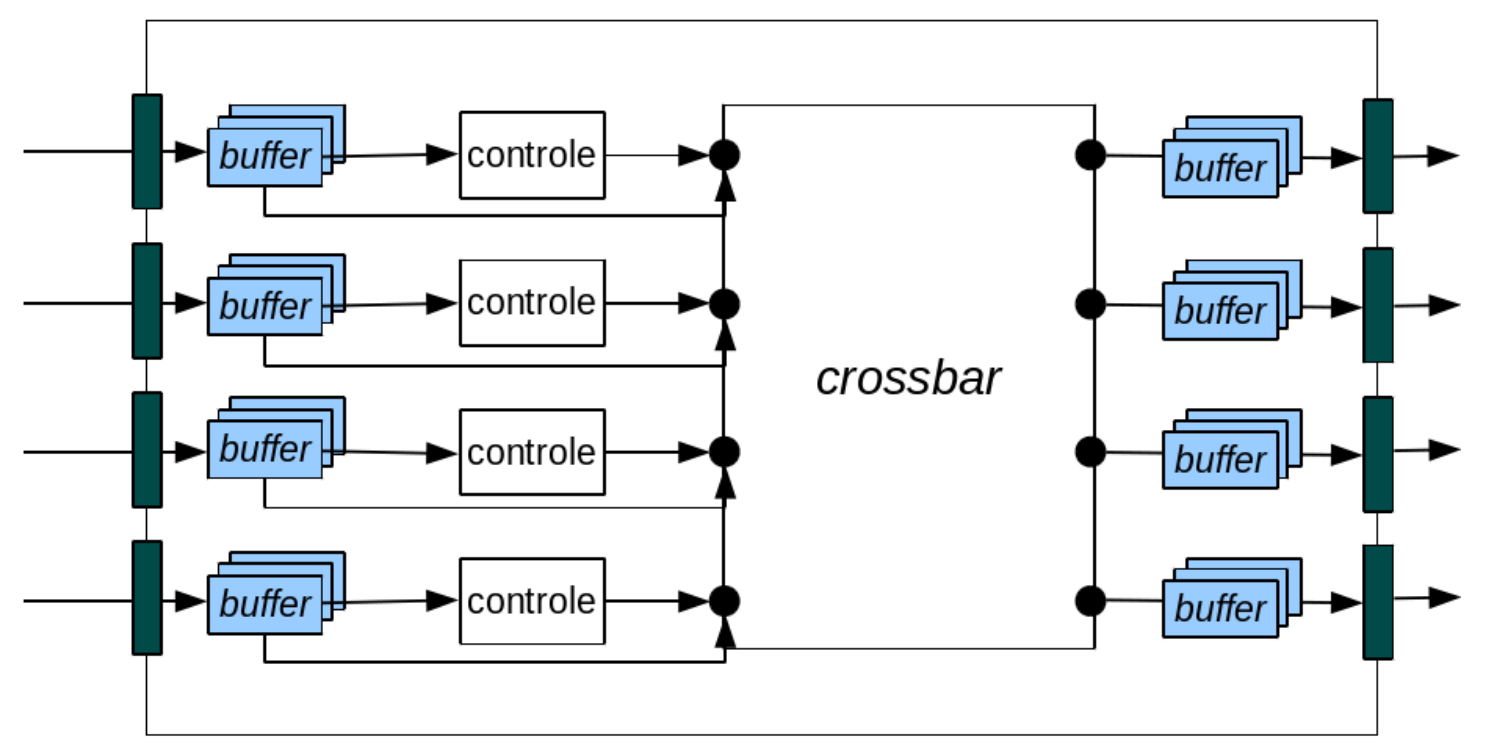

Figura 2.2: Arquitetura básica de um switch

\footnotetext{
${ }^{1}$ Conjunto de comutadores organizados em uma configuração de matriz
} 
O roteamento estático utiliza sempre o mesmo caminho entre um determinado par de origem e destino, definido a partir de um padrão de tráfego uniforme e regular. A definição desse roteamento pode ser em tempo de instânciação ou durante os primeiros instantes de funcionamento da rede, que uma vez definido, mantém-se sempre a mesma rota. O roteamento dinâmico usa informações sobre as condições dos canais e tráfego da rede com o intuito de evitar regiões criticas de congestionamento. Esse algoritimo lida melhor com tráfegos irregulares e com links e nos da rede não confiáveis. As mudanças no roteamento podem ser ocasionadas pelo mecanismo de arbitragem ou pela política de privilégio implementada em pacotes da rede.

A topologia da rede é determinada pela forma como os switches estão ligados entre si e aos nós da NoC. Como citado em Salminen et al. (2008), 60\% das NoCs utilizam topologia mesh-2D ou torus. Essas duas topologias distribuem os switches conectados com quatro vizinhos e uma quinta ligação com o core da rede. Porém, na torus, os switches que estão no extremo da arquitetura são interligados. Essas duas topologias são consideradas regulares e são ilustradas na Figura 2.3. Nessa figura também apresenta-se a topologia regular no formado de árvore binária, que é menos adotada. As topologias não regulares são as que não seguem um padrão de interconexão entre os nós e switches da rede. Elas podem ser interessantes quando se trata de um sistema totalmente customizado, que possuem restrição de recursos de hardware e/ou de consumo de energia.

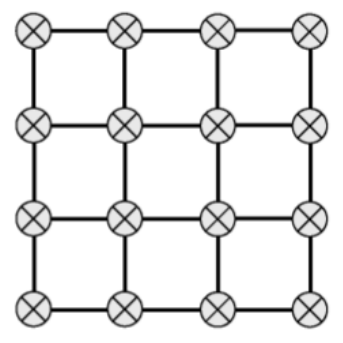

(a) Mesh 2D

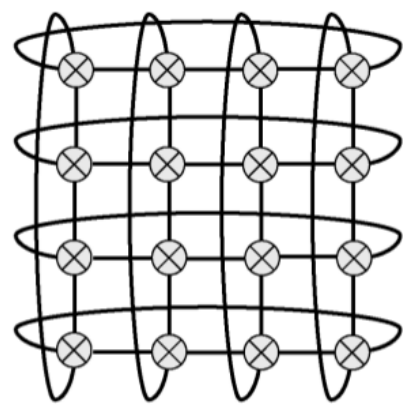

(b) Torus

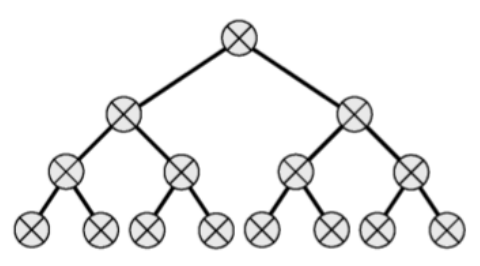

(c) Árvore Binária

Figura 2.3: Topologias de NoC

O controle de fluxo da rede define como deve ser utilizado a quantidade limitada de recursos de buffers dos switch. Várias abordagens tem sido exploradas nesse contexto, como os fluxos de controle store-and-forward, wormhole e virtual cut-through.

1. Store-and-forward: um pacote inteiro é armazenado antes de ser encaminhado para o próximo switch. Os buffers do switch devem ser capazes de armazenar um pacote inteiro para implementar esse fluxo de controle. Isso torna essa abordagem mais onerosa para recursos de memória do switch.

2. Wormhole: pode ser implementado para reduzir os requisitos de recursos de memória com baixa latência de comunicação. O primeiro flit que chega contém a informação 
de roteamento e a sua decodificação permite ao switch estabelecer uma rota para o pacote que está chegando. Então os flits subsequentes passam pelo switch diretamente para a porta de saída, determinada pelo roteamento. Esse esquema de controle de fluxo permite a economia de recursos de memória e mantém uma baixa latência de transmissão, pois os pacotes não são armazenados nos switches. Porém, são mais sensíveis a deadlock e a subutilização de um determinado link.

3. Virtual cut-through: com o funcionamento similar ao wormhole, essa abordagem também verifica apenas os flits do cabeçalho necessários para o roteamento e encaminha o restante do pacote para porta de saída. Porém, o switch que receberá o pacote encaminhado deve garantir, através de uma mensagem de controle, que é capaz de armazenar o pacote inteiro, mesmo que isso não seja necessário. Só assim, o switch que está encaminhado o pacote o envia.

\subsubsection{Modo de operação e QoS}

A qualidade de serviço (Quality-of-Service (QoS)) está relacionada com o tempo, a integridade e a entrega do pacote. Os switches possuem duas características de implementação que definem como a transmissão dos dados vai ser realizada na rede, operando dos seguintes modos:

- Time division circuit: nesse esquema de roteamento, a banda é compartilhada entre os circuitos, conseguindo garantir o tempo de transmissão;

- Packet switching: nesse esquema a contenção é inevitável, pois a chegada de um pacote não pode ser preditada. No entanto, mecanismos de arbitragem e recursos de armazenamento podem ser implementados em cada switch.

As arquiteturas de switches podem ser implementadas com o intuito de prover as garantias de QoS com diferentes características:

- Guaranteed Throughput (GT): a transferência garantida é baseada em uma abordagem de comutação de circuitos TDM. Ela utiliza uma tabela de slots 'T' para: (i) evitar contenção em um link; (ii) dividir a taxa de transmissão entre as conexões; e (iii) comutar os dados para a saída correta. A GT possui 'S' time slots (linhas) e 'N' saídas do roteador ou swtich (colunas). Esse modelo provê boas garantias em termos de atraso determinístico e da banda em cada fluxo.

- Best $\boldsymbol{E f f o r t}$ (BE): neste modo de operação o switch utiliza comutação de pacotes que possui intrinsecamente contenção. Desta forma, o pacote é transmitido assim que possível, não tendo garantia de vazão ou de atraso. Contudo, caso seja utilizado uma política de prioridade para os pacotes, esse modelo pode oferecer certas garantias, como por exemplo, baixo atraso para pacotes com alta prioridade. 


\subsubsection{Camadas funcionais de NoC}

Como nas redes comuns, as NoCs também possuem camadas que dividem responsabilidades da comunicação. As camadas são outra forma de classificação das responsabilidades de uma rede. Elas são muito próximas dos componentes básicos e de suas características, e são utilizadas para mapear as características de uma NoC (Benini e De Micheli, 2002). Como exemplo, a camada Data Link/Física pode ser comparada com o componente link, acrescentando algumas características passíveis de implementação, como os protocolos de detecção de erro em uma transmissão. A camada rede tem características muito próximas ao componente switch, acrescentando protocolos para lidar com previsibilidade, desempenho médio, complexidade, velocidade do roteamento, utilização de um canal, robustez e agressividade. A última comparação, fica entre a camada transporte e o componente network adapter. Nessa caso, questões relacionadas com o tamanho do pacote, informações de roteamento do cabeçalho e parte do controle de fluxo são características adicionais que são responsabilidades dessa camada e implementadas nesse componente. A camada Aplicação/Software não pode ser comparada a um componente, mas parte dele, no caso o CI. Essa camada possui uma das tarefas do NA, no caso a de fornecer serviços de alto nível para controle e utilização desse componente.

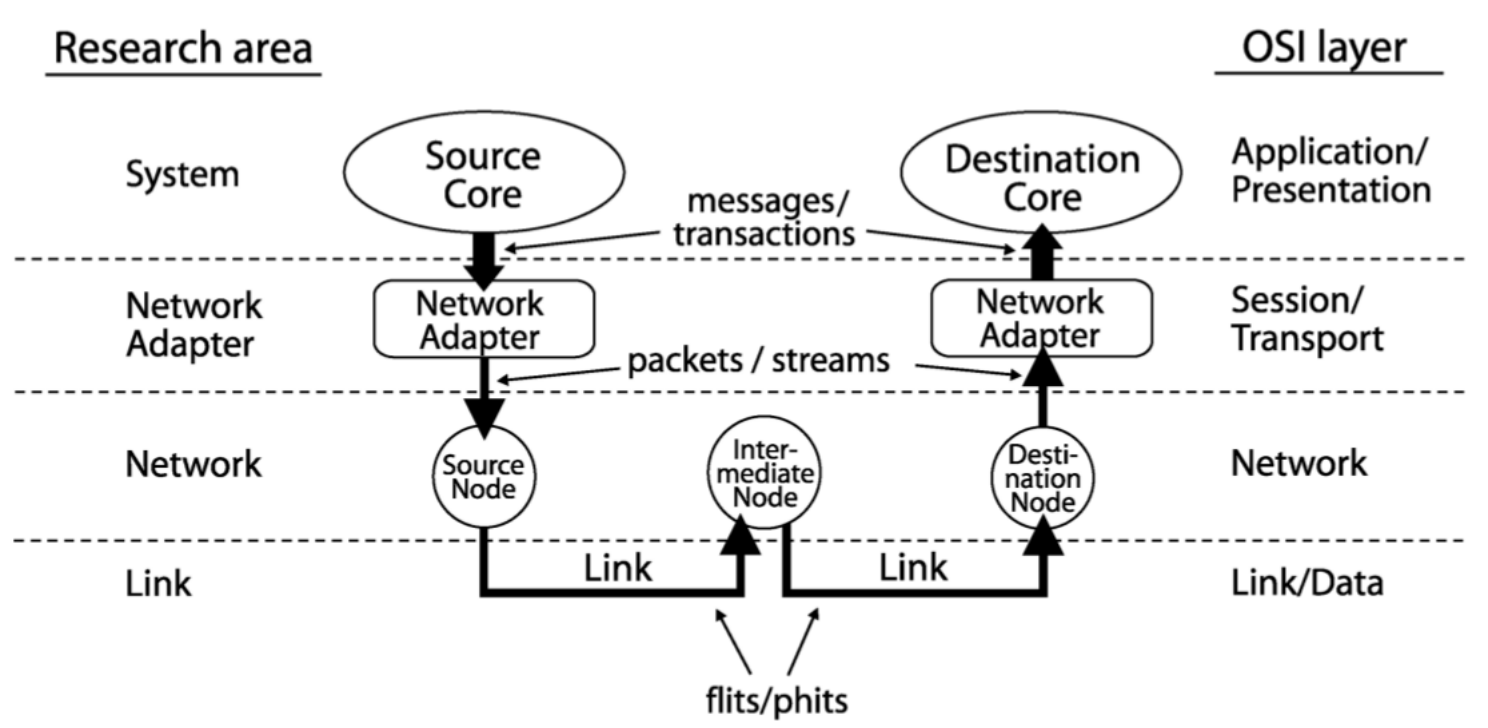

Figura 2.4: Fluxo de dado através dos componentes de uma NoC. (Bjerregaard e Mahadevan, 2006)

A Figura 2.4 apresenta um fluxo de dado comparando as camadas do modelo OSI (OSI, 1996) com os módulos de uma NoC. A divisão apresentada por Bjerregaard e Mahadevan (2006) nessa figura organiza as camadas da área de pesquisa de NoC em System, Network Adapter, Network e Link. O Source core inicia o envio de um dado através de uma mensagem ou de uma transmissão para a Network Adapter, que encapsula esse dado em pacote e repassa para interface de rede, representada pelo Source node. O Link, que 
transfere flits / phits pela rede, interconecta o Source node ao Intermediate node, no caso representando um switch. E por fim, o switch entrega o pacote transferido ao destinatário, que executa o processo inverso até que a mensagem enviada chegue ao Destination core.

Alguns autores, como Murillo (2009), prefere separar a camada data link da camada física. No entanto, a maioria como Benini e De Micheli (2002), Tsai et al. (2012) e Bjerregaard e Mahadevan (2006) trata como uma só. Assim, se seguir essa forma de divisão, as responsabilidades são divididas em quatro camadas:

- Enlace (Data Link): camada física, representa a parte física de interconexão da rede. Define o protocolo para transmitir um flit ente os componentes da rede;

- Rede: essa camada implementa o controle de entrega fim-a-fim nas arquiteturas de rede com muitos canais de comunicação. Define como um pacote é entregue na rede a partir de um remetente para um destinatário endereçado;

- Transporte: a camada de transporte decompõe mensagens em pacotes na origem e pacotes em mensagens no destino;

- Aplicação/Software: a camada onde fica os software do sistema e de aplicação. Essa camada é independente de tecnologia e é transparente para o usuário final.

\subsection{Estado da arte}

Sparsoe (2007) apresenta uma gama de possíveis organizações de tempo para NoC. As quatro apresentadas e discutidas são as globally-synchronous, mesochronous, globally-asynchronous locally-synchronous (GALS) e fully asynchronous. Além disso, o autor discute a necessidade de implementação dessas organizações de tempo em NoC. A comunicação que usa a organização de tempo globally-synchronous opera com o sistema todo sincronizado, o que não implica um um único domínio de clock para todo o sistema, apesar de também ser considerado um globally-synchronous para esse caso. A operação mesochronous tolera uma fase diferente entre os clocks dos blocos de comunicação. Agora, na operação GALS os domínios de clock são confinados para cada bloco IP (intellectual property) individual e routers individuais da NoC. Quando a comunicação é realizada usando operação asynchronous, é necessário um protocolo de comunicação baseado em mensagem de confirmação (ACK/NACK). E por último, a proposta fully asynchronous possui domínios de frequências de clock individuais para cada elemento da NoC. Essa abordagem não possuiu sincronismo, exceto quando um dado entra no domínio de clock de um IP da rede. Para validar essas abordagens, o trabalho apresenta dois estudos de caso. O primeiro com uma NoC totalmente customizada e de baixa complexidade para comunicação de elementos DSP utilizando multiplexadores. O outro estudo de caso, utiliza a MANGO NoC (Message-passing, Asynchronous, Network-on-chip, provinding Guaranteed services, over 
OCP-interfaces), que combina em um único bloco um router GS (GT) e um router BE. Para esse experimento, a MANGO NoC conta com topologia 2D-mesh, com cinco portas cada router, oito canais virtuais por link e flit de 32-bits. Os teste com a rede MANGO alcançaram uma velocidade de $3,180 \mathrm{~GB} / \mathrm{s}$ em cada link. Esse trabalho é implementado utilizando o padrão de células em tecnologia 0.130 microns.

O trabalho de Amory propõe uma arquitetura de MPSoC que tem a comunicação baseada em NoC com o objetivo de reduzir o tempo de testes e garantir uma alta reusabilidade do sistema (Amory et al., 2005). Nesse trabalho, a caracterização da NoC recebe destaque e é dividida em dois termos, o primeiro em relação ao tempo (desempenho) e o outro em relação ao consumo de energia. Além disso, também é descrito duas formas principais de avaliação de uma $\mathrm{NoC}$, que são a latência de roteamento e a latência do controle de fluxo. Essa latência de roteamento pode ser descrita sendo o tempo requerido intra-router para criar uma ligação através do roteador. A latência de controle de fluxo é descrita como sendo o tempo necessário inter-router para enviar os flits para os canais. Os resultados apresentados utilizam as arquiteturas open cores MIPS e SPARC com a comunicação baseada em NoC. O nível de reusabilidade do sistema, utilizando a NoC como meio de testes é considerado satisfatório, pois, mesmo aumentando o número de cores no MPSoC, não existia a necessidade de aumentar o número de pinos para a execução de testes na arquitetura.

O trabalho de JAFRI et al. (2009) apresenta uma arquitetura e a implementação de NoCs adaptativas, visando a melhoria de desempenho e o menor consumo de energia. Esse trabalho tem o foco voltado para a fase de designer arquitetural das NoCs, justificado por essa fase ser de suma importância para a automatização do processo. A arquitetura proposta possui dois tipos de agentes, o agente a nível de sistema e o agente local. O agente de sistema é responsável pelo monitoramento do sistema e operações de reconfiguração e o agente local opera de acordo com os comandos do agente de sistema. Além dessa divisão dos agentes, o trabalho apresenta técnicas de redução do consumo de energia, como o gerenciamento da tensão e de frequências distribuídas. A avaliação da arquitetura foi realizada a partir de resultados obtidos utilizando quatro benchmarks, matrix multiplication, FFT, wavefront, e hiperLAN transmitter, executados em um processador Leon3. Com o agente local fornecendo o rastreamento e reconfiguração a nível local do sistema, com base nos comandos do agente de sistema, os resultados se mostraram favoráveis, quando comparados com a arquitetura de uma NoC original. Com melhoria de $33 \%$ à $36 \%$ no consumo de energia, além da redução em $4 \%$ da área ocupada pelo sistema (JAFRI et al., 2009). Todos os resultados foram obtidos utilizando um simulador de NoC em nível RTL com ciclos precisos.

Um trabalho similar ao proposto, é o publicado por Zeferino e Susin (2003) que apresenta uma NoC parametrizável e escalável, que possui topologia direta, podendo ser configurada como uma 2D-mesh ou um 2D-tours. Suas principais características são: controle 
de fluxo do tipo handshake; roteamento tipo fonte e determinístico (XY); chaveamento por pacote do tipo wormhole; arbitragem distribuída (round-robin) e; memorização de entrada usando buffers do tipo FIFO. A rede SoCIN, como é chamada, é composta pelo router RASoC (Router Architecture for Systems-on-chip), um soft-core descrito em VHDL com as seguintes características parametrizáveis: largura dos canais de comunicação (n), profundidade dos buffers (p) e largura de informação de roteamento no cabeçalho do pacote $(\mathrm{m})$. O router possui cinco portas de comunicação bidirecional, com uma porta dedicada à comunicação com o core local e quatro para a comunicação: N (North), S (South), W(West) e E (East). A plataforma utilizada para obtenção dos resultados é a FPGA da Altera. Alguns resultados da síntese apresentados fixam o parâmetro 'm' em 8-bits e varia os parâmetros 'n' e 'p'. O primeiro deles, onde 'n' é igual a 8 e 'p' igual a 1, são necessários 420 elementos lógicos da FPGA. Mas, se 'n' for configurado para 32 e 'p' para 4, a quantidade necessária sobe para 1754 elementos lógicos. Mais recentemente, em (Zeferino et al., 2004), foi apresentada a continuação deste trabalho, que resultou na rede SoCINfp. A rede é formada por um router chamado ParIS, composto por blocos parametrizáveis que permitem diferentes alternativas e implementações para os circuitos usados no router.

As NoCs podem ser construídas de muitas maneiras. Segundo Benini e De Micheli (2002), requisitos como a padronização da infraestrutura de rede e a compatibilidade são menos restritivos em projetos de NoC, onde apenas nós finais necessitam de padronização. Com isso, projetos de NoC tendem a não seguir um padrão de implementação, com suas arquiteturas customizadas para aplicações, classe de aplicações e projetos de SoC. Esse comportamento no desenvolvimento de NoCs pode ser observado nos trabalhos de Sparsoe (2007), no primeiro estudo de caso, e de Xu et al. (2006), apresentados nesse capítulo.

Os padrões difundidos em projetos de NoC são limitados a CI do NA, que são os open core protocol (OCP) (OCPIP, 2009) e virtual component interfaces (VCI) (ALLIANCE, 2000). Os projetos de NoC da MANGO, Xpipes, ÆTHEREAL utilizam o padrão OCP e os da SPIN e Proteo utilizam o VCI. A rede HERMES proposta por (Ost et al., 2005), apresenta um protocolo para CI nativo e compara resultados de desempenho com o padrão OCP. Nessa comparação, os resultados mostram que o padrão é $50 \%$ mais lento que o protocolo nativo. O trabalho de Zeferino et al. (2004) apresenta uma NoC totalmente parametrizável, a SoCINfp, que implementa ambos os padrões para a CI. 
O padrão Ethernet é definido pelo IEEE no documento 802.3 (The Institute of Electrical and Electronics Engineers, 2012) para comunicação de redes LAN. Ele é um padrão difundido e está relacionado com a implementação e o modo de operação da camada 1 e parte da camada 2 do modelo OSI (OSI, 1996), conforme apresentado na Figura 3.1. Com a transmissão baseada em comutação de pacotes, esse padrão possui basicamente quatro componentes: frame, protocolo MAC, componentes de sinalização e meio físico.

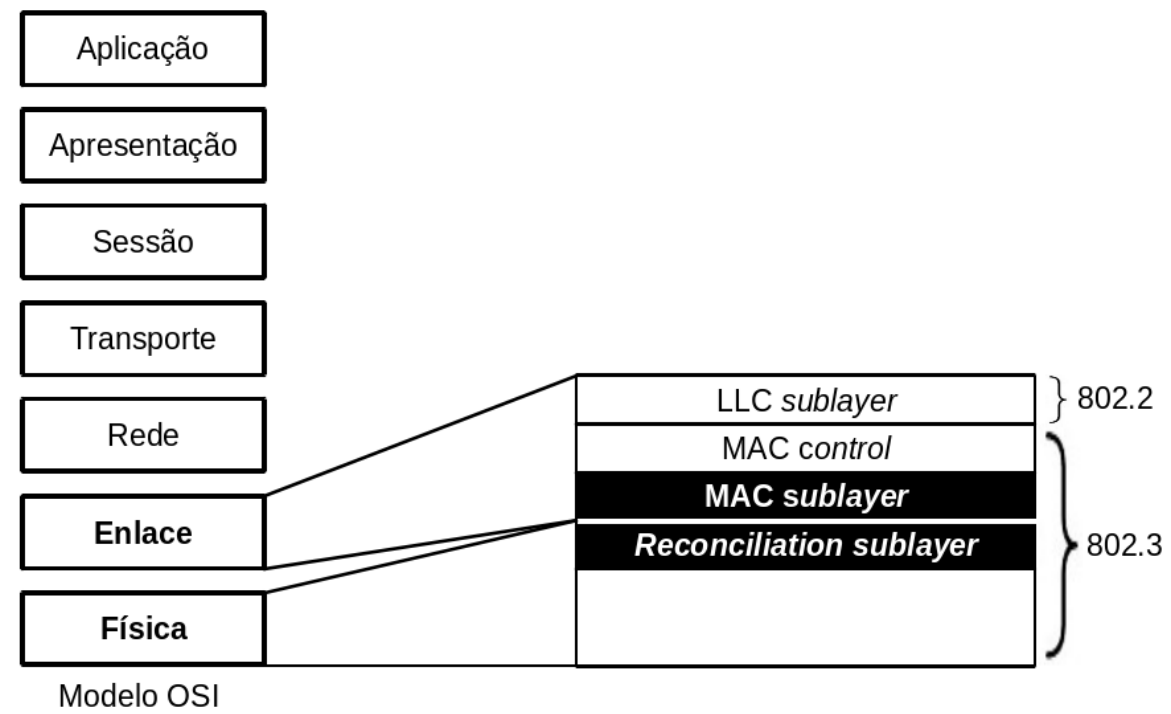

Figura 3.1: Relação do padrão IEEE 802.3 com as camadas do modelo OSI.

As sub camadas logical link control - LLC (definida pelo IEEE 802.2) e MAC Control, apresentadas na Figura 3.1, são opcionais para a implementação do padrão Ethernet. 
As camadas em destaque na figura, MAC sublayer e reconciliation sublayer (RS), são definidas pelo padrão e implementadas nesse trabalho. Na RS são implementadas as primitivas de serviço de physical layer signaling (PLS), ambas discutidas na Seção 3.4.

\subsection{Modelo dos serviços providos pelo MAC}

O padrão Ethernet define um modelo dos serviços provido ao cliente. Esses serviços estão divididos em duas funções: a requisição e a indicação. Essas funções permitem que o módulo ou cliente que esteja usando o MAC Ethernet tenha acesso as suas funcionalidades.

\subsubsection{Requisição}

A função requisição permite transmitir informações através do MAC Ethernet para uma ou mais entidades de destino. O padrão define alguns parâmetros para executar essa transmissão. O primeiro parâmetro, que é o endereço de destino, deve ser preenchido com o endereço da entidade a qual a mensagem deve alcançar. O segundo parâmetro é o endereço de origem, que pode ser preenchido com o endereço de origem. Caso esse campo não seja preenchido, o endereço de origem do MAC Ethernet atual será anexado. O outro campo é a unidade de dados, que deve conter os dados que serão transmitidos no pacote. E por último, o campo de sequência de checagem do pacote. Apesar do MAC Ethernet possuir um módulo para calcular essa sequência de checagem, ela pode opcionalmente ser passada por parâmetro.

\subsubsection{Indicação}

A função indicação permite a transmissão de informações entre a entidade MAC Ethernet e seu Cliente. Essa função indica que um pacote chegou com uma mensagem destinada ao cliente. Ela possui cinco parâmetros: endereço de destino, endereço de origem, unidade de dados, sequência de checagem do pacote e estado da recepção. O primeiro campo contém o endereço de destino especificado no pacote que chegou. O segundo campo está preenchido com o endereço de origem do pacote, que no caso é o endereço da entidade em questão. Os dados da mensagem estão no campo unidade de dados. Como na função requisição, caso o campo de sequencia de checagem esteja preenchido, ele contém a sequência de checagem do pacote, que não foi verificado pelo MAC Ethernet. E por último, o estado da recepção, que indica ao cliente o estado da informação do pacote. 


\subsection{Frame Ethernet}

O principal módulo do padrão Ethernet é a definição da semântica e da sintaxe do pacote e seus campos. Como ilustrado na Figura 3.2, o quadro (frame) possui características diferentes do pacote. Um quadro Ethernet está inserido no pacote Ethernet. A adição de campos de controle da transmissão como o preâmbulo, SDF (Start Frame Delimiter) e o extensão ilustram essa diferença. Todos os campos são de tamanho fixo, exceto o de dados, pad e extensão. O campo de dados possuiu um espaço para padding, utilizado apenas em situações onde a soma dos campos fixos mais o campo dados não é maior ou igual a 64 Bytes. O campo extensão só é requerido quando o modo de operação é $1000 \mathrm{MB} / \mathrm{s}$ half-duplex, e não será detalhado. O encapsulamento do quadro Ethernet em pacote e o seu desencapsulamento é realizado pelo MAC Ethernet. Os campos adicionais para esse encapsulamento e os pertencentes ao quadro são descritos em ordem de transmissão.

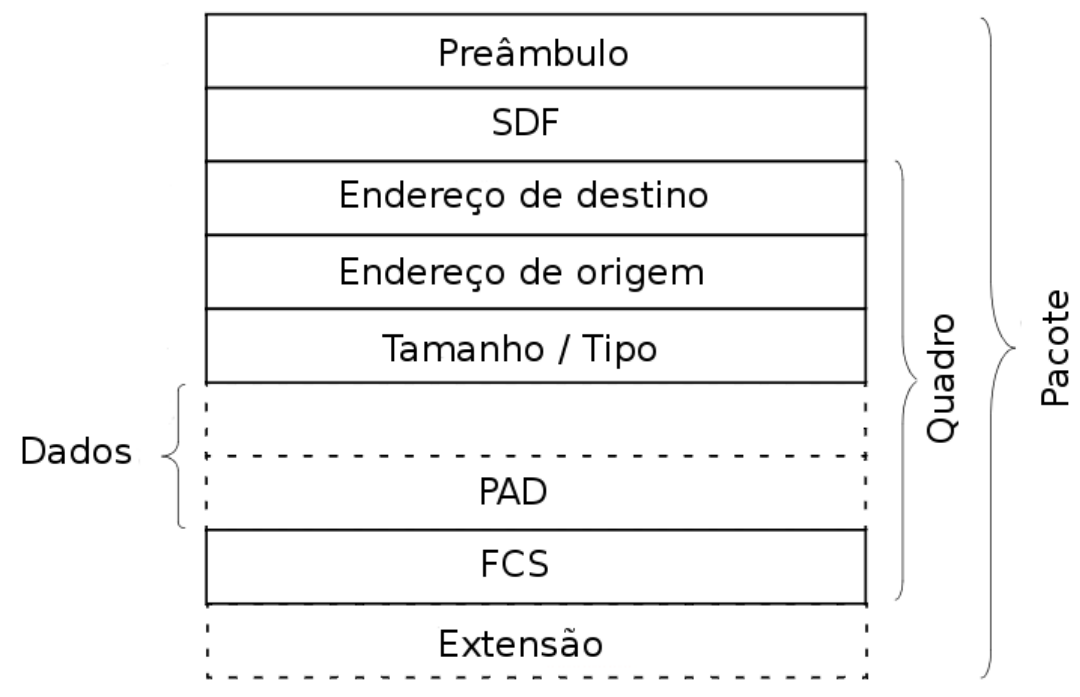

Figura 3.2: Pacote Ethernet. Adaptado de The Institute of Electrical and Electronics Engineers (2012)

O campo preâmbulo da Figura 3.2 contém uma sequência pré definida de sete octetos utilizada para permitir que a camada física de um MAC Ethernet receptor saiba o início de um pacote transmitido. Esse sequência é 1010101010101010101010101010101010101010 10101010 10101010. Seguido da sequência do preâmbulo, o campo delimitador de início de quadro (SDF) contém apenas um octeto, 10101011, que indica o fim do preâmbulo e o início do quadro Ethernet.

O primeiro campo do quadro Ethernet é o endereço de destino. Ele contém seis octetos (48-bits) que representam o endereço de destino do quadro. O primeiro bit desse campo indica se o endereço de destino é individual ou de grupo. Se o primeiro bit desse campo é '0', isso significa que o endereço de destino é individual, e caso seja '1' o endereço de destino é de grupo. A informação de que se esse endereço é localmente ou globalmente 
administrado está no segundo bit, onde o valor é '0' ou '1', respectivamente. Os 46-bits restantes completam o endereço de destino do quadro Ethernet.

O endereço de um MAC Ethernet é dividido em duas classes, o individual e o de grupo. O endereço individual é um endereço único que está associado a uma estação/nó da rede em particular. A segunda classe é classificada em dois tipos de endereço de grupo, o multicast e o broadcast. O multicast está associado a um grupo de endereços pertencentes a um grupo de estações/nós da rede. Diferente do multicast, o endereço de grupo broadcast atinge todas as estações/nós da rede, que possui os 48-bits preenchidos com '1'.

O próximo campo apresentado na Figura 3.2 é o endereço de origem. Esse campo deve conter o endereço da entidade MAC Ethernet que gerou e transmitiu o pacote. Como no campo endereço de destino, esse campo também tem tamanho de seis octetos (48-bits) e as mesmas características dos valores reservados, como o de broadcast.

O tamanho dos dados do pacote ou o tipo desses dados são representados pelo campo tamanho / tipo do quadro da Figura 3.2. Esse campo contém 2 octetos (16-bits) que podem significar o tamanho dos dados ou o tipo dos dados. Caso o valor desse campo seja menor ou igual a 1500 (0x05DC), ele é interpretado como tamanho dos dados, que indica a quantidade de octetos no campo dados. Mas, se o valor for maior ou igual a 1536 (0x600), esse campo é interpretado como tipo dos dados, que é um Ethertype de um protocolo cliente. Caso ele seja interpretado como tipo de dados, é de responsabilidade do cliente (camada superior) interpretar o Ethertype e os dados contidos no pacote.

A mensagem transmitida está no campo dados, que pode ser visualizado na Figura 3.2. Com o tamanho flexível, esse campo pode assumir valores de 46 a 1500 Bytes, 1504 Bytes ou 1982 Bytes. A primeira classe de valores representa os quadros básicos, o segundo valor os quadros com tag, e o último valor os quadros envelopados (jumbo frames). A entidade MAC Ethernet requer um tamanho mínimo do quadro para transmissão. Esse tamanho mínimo é de 64 Bytes, que deve ser alcançado somando os tamanhos dos campos endereço de destino, endereço de origem, tamanho/tipo, o valor mínimo do dados mais o PAD (46 Bytes) e o FCS, campo esse descrito a seguir. Caso o campo dados seja menor que 46 Bytes, um "padding" é adicionado ao final do campo dados, com octetos suficientes para alcançar esse mínimo.

O último campo do quadro Ethernet é o frame check sequence (FCS). O objetivo desse campo é verificar a integridade de todos os outros campos do quadro Ethernet, que é conferido na entidade de destino do pacote. Ele possuiu 4 octetos (32-bits) e pode ser preenchido pelo cliente, passando o valor pela função requisição, ou pela entidade MAC Ethernet. O conteúdo desse campo, o cyclic redundancy check (CRC), é calculado por meio de um CRC polinomial dos campos protegidos do quadro Ethernet: endereço de destino, endereço de origem, tamanho/tipo, dados e pad. Esse calculo é detalhado na Seção 3.2.9 do documento 802.3 (The Institute of Electrical and Electronics Engineers, 2012). 
A ordem de transmissão de todos os campos do quadro Ethernet é d esquerda para a direita, com exceção do FCS, que tem sua ordem de envio baseada nos coeficientes do polinômio. Os pacotes que contém tamanho entre 1518 e 1522 Bytes possuem cabeçalho VLAN. Esse cabeçalho permite que equipamentos e interfaces separem tráfegos em LANs virtuais. Caso uma interface não esteja configurada para receber esse tipo de pacote, ele será descartado. Esse caso entra nos três possíveis tipos de pacotes inválidos: tamanho inconsistente, tamanho não divisível por 8 (bits), e CRC diferente do calculado para verificação. O conteúdo de pacotes que são inválidos não são repassados para o cliente do MAC Ethernet.

\subsection{Protocolo MAC}

O protocolo media access contol (MAC) consiste em um conjunto de regras para comunicar a camada física com a sub camada superior da camada link de dados. Além da comunicação entre camadas, o protocolo MAC regula a movimentação de seus pacotes e gerencia a largura de banda para ordenar a utilização dos recursos da rede de forma eficiente (Peyravi, 1999). A Tabela 3.1 mostra, destacado em negrito, onde o protocolo MAC deve ser implementado e apresenta uma característica intrínseca de cada camada e sub camada em questão.

Tabela 3.1: Características das sub camadas

\begin{tabular}{l|c|c}
\hline Camada & Sub camada & Característica \\
\hline \hline Link de dados & Superior (LLC/Cliente) & Independente de camada de acesso \\
\hline Link de dados & MAC & Independente de meio \\
\hline Camada física & - & Dependente de meio \\
\hline
\end{tabular}

A divisão de responsabilidades para essas camadas e sub camadas requer duas atividades principais para o controle do link de dados realizado pelo MAC Ethernet, o encapsulamento de dados e a gestão de acesso ao meio. A primeira atividade é dividida em três subfunções: (i) framing, responsável por delimitar o limite do quadro e sincronizar o quadro; (ii) addressing, que deve lidar com endereços de origem e destino e (iii) error detection, detecta erros da transmissão no meio físico. A atividade gestão de acesso ao meio é dividida em duas subfunções: (i) medium allocation, responsável em alocar o uso do meio compartilhado, com o intuído de evitar colisão; (ii) contetion resolution, que deve lidar com as possíveis colisões no meio. A atividade de gestão de acesso ao meio só é utilizada no modo de operação half-duplex, onde o meio físico de comunicação é compartilhado entre estações/nós da rede.

A coordenação de funcionamento do protocolo MAC é baseado em um algoritmo que pode ser centralizado ou distribuído. No algoritmo de controle distribuído, cada estação/nó da rede toma suas decisões individualmente que lida com a reconfiguração 
e queda de estações/nós da rede, de forma mais eficiente comparado ao centralizado (Peyravi, 1999). Na coordenação centralizada, um único nó da rede toma as decisões relacionadas ao tratamento de colisão, retransmissão de pacotes, acesso ao meio, reconfiguração da rede e queda de nós da rede.

\subsubsection{Modo de operação}

O padrão Ethernet define dois modos de operação para a sub camada MAC, o half-duplex e o full-duplex. O modo half-duplex, utilizado em redes que possuem meio compartilhado, não é implementado na proposta desse trabalho. Portanto, ele será brevemente introduzido, sem detalhamento de algoritmos e dos seus problemas. O mesmo acontece para o algoritmo Carrier Sense Multiple Access / Collision Detect (CSMA/CD), que também é definido pelo padrão Ethernet proposto para controlar o acesso ao meio compartilhado, no modo half-duplex, e lidar com possíveis colisões.

No modo half-duplex, estações disputam o uso do meio físico, usando o algoritmo CSMA/CD. As comunicações bidirecionais são realizada por trocas rápidas dos quadros transmitidos. Esse modo de operação é possível em todas as mídias suportadas e é requerido nos meios que são incapazes de suportar transmissão simultânea e recepção sem interferência.

A operação full-duplex permite comunicação simultânea entre os pares de uma estação usando um canal dedicado (ponto a ponto). Nesse modo de operação não é necessária a utilização do algoritmo CSMA/CD, pois ele permite que a interface transfira a qualquer momento. Essa operação não exige que transmissores adiem uma transmissão, nem que eles monitorem ou reagem para receber uma atividade, pois não há nenhuma disputa de meio compartilhado. O modo full-duplex pode apenas ser usado quanto todos os seguinte itens são atendidos:

- O meio físico é capaz de suportar transmissões e recepções simultâneas sem interferência.

- Existir exatas duas estações conectadas com um link ponto a ponto full-duplex. Desde que não exista nenhuma disputa pelo meio compartilhado, os algoritmos de acesso múltiplo são desnecessários.

- Ambas as estações da rede são capazes de operar em full-duplex (e terem sido configuradas para usar).

A configuração mais comum por operação full-duplex consiste em uma ponte central (switch) com uma rede dedicada, conectando em cada porta um único dispositivo. 


\subsubsection{Procedimento de transmissão e recepção}

A Figura 3.3 representa a estrutura e os módulos de um MAC Ethernet básico. No bloco interface está implementado os serviços providos pelo MAC para o client. No caso, esse serviço está indicado pelas funções indication e request da figura. Os blocos Transmit/Receive Data Encapsulation/Decapsulation são responsáveis pela atividade de encapsulamento de dados. Os dois próximos blocos, Transmit/Receive Media Accesss Management, são responsáveis pela atividade de gestão de acesso ao meio. O bloco em destaque, com as letras RS (reconciliation sublayer), é uma sub camada da camada física que traduz primitivas de serviço PLS para media independent interface (MII) e de MII para primitivas de serviço PLS. Por fim, o bloco Physical, representa a camada física responsável por interfacear com o meio (medium). A seta bidirecional que liga o bloco Interface ao bloco Physical indica comunicação utilizada pelo cliente para gestão/configuração do $\mathrm{PHY}^{1}$.

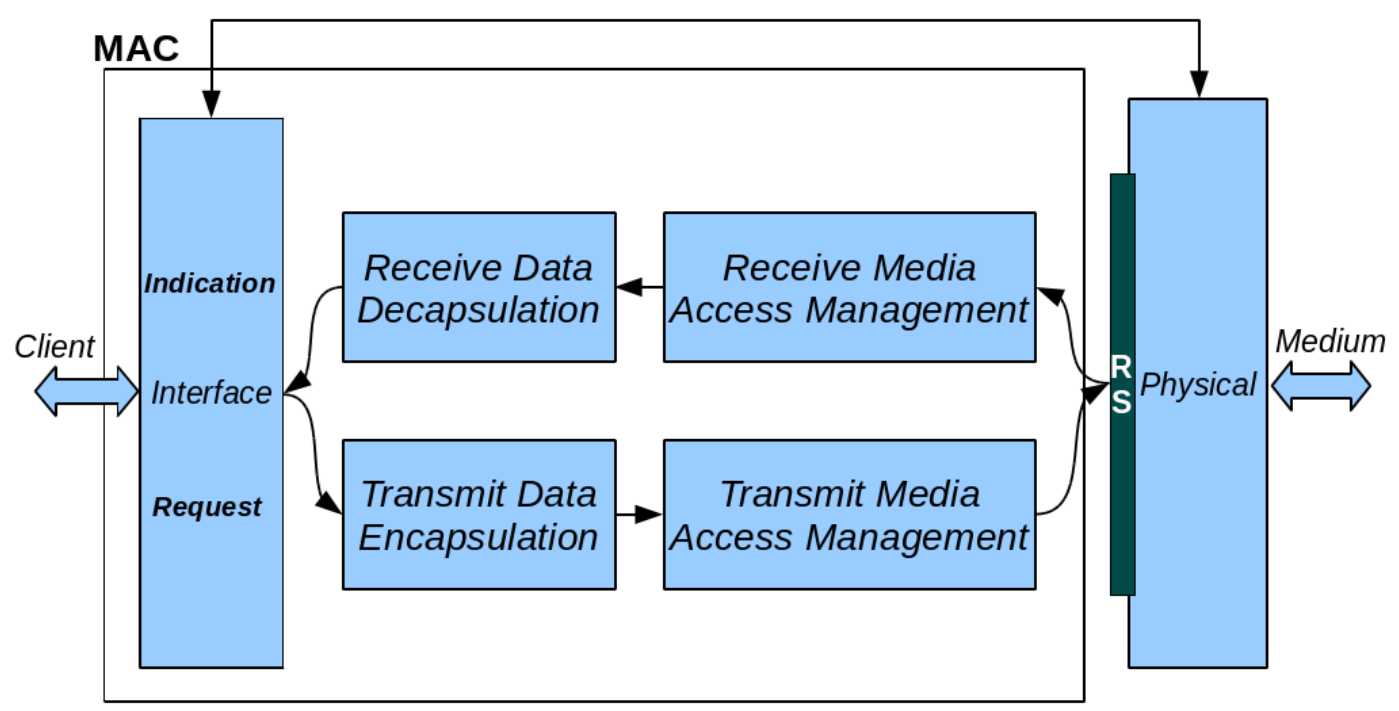

Figura 3.3: Modelo genérico de um MAC Ethernet

O protocolo MAC define um processo para transmissão de uma mensagem. Para exemplificá-lo, os passos listados a seguir são válidos apenas para a sub camada MAC, que considera uma operação normal, sem desvios ou tratamentos. Esses passos utilizam como referência a Figura 3.3.

- A função requisição (request) inicia o processo;

- Um quadro é gerado no componente Transmit Data Encapsulation com os dados informados na requisição;

- O preâmbulo e o SFD são anexados ao quadro;

\footnotetext{
${ }^{1}$ Abreviação de physical layer device
} 
- Se necessário, o pad é calculado e anexado ao quadro;

- Ao mesmo tempo do processo de anexar o pad, os campos endereço de destino, endereço de origem e tamanho/tipo são anexados;

- O CRC é calculado e anexado ao campo FCS do quadro;

- O quadro é entregue ao componente de Transmit Media Access Management para transmissão.

Os mesmos critérios adotados no exemplo de transmissão são utilizados para o processo de recepção:

- A camada física (Physical) detecta a chegada de um preâmbulo;

- A camada física ativa o sinal receiveDataValid (via $\mathrm{RS}$ );

- A camada física decodifica e traduz os bits recebidos para dados binários (se os bits recebidos forem codificados);

- A camada física encaminha para camada subsequente acima (Receive Media Access Management) os dados binários, removendo os bits do preâmbulo e do SFD.

- A sub camada Receive Media Access Management do MAC recebe os bits enviados a ela enquanto o sinal receiveData Valid estiver ativo;

- Quando o sinal receiveDataValid é removido, a sub camada Receive Media Access Management do MAC trunca o quadro recebido e passa para sub camada Receive Data Decapsulation para processamento;

- A sub camada Receive Data Decapsulation checa se o endereço de destino é igual ao seu endereço;

- Se os endereços são iguais, a sub camada Receive Data Decapsulation passa os dados através da função indicação (indication) para o próximo nível (cliente MAC ou sub camada superior).

No modo full-duplex, o componente Transmit Media Access Management não precisa se preocupar com outro tráfego no meio. Então, a transmissão dos quadros pode iniciar logo após o atraso entre quadros. Nesse modo, a sub camada MAC não realiza processos de frame bursting (envio seguido de dados no meio) ou carrier extention (estender uma transmissão atual). 


\subsection{Media independent interface - MII}

Considerando que o projeto é baseado em um componente MAC Ethernet que suporta $10 \mathrm{Mb} / \mathrm{s}$ e $100 \mathrm{Mb} / \mathrm{s}$, protocolos alternativos como XGMII (10 Gb/s) ou GMII (1 Gb/s) não serão discutidos. O MII é uma interface padrão, que possuiu protocolo definido no padrão Ethernet, desenvolvida para ter compatibilidade com componentes de terceiros (PHYs). Isso para permitir uma flexibilidade no desenvolvimento desses componentes, provendo uma interface independente de mídia. O objetivo principal do MII é interligar um MAC Ethernet a um PHY. No entanto, ele permite outros tipos de ligações, como interligar diretamente dois circuitos integrados, interligar uma placa mãe a uma placa filha ou interligar dois componentes via cabo. Além da interface para envio e recepção de pacotes, o MII também implementa uma interface de gestão. A Figura 3.4 apresenta as primitivas de serviços PLS e os sinais MII na sub camada RS da camada física.

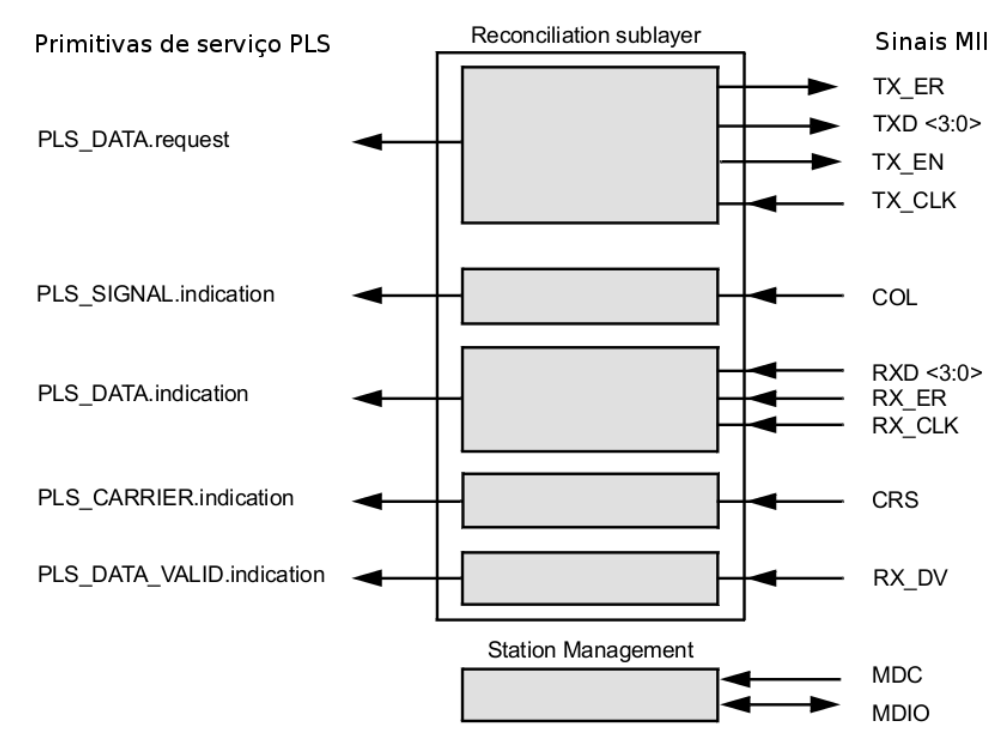

Figura 3.4: Entrada e saída da sub camada RS. Adaptado de The Institute of Electrical and Electronics Engineers (2012).

As primitivas de serviço PLS são um conjunto de sinais definidos para comunicação entre a sub camada MAC e a RS. Esses sinais estão muito próximos das funções requisição e indicação que representam as atividades na rede. Como exemplificado na Figura 3.4, a primitiva de serviço PLS_DATA.request representa uma transmissão de um novo quadro da sub camada MAC para a RS. Essa transmissão gera sinais como TX EN, que representa um início de transmissão válida, e $\mathrm{TXD}<3: 0>$, que são os dados do pacote. O sinal TX_ER só é utilizado caso ocorra um erro na transmissão atual. A RS espera que o componente ligado a MII gere um clock de $25 \mathrm{MHz}$, em transmissões a $100 \mathrm{Mb} / \mathrm{s}$, no sinal TX_CLK. Esse clock é utilizado para sincronizar a transmissão do pacote. Os sinais PLS_SIGNAL.indication - COL e PLS_CARRIER.indication - CRS são utilizados apenas no modo half-duplex, os quais servem para indicar uma colisão no meio e o início de 
uma transmissão, respectivamente. O PLS_DATA_VALID.indication informa atividade no sinal RX_DV da MII, indicando o início de uma recepção válida. Os dados do pacote recebido estão no sinal $\mathrm{RXD}<3: 0>$, que é traduzido em conjunto com o RX_ER, para um PLS_DATA.indication. E por último, o sinal RX_CLK, conforme o TX_CLK, é um sinal que a RS espera ser gerado para realizar a leitura sincronizada dos dados do pacote.

Como representado na Figura 3.3, a Figura 3.4 também possui a parte de gestão de componente (station management) representada pelos sinais MDC e MDIO. O sinal de MDC é o clock do canal de comunicação, com o intuíto de sincronizar os dados transmitidos pelo sinal bidirecional MDIO. 


\section{Aplicações e Arquiteturas DSPs}

Neste capítulo apresenta-se as principais características de uma aplicação DSP, com exemplo de aplicações e arquiteturas. Dentre essas arquiteturas apresentadas, algumas são multicore e utilizam NoC (mesh) para comunicação interna dos cores.

\subsection{Processamento digital de sinais}

Um sinal pode ser definido como qualquer quantidade física que varia com o tempo, espaço, ou qualquer outra variável independente (Proakis e Manolakis, 1996). Ele desempenha um papel importante no cotidiano do ser humano, como por exemplo a comunicação por meio do sinal de voz. Outros exemplos, são os sinais de música, de vídeo e até mesmo de imagem. Um sinal pode carregar informações, e extrair essas informações, de forma que ela seja útil, é um dos objetivos do processamento de sinais. Existe dois tipos de processamento de sinais, o processamento analógico e o processamento digital (DSP Digital Signal Processing).

O processamento analógico assume que o sinal é contínuo, o qual representa uma quantidade física que varia continuamente. Para que seja possível extrair as informações desse sinal, é necessário submetê-lo a um processo de transformação. Esse processo é realizado normalmente por um sistema de baixa confiabilidade, alto custo e de difícil alteração de suas características, devido ao hardware utilizado (Diniz et al., 2004). Os três fatores citados acima representam as principais desvantagens do processamento analógico comparado ao processamento digital, os quais motivaram o desenvolvimento de sistemas DSP. 
Até a década de 60, a tecnologia para processamento de sinais era basicamente analógica. A evolução de computadores e microprocessadores juntamente com diversos desenvolvimentos teóricos causou um grande crescimento da tecnologia digital, introduzindo o DSP. Um marco na introdução dessa nova tecnologia foi a divulgação de uma classe de algoritmo eficiente para processar a DFT (Discrete Fourier Transform), que é discutida por Meyer-Baese (2007). Um outro fator que contribuiu para o desenvolvimento de DSP foi o surgimento dos PDSPs (Programmable digital signal processor) na década de 1970 (Meyer-Baese, 2007). Esse processador podia executar as operações MAC (multiplicar e acumular) utilizando ponto fixo em um único ciclo de clock, o que foi um aprimoramento essencial para a arquitetura dos processadores daquela época. Houveram outros acontecimentos históricos que ajudaram a consolidar a adoção de DSP. Um dos principais marcos foi a publicação de dois livros em meados da década de 70, os quais são considerados os primeiros livros sobre o assunto, o Digital Signal Processing dos autores Oppenheim e Schafer (1975) e o Theory and Application of Digital Signal Processing escrito por Rabiner e Gold (1975). No entanto, a evolução desta tecnologia em consequência do advento da tecnologia VLSI (very-large-scale integration) em circuitos eletrônicos, possibilitou o desenvolvimento de hardware digital de propósito geral ou específico, que possuía características específicas para o DSP, como a redução do consumo de energia, da área de ocupação e o aumento da capacidade de processamento. Assim tornou possível a construção de sistemas de DSP mais sofisticados capaz de executar funções e tarefas mais complexas. Com isso, os sistemas de processamento analógico de sinais foram gradativamente sendo substituídos por sistemas de DSP. Mesmo com todo esse avanço tecnológico, algumas aplicações que contêm vários sinais de entrada, um grande fluxo de dados e o requisito de processamento em tempo real, pode ser que um sistema DSP não consiga atender toda a demanda de processamento necessária (Proakis e Manolakis, 1996). Atualmente, um único circuito integrado digital pode conter milhões de portas lógicas operando a altas velocidades, permitindo, assim, construir processadores digitais rápidos a custo relativamente baixo (Diniz et al., 2004). Por esses e outros motivos, DSPs são utilizados em diversas aplicações e implementados por uma grande variedade de arquiteturas.

\subsection{Aplicações DSPs}

Com o aperfeiçoamento da tecnologia, as técnicas de DSP estão presentes em diversas áreas. A Tabela 4.1 exibe uma lista das principais áreas e suas respectivas aplicações.

Dentre as técnicas e aplicações apresentadas na Tabela 4.1, a compressão de dados, filtros de sinais, reconhecimento e análise de voz e o processamento de imagens podem ser consideradas as que mais são utilizadas atualmente. Um exemplo do uso dessas técnicas e aplicações, tem o trabalho proposto por Derbel et al. (2009), que utiliza técnicas DSP com o intuito de implementar um processamento de sinal de voz em um processador DSP para 
Tabela 4.1: Áreas e aplicações de DSP.

\begin{tabular}{l|c}
\hline Área & Exemplo de aplicação \\
\hline \hline DSP de proposito geral & Filtros digital \\
Imagens e Gráficos & Visão na robótica \\
Voz (Fala) & Reconhecimento e análise de voz \\
Controle & Controle de impressoras a laser \\
Militar & Processamento de radar \\
Telecomunicação & Cancelamento de eco \\
Automotivo & Controle do ABS \\
\hline
\end{tabular}

Fonte: Adaptado de Mitra (1998)

implante coclear. Nesse caso, a transformada de wavelet é escolhida por ser caracterizada pela sua resolução de tempo e frequência, o que é semelhante ao sistema auditivo (Derbel et al., 2009).

Um trabalho mais recente, apresenta um sistema DSP de reconhecimento de voz baseado na melhoria de desempenho em termos de precisão de reconhecimento e de custo computacional. Nesse trabalho, são levantadas e discutidas várias abordagens de extração de características, como o uso de Mel Filter Banks em conjunto com Mel Frequency Cepstrum Coefficients (MFCC) e de bancos de filtros coclear (Cochlear Filter Banks - CFB), além das adaptações da técnica de classificação (Daphal e Jagtap, 2012).

A compressão e descompressão de dados são bastante utilizadas na área de telecomunicação. A compressão de sinal em banda usada em celulares permitiu que um grande número de chamadas possa ser administrada simultaneamente por um único aparelho. Outro exemplo do uso dessa técnica é a compressão realizada nos frames de vídeos produzidos por uma câmera de computador, para que a imagem possa ser transmitida em tempo real pela internet. Além disso, o uso de processadores digitais de sinais em conjunto com as técnicas de compressão e descompressão tornou possível a implementação de diversas tecnologias de codificador/decodificador (CODEC) de sinal.

Os filtros têm como principal objetivo remover partes indesejadas de um sinal, como, por exemplo, um ruído. Mas também, podem ser usados para extrair apenas uma parte desejada de um sinal, como um banda de frequência específica. Outro aspecto importante dos filtros, é o seu uso para melhoria de um determinado sinal, podendo ser um sinal de áudio ou até mesmo uma imagem.

\subsubsection{Características das aplicações DSP}

As aplicações DSP possuem características típicas, como, por exemplo, terem algoritmos de computação matemática intensiva. Normalmente, a operação matemática dominante nesses algoritmos é a de multiplicar e acumular. Para ilustrar essa característica, os algoritmos de filtros FIR (Finite Impulse Response) podem ser citados, pois geralmente 
possuem como principal operação um somatório (acúmulo) de multiplicações (Diniz et al., 2004).

Uma das principais características das aplicações DSP é a grande quantidade de dados de entrada para o processamento. Esse grande fluxo de dados pode variar conforme a aplicação, mas também, com a taxa de amostragem dos dados. A Figura 4.1 apresenta um gráfico da evolução da demanda de processamento de quatro aplicações, conforme a taxa de amostragem dos dados. Com o crescimento da complexidade em aplicações DSP, foi necessário executar cada vez mais ciclos de instruções para cada intervalo amostrado, para atender a demanda computacional dessas aplicações em tempo real. Como por exemplo, o processamento de um pixel de vídeo na resolução Standard Definition (SD) ou em High Definition (HD) passou de 5000 instruções por volta do ano de 2009. Isso ocorre, pois cada vez mais utiliza-se diferentes técnicas e algoritmos sobre a mesma amostra, com o intuito de extrair mais informações desse período amostrado.

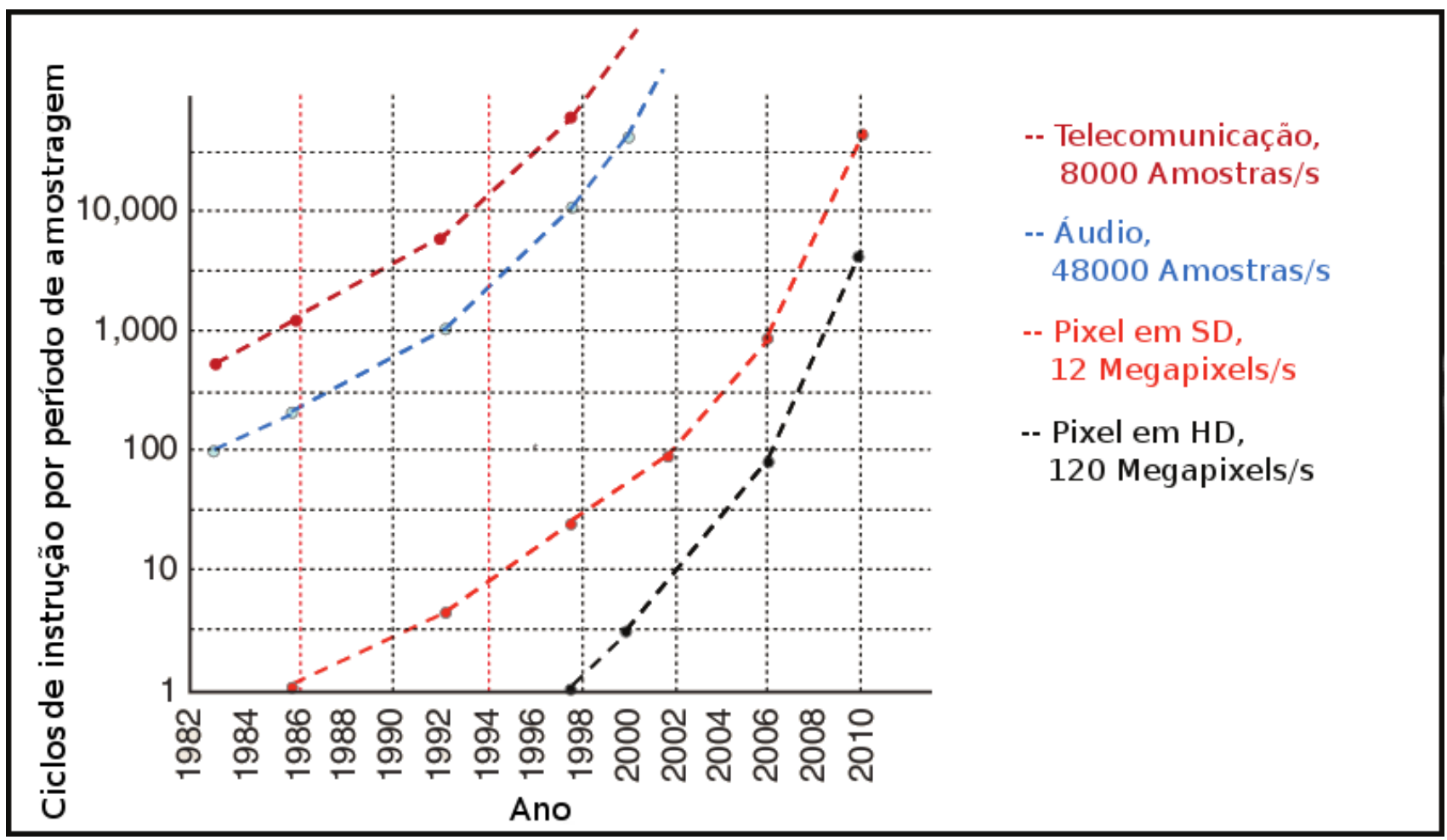

Figura 4.1: Evolução da demanda de processamento das aplicações, de acordo com o número de instruções por período de amostragem. Adaptado de Karam et al. (2009).

No DSP, o sinal possui valor discreto ou digital, e pode ter duas origens diferentes. A primeira é a partir de uma amostragem de um sinal contínuo, o tornando em um sinal digital. Essa primeira abordagem pode ser realizada pelos conversores A/D (Analógico/Digital). A outra é a partir de uma fonte que já fornece o sinal amostrado. A Tabela 4.2 mostra alguns exemplos de aplicação com suas taxas de amostragens. Nos dados dessa tabela, é possível notar que para aplicações como o processamento de áudio 
e que envolvem processamento de vídeo, a taxa de amostragem é consideravelmente alta, chegando a $14 \mathrm{MHz}$ em algumas aplicações.

Tabela 4.2: Aplicações e suas taxa de amostragem

\begin{tabular}{l|c}
\hline Aplicação & Taxa de amostragem nominal \\
\hline \hline Telecomunicação & $8 \mathrm{KHz}$ \\
Processamento de voz & $8-10 \mathrm{KHz}$ \\
Processamento de áudio & $40-48 \mathrm{KHz}$ \\
Taxa de frame de vídeo & $30 \mathrm{~Hz}$ \\
Taxa de pixel de vídeo & $14 \mathrm{MHz}$ \\
\hline
\end{tabular}

Fonte: (Papamichalis, 1990)

Além do grande fluxo de dados, outra característica comum entre as aplicações DSP, é que seus algoritmos devem ser processados em tempo real. Essa característica pode ser definida como um processo que é realizado pelo processador DSP sem criar um atraso visível para o usuário (Papamichalis, 1990). Um exemplo em processamento de imagem, que pode ser considerada de tempo real, é que o processador deve terminar o processamento dentro do período de atualização de quadro. Se as informações de pixel não forem atualizadas dentro desse período, pode ocorrer problemas como Flicker (um atraso visível), manchas, ou falta de informação.

E por fim, uma característica citada por Papamichalis (1990), é o fato de possuírem um sistema flexível, pois, em muitas das aplicações DSP, as técnicas ainda estão na fase de desenvolvimento e, portanto, os algoritmos tendem a mudar ao longo do tempo.

\subsubsection{Classes de aplicações DSP}

As aplicações DSP podem ser classificadas em quatro classes, de acordo com Diniz et al. (2004). Essas classes são:

- Processamento de imagem. Uma característica dessa classe é possuir o sinal no domínio do espaço, e não do tempo. Esse sinal, que é uma imagem, basicamente representa uma variação de intensidade de luz e de cor no espaço. Essa imagem normalmente já está digitalizada, sendo desnecessário a amostragem do meio analógico. A representação de sinais bidimensionais, os filtros e as transformadas são as principais características e técnicas dessa classe.

- Sistemas multimídia. Tal como na classe de processamento de imagem, aqui a informação é representada em forma digital. Essa classe tem como característica a compressão dos dados para armazenamento ou até mesmo transmissão. As transformadas, os bancos de filtros, e as wavelets são bastante utilizadas para compressão, pois são capazes de explorar a alta correlação presente nos sinais dessa classe. 
- Sistemas de comunicação. Nos sistemas de comunicação, a compressão e a codificação das fontes de informação são bastante utilizadas, para atender sua principal característica, que é a transmissão dessas informações. Em alguns casos, a compactação dos sinais permite perder alguma informação, deixando-o, assim, com baixa qualidade. No entanto, esse sinal é pequeno o bastante para que a transmissão das suas informações seja realizada com maior velocidade e para mais usuários. Wavelets, transformadas e bancos de filtros são as técnicas mais utilizadas nessa classe, podendo desempenhar, como por exemplo, acesso múltiplo por divisão de código (CDMA, do inglês Code-Division Multiple Access) e multiplexação ortogonal por divisão de frequência, utilizadas em teledifusão de áudio e TV digitais.

- Processamento de sinais de áudio. Com uma leve diferença entre a segunda classe apresentada, as aplicações que fazem parte dessa classe se preocupam com a restauração fiel de sinal digital para o meio analógico. Além disso, as aplicações se baseiam principalmente em modelos estimados, que procuram restaurar informações perdidas de um sinal. Entretanto, esses modelos estimados podem ser simplificados, tornando-os mais eficazes quando usados com algum tipo de processamento via banco de filtros e transformadas (Diniz et al., 2004).

Mediante todas essas características e requisitos, as aplicações DSP dependem de um hardware capaz de atender a demanda de processamento que elas necessitam. Com isso, o desenvolvimento de hardware específico para aplicações DSP alavancou conforme a demanda de crescimento dessa área.

\subsection{Arquiteturas DSPs}

O processamento digital de sinais pode ser realizado de duas formas. A primeira e mais simples, é utilizando rotinas de software compiladas para processadores de propósito geral. Nesse caso, a preocupação do desenvolvedor é com a escolha da técnica e do algoritmo a utilizar e como implementar essa escolha. Porém, essa opção pode ser inviável, dependendo da aplicação e de seus requisitos, dado a limitação dos recursos disponíveis pelo hardware para a computação dos algoritmos que possuem propriedades típicas, tornando o processamento ineficiente em relação a desempenho, consumo de energia e previsibilidade.

Uma estratégia para contornar esses problemas é a implementação de um hardware específico para a aplicação em questão. Nesse cenário, a arquitetura do sistema deve ser projetada para atender aos requisitos da aplicação, usando o mínimo de recursos necessários. Há quatro formas principais de definir um hardware específico apropriado para aplicação (Diniz et al., 2004), através do uso de:

- Componentes eletrônicos básicos e circuitos integrados; 
- Circuito integrado de aplicação específica (ASIC);

- Processadores DSP;

- Dispositivos lógicos programáveis (FPGA - Field-programmable gate array).

A opção de implementar um hardware específico para DSP utilizando componentes eletrônicos básicos e circuitos integrados, normalmente é viável quando se tem um sistema pequeno e simplificado. Mas, conforme a complexidade desse sistema cresce, essa opção se torna inviável, dado a dificuldade de alteração do sistema e a baixa escalabilidade. O uso da segunda opção, a implementação de um ASIC próprio para aplicação, é viável quando se tem um sistema robusto, uma arquitetura já amadurecida e que não sofrerá modificações. Portanto, essa opção não é uma boa escolha para um sistema em desenvolvimento, além de possuir um custo elevado.

Por outro lado, o uso de processadores DSP é a uma opção vantajosa, pois, eles são desenvolvidos especialmente para aplicações DSP, e possuem uma arquitetura preparada para executar operações matemáticas de multiplicação e soma de maneira eficiente. Isso é uma vantagem, já que boa parte das aplicações DSP possuem muitas operações matemáticas desse tipo. Além disso, os fabricantes desses processadores disponibilizam IDE de programação para os mesmos, os quais são facilmente programados, normalmente em código $\mathrm{C}$, permitindo uma boa flexibilidade na programação. No entanto, a escalabilidade desses sistemas pode ser comprometida, pois não há possibilidade de alterar os recursos de hardware disponíveis nos processadores DSP. Dada essa limitação, os fabricantes de produtos finais começaram a utilizar vários processadores DSP trabalhando em conjunto para ampliar seu poder de processamento (Karam et al., 2009).

O uso de FPGA tem sido uma opção bastante utilizada no desenvolvimento de sistemas de DSP para arquiteturas de uma dada aplicação (Meyer-Baese, 2007). Uma vantagem do uso de dispositivos como o FPGA é sua reprogramação, que garante uma certa flexibilidade durante o desenvolvimento do sistema. Além disso, é possível desenvolver sistemas utilizando diversos tipos de processadores DSP, simultaneamente ou não, emulados em um FPGA.

No início dos anos 80 surgiram os quatro primeiros processadores DSP, também conhecidos como microprocessadores de sinal. O S2811 da American Microsystems Inc (AMI) foi o pioneiro nessa área. Na mesma época, foi apresentado o Intel 2920, com conversores A/D e D/A incorporados, e o NEC uPD77P20, que permitiam realizar, por exemplo, operações de modulação de demodulação de sinais. O último, mas definitivamente o mais avançado, foi o TMS32010, da Texas Instruments (TI). Uma característica comum entre esses processadores DSP era a adoção da arquitetura de Harvard com memória de programa e memória de dados distintas, o que permitia o acesso simultâneo a uma instrução e ao dado. Entretanto, o surgimento de novas tecnologias e dispositivos no mercado não 
advêm apenas da evolução dos processadores DSP, mas também do progresso dos componentes analógicos, mais especificamente no amplificador operacional, bem como dos conversores A/D e D/A e os comparadores.

Atualmente, existem companhias fornecedoras de dispositivos que permitem realizar operações de DSP altamente sofisticadas. A Tabela 4.3 lista algumas dessas companhias e os principais dispositivos disponíveis no mercado.

Tabela 4.3: Processadores DSP e seus fabricantes

\begin{tabular}{l|l}
\hline Fornecedor & Dispositivos de DSP \\
\hline \hline Texas Instruments & TMS320Cxx (PAPAMICHALIS, 1999) \\
Motorola & M56K e M96K Family (MOTOROLA, 1995) \\
NEC Corporation & uPD77P Family (NEC, 2000) \\
AT\&T & DSP16 e DSP32 (HAYNIE, 1992) \\
Inmos (STMicroelectronics) & IMS A100, A110 e A121; STM32Fx, STM32F405xx e STM32F407xx \\
& (STMICROELECTRONICS, 2013) \\
Analog Devices & Blackfin; SHARC; SigmaDSP; TigerSHARC; ADSP-21xx (ANALOG \\
& DEVICES, 2013) \\
\hline
\end{tabular}

Além de compartilharem a arquitetura de Harvard, os processadores possuem outras características em comum, como a implementação de um processador de ponto fixo ou de ponto flutuante acoplado ao processador DSP. A família de processadores TMS320C5000 da TI e 56000 da Motorola possuem o processador de ponto fixo acoplado. Processador de ponto flutuante é um atributo da família TMS320C67, da TI, e 96000, da Motorola. Uma outra característica marcante nos processadores DSP é sua arquitetura otimizada para computação intensiva. Para exemplificar essa otimização, os processadores da TI, pertencentes a família TMS320C67, conseguem executar aproximadamente 1 Bilhão de operações de ponto flutuante por segundo (Papamichalis, 1999).

Outras características em comum, é que os processadores DSP possuem um pequeno barramento de endereços que suporta apenas quantidades limitada de memória, no entanto, o barramento de dados é múltiplo/duplo. Além de possuírem modos de endereçamento especializado que suportam de maneira eficiente operações de processamento de sinal, como, por exemplo, endereçamento circular para filtros e endereçamento de bit reverso para FFT. E também, a característica do seu pequeno formato de dados comum nesses processadores, que, tipicamente, são de 16 ou 32 bits. E por fim, os vários periféricos especializados integrados no chip, como por exemplo portas seriais, memórias, e timers. Não podendo esquecer das principais, baixo consumo de energia, baixo custo, multiplicadores em hardware, lógica de prevenção de overflow, e instruções especiais.

Os processadores DSP sofreram muitas mudanças durante sua evolução, como já citadas, a redução do tamanho, o aumento de desempenho, e a limitação do consumo de energia. Os primeiros processadores eram apenas mono core, e conforme foram evoluindo, começaram a acoplar processadores de ponto fixo. Um pouco mais tarde, os proces- 
sadores de ponto fixo já não eram suficientes, acoplando os processadores de ponto flutuante. Acompanhando essa evolução, o clock interno dos processadores DSP também foram gradativamente aumentando. As estruturas de comunicação e de memória foram outros aspectos que sofreram modificações. Mais adiante, se tornou comum o uso de processadores DSP para desenvolvimento de ASIP (Application Specific Instruction-set Processor) (Guzma et al., 2008; Karuri e Leupers, 2011; Zhang et al., 2006). E por fim, com o crescimento mais acentuado da demanda de processamento (Figura 4.1), sugiram os processadores DSP multicores.

\subsubsection{Arquiteturas DSP multicore}

As arquiteturas de processadores DSP multicores podem ser definida pelos tipos de cores disponíveis no chip, podendo ser arquiteturas homogêneas ou heterogêneas. Arquiteturas que possuem cores do mesmo tipo, são classificadas como Homogêneas. Se os cores contidos na arquitetura são diferentes, ela é denominada heterogênea (Karam et al., 2009). Há outras classificações para as arquiteturas de processadores DSP multicores, como o tipo de interconexão interna do chip, a organização da memória, quantidade de cores e seus clocks, e os periféricos acoplados (Karam et al., 2009). Alguns dos dispositivos com arquitetura de processadores DSP multicores são listados na Tabela 4.4, com os seus respectivos fabricantes.

Tabela 4.4: Processadores DSP multicores, seus fornecedores e suas características

\begin{tabular}{|c|c|c|c|c|c|}
\hline & $\mathrm{TI}$ & FREESCALE & PICOCHIP & TILERA & SANDBRIDGE \\
\hline Processador & TNETV3020 & MSC8156 & PC205 & TILE64 & SB3500 \\
\hline Arquitetura & Homogênea & Homogênea & Heterogênea & Heterogênea & Heterogênea \\
\hline Número de núcleos & 6 DSPs & 6 DSPs & $\begin{array}{l}248 \text { DSPs e } \\
1 \mathrm{GPP}\end{array}$ & 64 DSPs & $\begin{array}{l}3 \text { DSPs e } 1 \\
\text { GPP }\end{array}$ \\
\hline $\begin{array}{l}\text { Topologia de inter- } \\
\text { conexão }\end{array}$ & Hierárquico & Hierárquico & Mesh & Mesh & Hierárquico \\
\hline Aplicações & $\begin{array}{l}\text { Wireless, } \\
\text { vídeo } \\
\text { VOIP }\end{array}$ & Wireless & Wireless & $\begin{array}{l}\text { Wireless, } \\
\text { rede e vídeo }\end{array}$ & Wireless \\
\hline
\end{tabular}

Fonte: (Karam et al., 2009)

A Tabela 4.4, apresenta cinco diferentes processadores DSP, com arquiteturas homogênea e heterogênea. O primeiro processador com uma arquitetura homogênea é o da TI, que possui seis cores DSP, interconexão do tipo hierárquico e suas principais aplicações são sem fio, vídeo e VOIP (Texas, 2008). O próximo processador é o da Freescale, que tem uma arquitetura homogênea, seis cores DSP como no da TI, interconexão interna e é utilizado para aplicações sem fio (Freescale, 2011). O último processador apresentado com arquitetura homogênea, diferente dos outros dois, possui uma comunicação em malha. 
Esse processador da Tilera possui sessenta e quatro cores DSP e é usado em aplicações sem fio, de redes e de vídeo (Tilera, 2008).

O processador da Picochip, diferente dos processadores da TI, da Freescale e da Tilera, possui uma arquitetura heterogênea. Esse processador possui uma quantidade de cores bem diferente dos outros, pois foi desenvolvido com duzentos e quarenta e oito cores DSP e um core de proposito geral. Sua arquitetura de comunicação interna é em malha, e é utilizado principalmente para aplicações sem fio (Picochip, 2012). E por último, o processador DSP da SandBrigde possui uma arquitetura heterogênea, como o da Picochip, com três processadores DSP e um processador de propósito geral. A comunicação interna desse processador é do tipo hierárquico, e também é utilizado em aplicações sem fio (Glossner et al., 2006).

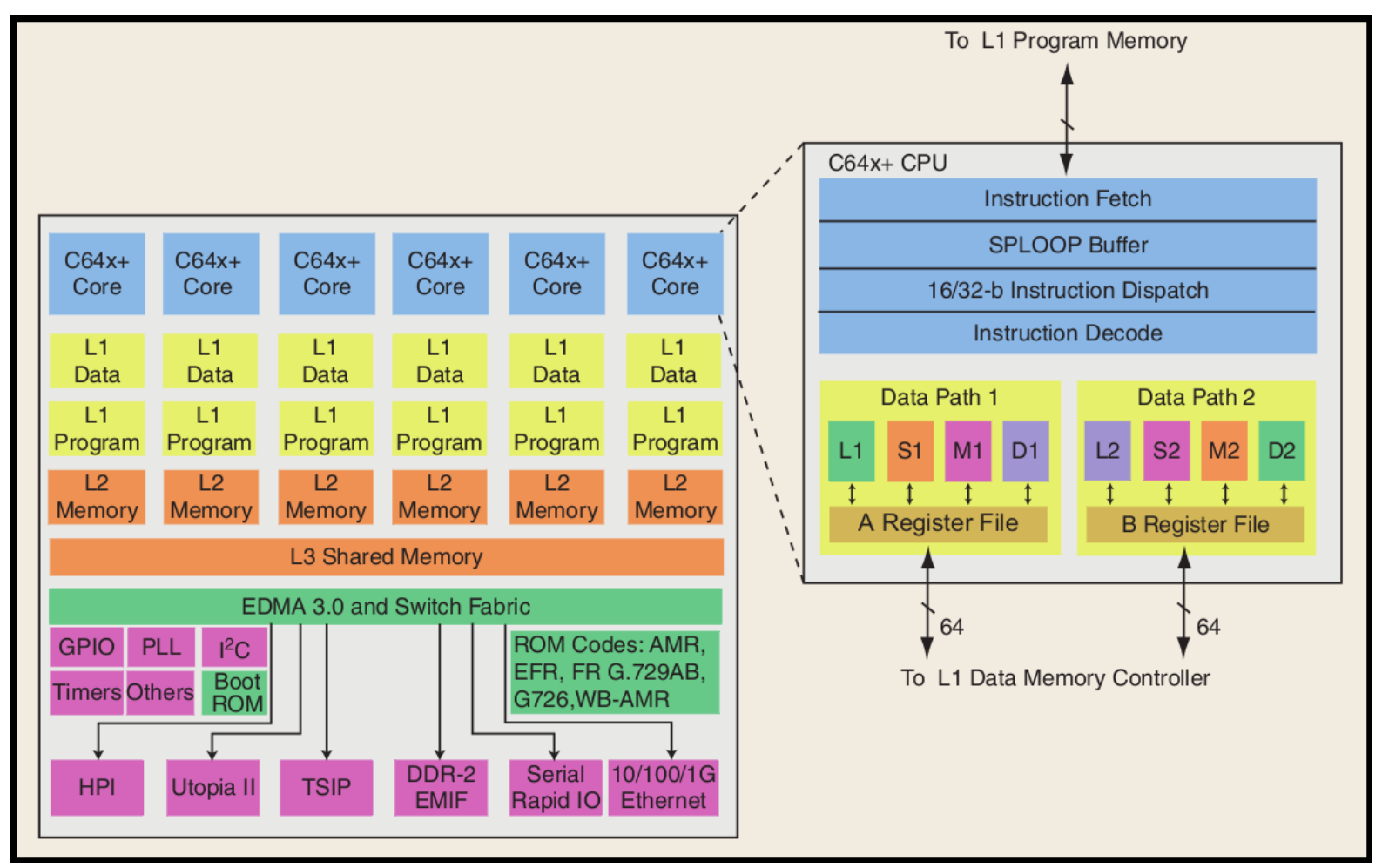

Figura 4.2: Arquitetura do processador DSP multicore TNETV3020 da TI (Karam et al., 2009)

A Figura 4.2 ilustra a arquitetura do processador TNETV3020 da TI, que é um processador DSP multicore. Esse processador é uma das mais recentes plataformas disponíveis, a qual é otimizada para processamento de voz de alto desempenho e aplicações de vídeo baseadas em comunicação sem fio. Cada um dos seis núcleos de processamento DSP C64x1 desse processador é capaz de rodar a $500 \mathrm{MHz}$ e consome 3,8 W de potência. 


\subsection{Considerações Finais}

Nesse Capítulo foi apresentado um breve histórico do surgimento da tecnologia DSP, as principais aplicações DSP, e as arquiteturas de um modo geral dos processadores DSP. Assim, o uso desses processadores são aplicados em diversas áreas, e conforme o passar do tempo, o aumento da complexidade em aplicações DSP demandam mais processamento. Como apresentado por Karam et al. (2009), a tendência desses dispositivos é possuírem uma arquitetura multicore, com o intuito de explorar o paralelismo em aplicações DSP. No entanto, por se tratar de uma abordagem relativamente nova, existem poucas ferramentas disponíveis para auxiliar no desenvolvimento de arquiteturas de processadores DSP multicore, e as que existem, ainda não são maduras e robustas. 


\section{Implementação, Operação e Resultados da NoC em FPGA}

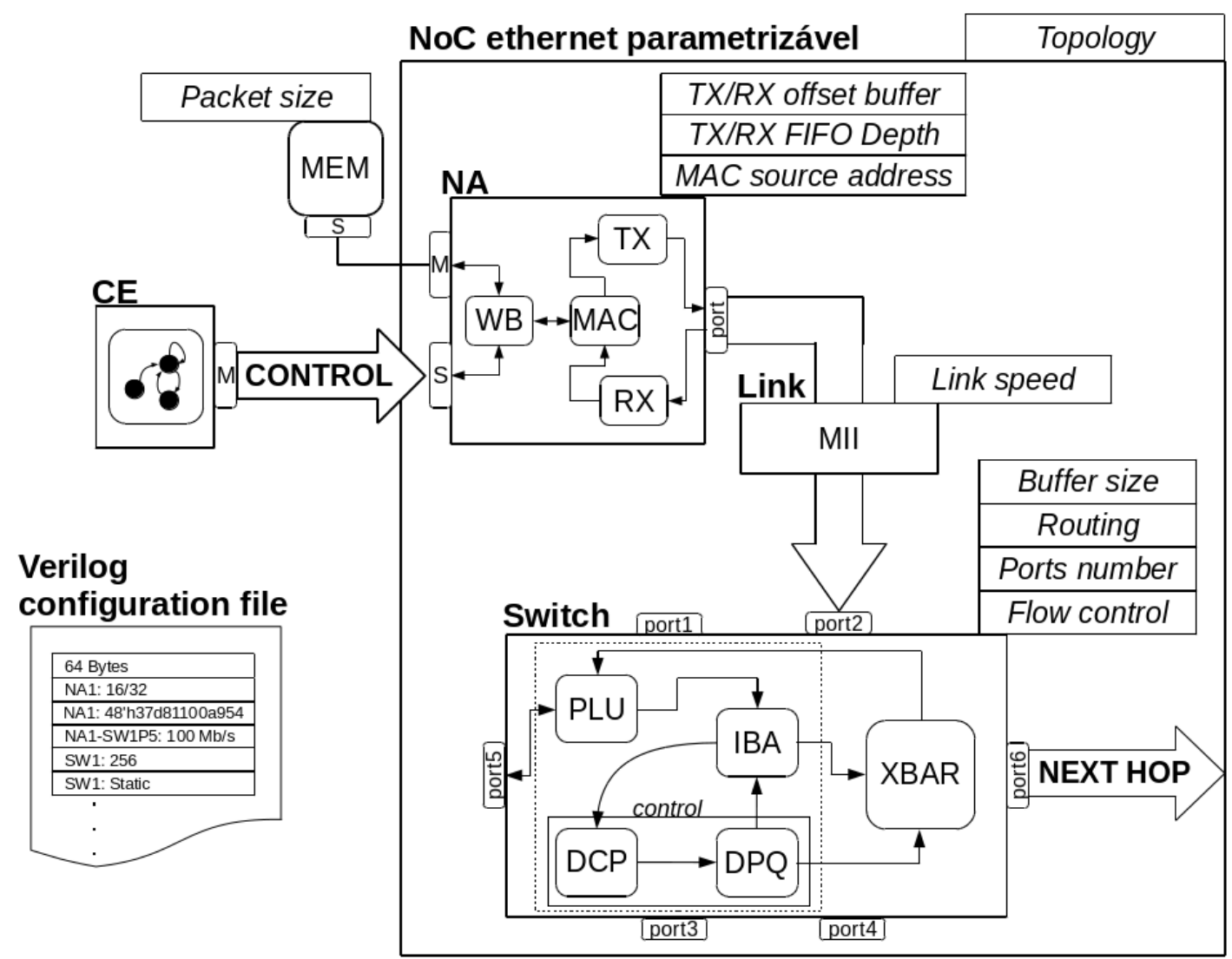

Figura 5.1: Diagrama de blocos da $N o C$ ethernet parametrizável 
Esse capítulo apresenta a implementação dos blocos da NoC, conforme ilustrados na Figura 5.1. Antes do detalhamento da implementação são apresentados os materiais e métodos, incluindo o core MAC ethernet, o core MAC layer switch e as ferramentas utilizados no desenvolvimento. A construção dos blocos macros ilustrados na Figura 5.1 utilizou varias abordagens como, o core MAC ethernet adaptado para o NA, o core MAC layer swtich que teve a estrutura básica aproveitada mas, sua lógica interna totalmente reimplementanda para o Switch, o bloco link baseado no padrão MII e o arquivo de configuração completamente implementado. Além disso, também é apresentado os detalhes de implementação dos parâmetros e os resultados obtidos.

\subsection{Materiais e métodos}

\subsubsection{OpenCore ethernet MAC}

O núcleo ethernet IP é um media access controller (MAC), desenvolvido na linguagem de descrição de hardware Verilog, disponibilizado no site do grupo OpenCores (OpenCores, 2013), que pode ser utilizado livremente. Esse core "ethmac", como é chamado, consiste em três módulos principais: o MAC, formado pelos módulos transmit, receive e control; o de gestão da MII; e a interface do host. Com todos os módulos funcionando, ele é capaz de operar em 10 ou 100 Mb/s para aplicações ethernet e Fast ethernet, respectivamente (Mohor, 2002). Além dessa característica, ele possui outras listadas a seguir:

- Interface de interconexão Wishbone Rev. B3;

- Funcionalidades da sub camada MAC do padrão IEEE 802.3;

- Geração e checagem automática de CRC de 32-bits;

- Suporte para operação em modo full-duplex;

- Memória interna para armazenar os 128 TX/RX buffer descriptors;

- Status das interfaces de transmissão (TX) e recepção (RX);

- MII do padrão IEEE 802.3 (Mohor, 2002).

Além dos módulos principais, o ethmac conta com o módulo Register, responsável por manter todos os registradores de configuração, e um módulo Status, incumbido de monitorar e coletar os status das interfaces TX/RX e repassá-los para o módulo Register. Os registradores do ethmac podem ser acessados pela interface do host, no caso a Wishbone, e são utilizados para configuração, transmissão, recepção e leitura de status. O conjunto dos módulos que formam o core ethmac e suas interconexões são apresentados na Figura 5.2 . 


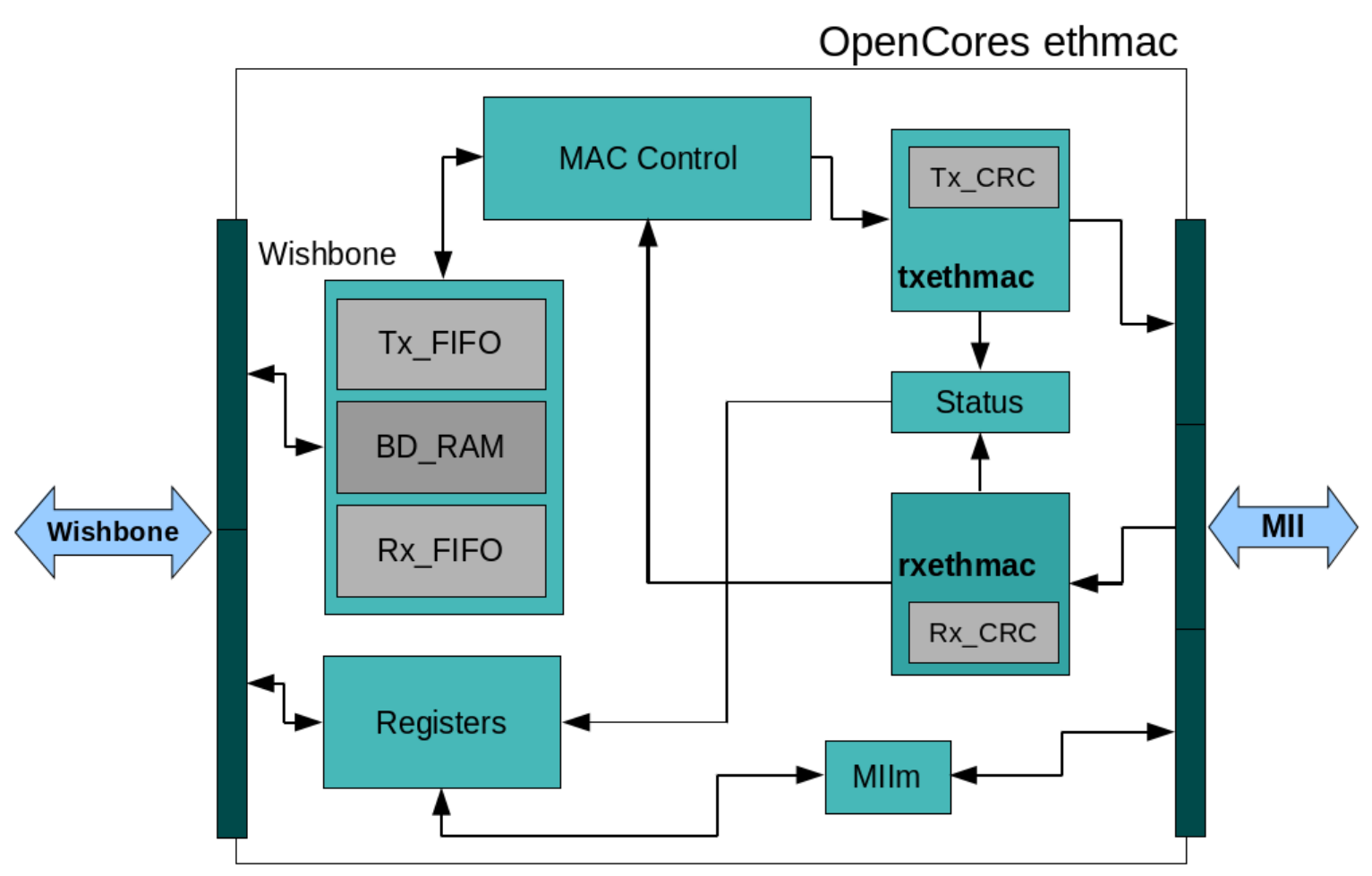

Figura 5.2: Estrutura interna do ethmac

O bloco que representa o módulo Wishbone na Figura 5.2 possui três blocos internos. Um desses blocos, o BD_RAM, representa a memória interna do ethmac utilizada para armazenar os buffer descriptors, descritos na Seção 5.2.1.2. Os outros dois blocos, Tx_FIFO e Rx_FIFO, são filas de organização dos pacotes a serem enviados e dos recebidos, respectivamente. Os módulos responsáveis pela geração e checagem do CRC são representados pelos blocos Tx_CRC e Rx_CRC na Figura 5.2. Esses dois blocos de CRC pertencem aos blocos txethmac, responsável pela transmissão, e rxethmac que lida com a recepção. O bloco MIIm dessa figura provê uma interface, componente - registers, para lidar apenas com a configuração e status do componente ligado a MII. Os outros sinais MII de transmissão e recepção são de responsabilidade dos módulos txethmac e rxethmac. O bloco MAC Control representa o módulo control que realiza o controle de fluxo dos dados quando o ethmac está configurado em modo full-duplex.

Os principais sinais conectados aos pinos de entrada ou saída do ethmac são referentes as interfaces Wishbone e MII e aos sinais globais de clock e reset. Os pinos referentes a interface Wishbone são os sinais apresentados e descritos na Seção A.1. Para os pinos da MII, os sinais já foram apresentados na Seção 3.4, tanto os de operação quanto os de gestão. O sinal global de clock, responsável pelo funcionamento e sincronismo do sistema, é conectado a todos os componentes internos, o mesmo acontece para o sinal global de reset, que permite a reinicialização completa do sistema. 


\subsubsection{OpenCore MAC layer switch}

O Switch pode ser considerado o componente mais complexo da arquitetura da NoC e, como base inicial para sua implementação, foi utilizada a estrutura do projeto de Minervi (OpenCores, 2014). Esse projeto, disponibilizado no site do grupo OpenCores, contempla um mac_layer_switch completo de seis portas MII implementado no padrão ethernet. No entanto, esse componente, descrito em Verilog, foi validado apenas em simulação utilizando a ferramenta Icarus Verilog. Como o projeto base não era sintetizável e não atendia o funcionamento ideal, utilizou-se apenas sua organização interna dos módulos, tendo sido reimplementanda toda a sua lógica interna para poder operar na NoC proposta.

\subsubsection{FPGA Altera Stratix IV e Ferramentas}

Para desenvolver o projeto foi utilizado um FPGA EP4SGX230KF40C2ES, que possui 182.000 elementos lógicos, o qual está integrado no kit de desenvolvimento Stratix IV da Altera (Altera, 2012).

Também foram utilizadas as seguintes EDA (Electronic Design Automation); para especificação e síntese, simulação e validação:

- Altera Quartus II 64-bit versão 11.1 build 173;

- Mentor Graphics ModelSim ALTERA STARTER EDITION 10.0c;

- Altera SignalTap II Logic Analyzer.

A ferramenta Quatus II suportou o desenvolvimento dos módulos da NoC na linguagem Verilog e foi utilizada como IDE para síntese (synthesis), "place \& route" (posicionar e rotear) e configuração do dispositivo. O processo de síntese consiste na tradução do código da linguagem HDL para uma representação mais próxima da implementação, conhecida como netlist. O próximo passo, place \& route, envolve mapear todas as estruturas lógicas descritas no netlist em macro células, interconexões e pinos reais de entrada e saída do FPGA. O resultado deste processo é um bitstream, bits de configuração do dispositivo, que determina sua função a partir do momento que ele é configurado ou reconfigurado.

A ferramenta ModelSim foi utilizada para suportar e prover um ambiente de simulação. O processo de simulação é um passo importante no desenvolvimento de SoC para FPGA. A simulação, durante o desenvolvimento do projeto, permite descobrir problemas relacionados com a lógica e com o sincronismo do sistema.

Para a validação do sistema em FPGA, utiliza-se a ferramenta SignalTap, que faz parte do conjunto de ferramentas disponibilizadas pelo Quartus II. Essa ferramenta permite analisar em tempo de execução sinais previamente definidos pelo usuário. O uso do SignalTap foi importante, pois alguns problemas foram identificados somente durante a execução do projeto no FPGA. 


\subsection{Implementação}

O primeiro bloco a ser detalhado é o NA, com as adaptações e o uso do ethmac para sua implementação. O segundo bloco apresentado, o elemento de controle (control element $(\mathrm{CE})$ ), foi desenvolvido com o intuito de realizar as operações com o NA permitindo a validação do componente e a realização de testes. O terceiro bloco definido é o Link, com implementação simples e alguns testes de validação. O último bloco pertencente a NoC apresentado é o Switch, com as hipóteses de projeto analisadas, detalhes da sua implementação e definições de alguns parâmetros. Para finalizar as implementações, são apresentados as definições dos parâmetros implementados nos blocos da NoC e o arquivo de configuração (configuration file) dos mesmos.

\subsubsection{NA}

O NA foi o primeiro módulo a ser construído, que utilizou como base o core ethmac apresentado na Seção 5.1.1. O detalhamento da sua implementação envolve algumas definições sobre o ethmac, como a divisão de funcionalidades da interface do host, os registros de configuração, os descritores ou Buffers Descriptors (BD), e o procedimento de transmissão e recepção de um quadro ethernet.

A interface de host do core ethmac pode ser considerada como a CI do NA. Essa interface é baseada no protocolo Wishbone que possui os sinais do master e do slave. Ela pode ser dividida em duas partes, de acordo com suas funcionalidades. A primeira divisão, a do slave, permite que o host conectado transfira BDs indicando a intenção de executar uma operação de transmissão ou recepção. A segunda parte a do master é utilizada pelo ethmac para obter ou repassar os dados dos pacotes referente a uma operação.

\subsubsection{Registradores de configuração}

O ethmac possui vários registradores de configuração. Para implementação desse trabalho alguns registradores foram modificados, mantendo os demais no valor padrão. Os registradores não utilizados são listados e detalhados na documentação do componente (Mohor, 2002).

O primeiro e mais importante registrador é o MODER register. Ele possui as principais configurações do componente, que são organizadas e descritas na Tabela 5.1.

Os dois primeiros bits listados na Tabela 5.1 são utilizados na Seção 5.2.1.3, que descreve o procedimento de transmissão e recepção. A terceira configuração, referente ao bit 5, foi utilizada para os testes iniciais da NoC, e depois mantido em 0 , que é seu valor padrão de operação. A configuração do bit 7 foi habilitado apenas em testes de validação do funcionamento dos blocos NA e CE. A configuração FULLD do bit 10 foi modificada para '1', alterando o modo de operação do ethmac de half-duplex para full-duplex. A 
Tabela 5.1: Principais configurações do registrador MODER

\begin{tabular}{c|l|l|l}
\hline \multicolumn{1}{c|}{ Configuração } & $\begin{array}{l}\text { Bit de } \\
\text { referência }\end{array}$ & $\begin{array}{l}\text { Leitura/ } \\
\text { Escrita }\end{array}$ & Descrição \\
\hline \hline Receive enable (RXEN) & 0 & RW & $\begin{array}{l}\text { '0' - desabilita a recepção | '1' - } \\
\text { Habilita a recepção }\end{array}$ \\
\hline Transmit enable (TXEN) & 1 & RW & $\begin{array}{l}\text { '0' - desabilita a transmissão | '1' } \\
\text { - Habilita a transmissão }\end{array}$ \\
\hline Promiscuous (PRO) & 5 & RW & $\begin{array}{l}\text { '0' - checa se o endereço de des- } \\
\text { tino do pacote | '1' - recebe os } \\
\text { pacotes sem checar o endereço de } \\
\text { destino }\end{array}$ \\
\hline Loop back (LOOPBACK) & 7 & RW & $\begin{array}{l}\text { '0' - loopback desativado | '1' - } \\
\text { a transmissão é conectada a re- } \\
\text { cepção }\end{array}$ \\
\hline Full-duplex (FULLD) & 10 & RW & $\begin{array}{l}\text { '0' - opera em modo half-duplex } \\
\text { '1' - opera em modo full-duplex } \\
\text { '0' - desabilita o padding | '1' - } \\
\text { habilita o padding }\end{array}$ \\
\hline
\end{tabular}

última configuração listada, do bit 15, foi modificada para '1', habilitando o padding de dados nos pacotes de transmissão. As outras configurações, não utilizadas, foram mantidas no seu valor padrão.

O próximo registrador é o PACKETLEN que contêm configurações de tamanho mínimo e máximo do quadro ethernet. Do bit 16 ao bit 31 deve ser preenchido um valor hexadecimal que indique o valor mínimo de tamanho do quadro que o ethmac pode transmitir e receber. Os bits do 0 ao 15 definem o valor máximo de tamanho do quadro. Caso algum quadro que for recebido esteja fora desse limiar definido, ele é descartado. Os valores padrões são 0x40 (64 Bytes) para o mínimo e 0x600 (1536 Bytes) para o máximo.

O próximo registrador que foi modificado é o TX_BD_NUM. Ele é um valor em hexadecimal que representa o número de BD de transmissão que o ethmac consegue armazenar na sua memória interna (BD_RAM do módulo Wishbone, Seção 5.1.1). Se o seu valor é zero, isso indica que a capacidade total da memória interna será utilizada apenas para BDs de recepção. Caso seu valor seja alterado para 0x80 (máximo), significa que a memória vai armazenar apenas BDs de transmissão. Seu valor padrão é 0x40, 64 em decimal, que representa a metade da capacidade total da BD_RAM para transmissão e metade para recepção. Esse registrador é utilizado como uma das configurações passíveis de parametrização da NoC, detalhado no bloco configuration file.

Uma outra configuração que teve seu valor padrão modificado pertence ao registrador MIIMODER. Esse registrador possui a configuração clock divider (CLKDIV), um campo de oito bits (bit 7-0) que contem um fator de divisão de clock. Esse fator é utilizado para determinar a frequência do módulo MII, que é calculado dividindo o clock de entrada do ethmac pelo valor informado nesse registrador. Seu valor padrão é 0x64 e foi alterado 
para 0x4, pois deseja alcançar um clock de $12,5 \mathrm{MHz}$ para o MII, derivado na frequência de 50Mhz de entrada do sistema. A frequência de 12,5Mhz é utilizado para transmissões a $100 \mathrm{Mb} / \mathrm{s}$ e o de $2,5 \mathrm{Mhz}$ pode ser utilizado para transmissões a $10 \mathrm{Mb} / \mathrm{s}$.

Os registradores MAC_ADDR0 e MAC_ADDR1 foram os últimos utilizados na implementação. Esses dois registradores juntos armazenam os 48-bits referentes ao endereço de origem do ethmac. A divisão de um exemplo de endereço de origem é demonstrada na Tabela 5.2.

Tabela 5.2: Representação do endereço de origem nos registradores MAC_ADDR0 e MAC_ADDR1

\begin{tabular}{|c|c|c|c|c|c|c|}
\hline Registrador & \multicolumn{4}{|c|}{ MAC_ADDR0 } & \multicolumn{2}{|c|}{ MAC_ADDR1 } \\
\hline Bit & $7-0$ & $15-8$ & $23-16$ & $31-24$ & $7-0$ & $15-8$ \\
\hline Byte & 5 & 4 & 3 & 2 & 1 & 0 \\
\hline Exemplo & 00 & 11 & D 8 & 37 & 54 & A 9 \\
\hline
\end{tabular}

Na Tabela 5.2, a linha 'Registrador' é o nome do registrador em questão, a linha 'Bit' representa os bits (MSB-LSB) do registrador, a 'Byte' é o Byte do endereço de origem e por fim, a linha 'Exemplo' é um exemplo de um endereço de origem. Para a configuração correta dos registradores utilizando o exemplo da Tabela 5.2, o MAC_ADDR0 deve ser configurado com o valor 0x37D81100 e o MAC_ADDR1 com 0x54A9. O valor padrão desses registradores é 0x0. Esse registrador também é utilizado como parâmetro de configuração do bloco NA da NoC.

\subsubsection{Buffer Descriptor}

Uma operação de transmissão ou recepção no ethmac é realizada através da interface do host (Wishbone). Como relatado na Seção 5.1.1, o módulo WB, responsável pela interface com o host, possui uma memória (buffer interno do NA) com capacidade de armazenar 128 BDs de 64-bits. O endereçamento dessa memória vai de 0x400 a 0x7FF, com a primeira metade $(0 \times 400$ - 0x5FF) reservada para descritores de transmissão (TX_BD) e o restante (0x600 - 0x7FF) reservado para descritores de recepção (RX_BD). Esses offsets intermediários não são fixos e são determinados pelo valor do registrador TX_BD_NUM, descrito na Seção 5.2.1.1. O endereço de cada BD tem 8-bits, que é utilizado para calcular os offsets intermediários de memória. O cálculo dos offsets intermediários é baseado no valor de TX_BD_NUM (0x40) multiplicado por 8, que somado com o offset inicial (0x400) resulta no offset inicial do RX_BD (0x600). O offset final do TX_BD (0x600) é igual ao offset inicial do RX BD menos 1 (0x5FF).

Havendo definido um ou mais descritores na memória, o host informa ao NA via Wishbone a intenção de executar uma transmissão ou uma recepção. Note que esses descritores são estruturas definidas para informar configurações, local e tamanho do pacote a ser transmitido ou recebido. O bloco de memória pertencente ao modulo WB tem 
capacidade de armazenar 128 descritores. Os descritores tem tamanho de 64-bits, onde os primeiro 32-bits são reservados para informar o tamanho e status, enquanto os outros 32-bits informam o endereço inicial de memória dos dados do pacote. No descritor de transmissão, além dos 16-bits reservados para informar o tamanho do payload, também possui cinco campos de opções de envio e seis de status. Os campos de opções de envio são, como por exemplo, o 'RD', que contem a informação se o descritor atual está pronto para envio, o PAD, que habilita o uso de padding de dados se necessário, e o CRC, que se ativo permite o envio do CRC no pacote. Os campos relacionados com status são úteis apenas no modo de operação half-duplex, e não serão detalhados.

O descritor de recepção possui semelhanças com o de transmissão, como os primeiros 16-bits reservados para o tamanho do pacote, e os últimos 32-bits contendo o endereço de memória do pacote recebido. No entanto, os campos de opções e status são diferentes, com três campos para opções e nove para status. Um dos campos de opção, por exemplo, é o 'E' (empty) que deve ser preenchido com '1', caso o descritor já tenha sido usado, ou mantido em '0', caso a informação não tenha sido obtida. Os campos de status são bem úteis para a recepção, como o 'CF' (Control Frame) que indica se o pacote recebido possui dados de controle ou de uma transmissão normal. Outro exemplo de campo de status é o 'CRC' que indica se o CRC do pacote recebido contem erro ('1') ou não ('0'). Como ambos os descritores possuem 64-bits e a interface do host (Wishbone) só transfere 32-bits por vez, são necessários dois ciclos de barramento para enviar cada descritor.

\subsubsection{Procedimento de transmissão e recepção}

O core ethmac define um procedimento que deve ser seguido para realizar uma transmissão ou uma recepção. Esse procedimento considera que possui um componente RISC e um componente de memória conectado a sua interface de host. Os passos que devem ser seguidos para a operação de transmissão são listados a seguir:

- Armazenar o quadro ethernet na memória;

- Enviar o TX_BD através da interface slave do NA com as configurações desejadas;

- Habilitar a transmissão ativando o TXEN (bit 1 - MIIMODER).

Depois desses passos, o NA busca na memória conectada a sua interface master os dados do endereço informado no TX_BD. A NA monta o quadro ethernet em um pacote e o transmite.

Os passos para a recepção são:

- Enviar um RX BD através da interface slave do NA, configurado como BD vazio $(' \mathrm{E} '=0)$; 
- Habilitar a recepção ativando o RXEN (bit 0 - MIIMODER).

Após esses passos, a NA deve enviar o quadro ethernet pela sua interface master para a memória, com o endereço preenchido no RX_DB, além de preencher os campos de status do quadro recebido. No passo final, ela configura o bit 'E' do BD para '1'.

\subsubsection{Elemento de controle}

O elemento de controle (CE) inicialmente foi construído para a validação das funcionalidades do NA. Mas, seu uso estendeu por todo desenvolvimento do projeto, incluindo até a obtenção de resultados. Esse bloco é composto por dois módulos, uma memória e uma máquina de estados interna. A memória, representada pelo bloco MEM da Figura 5.3, possui uma interface Wishbone slave para a comunicação com o NA, uma máquina de estados que controla a comunicação (Figura 5.5) e alguns registradores que servem para armazenamento dos dados. O bloco CE também possui uma máquina de estado para controle da comunicação (Figura 5.4), que é realizada através da interface Wishbone master. Os sinais referentes a interface Wishbone são apresentados e descritos no Apêndice A. Além da parte de comunicação, o bloco CE possui uma outra máquina de estado que controla a preparação e o envio dos BDs para a NA.

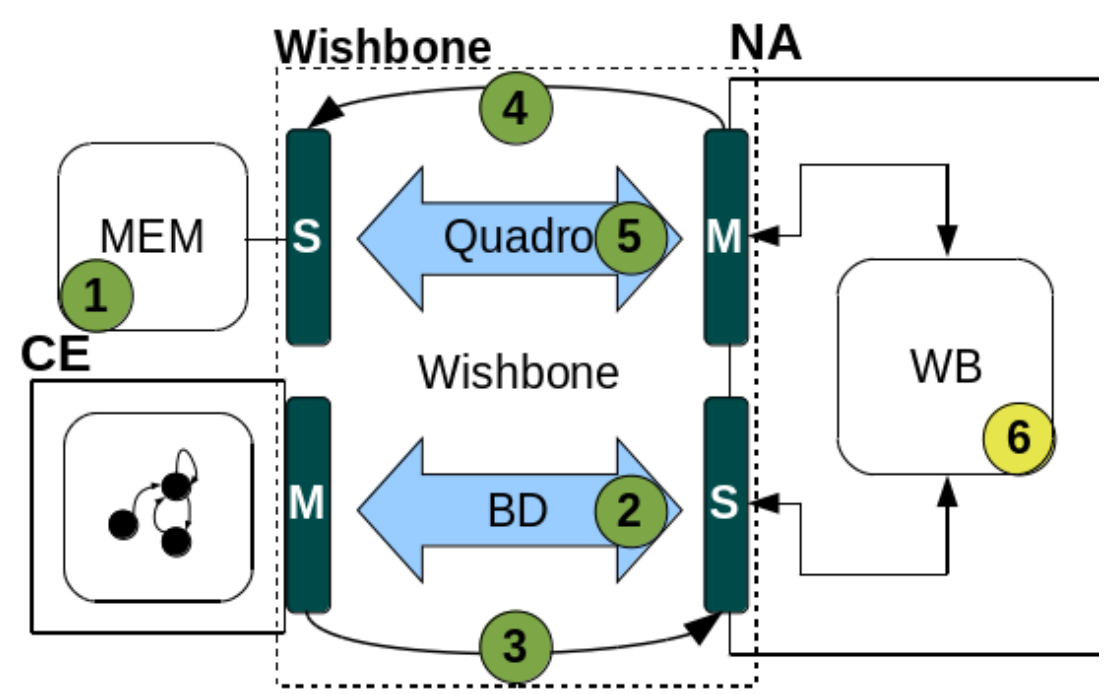

Figura 5.3: Passos para realizar uma transmissão utilizando o $\mathrm{CE}$

Os círculos numerados da Figura 5.3 representam os passos para uma operação de transmissão. No primeiro passo o módulo CE armazena o quadro ethernet completo nos registradores do módulo MEM. No passo número dois, o CE utiliza a máquina de estado que controla a comunicação com o NA para enviar o BD do quadro ethernet. Com o intuito de habilitar a transmissão, no passo três o $\mathrm{CE}$, através da mesma interface WB_master, preenche o valor bit TXEN do registrador MODER da NA com '1'. Com isso, o NA inicia o procedimento interno de transmissão, solicitando os dados armazenados 
no módulo MEM através da interface WB_slave do CE, que responde enviando o quadro ethernet referente ao endereço informado no passo cinco. No último passo, o seis, a NA realiza os procedimentos internos para transmissão do quadro ethernet.

A máquina de estado da Figura 5.4 tem o intuito de controlar a comunicação realizada pela interface Wishbone master do módulo CE. O estado inicial (INITIAL) aguarda o início de uma comunicação indicada pelo sinal start_i. Caso o módulo CTRL receba o sinal de reset ativo, a máquina de estado é reinicializada voltando para o estado inicial. O próximo estado CTRL é responsável por preencher os sinais referentes a uma operação, como o endereço e o dado, além de ativar os sinais de início de ciclo (CYC_O) e início de fase (STB_O). O próximo estado também é definido no estado atual, que deve decidir se a operação é de leitura ou escrita. Caso seja uma operação de leitura, o próximo estado é o READ, que preenche o sinal WE_O com '0', indicando uma leitura, configura o vetor SEL_O() com os bits '1111', informando o interesse em todos os Bytes do dado, e reafirma os sinais CYC_O e o STB_O. Agora, caso seja uma escrita, os mesmos passos são realizados, exceto pelo preenchimento do WE_O que deve ser '1'. O próximo estado é o ACK, que aguarda o sinal de reconhecimento da outra interface, informando a execução da operação. Enquanto esse sinal não estiver ativo, o estado atual é mantido. Caso o sinal recedido seja ACK, o dado é obtido e o próximo estado é o KACK, que apenas gera mais um ciclo de espera para retornar ao estado CTRL. Mas, se o sinal recebido for o de erro (ERR_I), a máquina de estado volta para o estado inicial. O estado KACK foi implementado para resolver problemas apresentados durante testes no FPGA utilizando a ferramenta SignalTap.

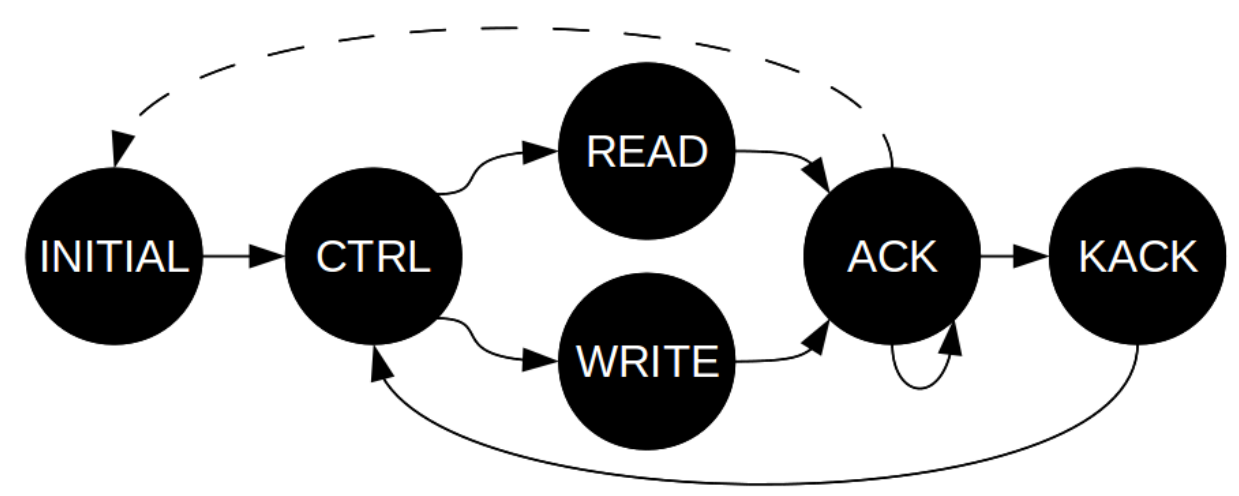

Figura 5.4: Máquina de estado de controle da comunicação do CE

A máquina de estado de controle da comunicação do módulo MEM (Figura 5.5) é mais simples que a do módulo CE. Um dos motivos é que ela controla a comunicação de uma interface Wishbone slave, diferente da CE que controla de uma Wishbone master. O primeiro estado da Figura 5.5 é o inicial e de decodificação, responsável por identificar se os sinais de ciclo e de fase estão ativos. Caso os dois sinais estejam ativos, é verificado o sinal WE_I para decidir o próximo sinal da máquina de estado. Se esse sinal estiver ativo, o próximo estado é o WRITE, caso contrário, é o READ. No estado READ, caso o ciclo 
seja de rajada incremental, o sinal CTI_I() é verificado, aguardando o end-of-burst. Até que isso não ocorra, o dado correspondente ao endereço ADR_I() é preenchido no sinal DAT_O(). Ao receber o end-of-burst, o dado é preenchido uma última vez, e o estado é alterado para o WAIT END. Se for um ciclo simples, o dado é preenchido uma única vez e a máquina de estado encaminha para o próximo estado. O estado WRITE possui os mesmos procedimentos do READ, com a diferença de em vez de preencher o dado no sinal de saída, ele lê o dado do DAT_I() e o armazena no endereço informado pelo ADR_I(). O último estado da Figura 5.5, WAIT END, aguarda o fim do ciclo indicado pela desativação dos sinais CYC_I e STB_I.

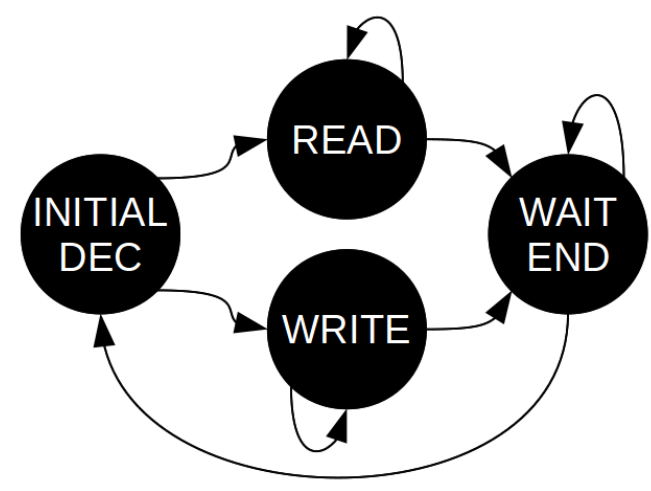

Figura 5.5: Máquina de estado de controle da comunicação do MEM

\subsubsection{Link}

O Link foi implementado seguindo o padrão MII para interface. Como apresentado na Seção 3.4, o MII possui sinais de transmissão e recepção de dados (Tx_D[3:0] e Rx_D[3:0]), recepção de dado válido (Rx_DV), transmissão habilitada (Tx_EN), carrier (CRS), colisão (COL), erro de transmissão (Tx_ER e Rx_ER) e os de clock (Tx_CLK e Rx_CLK), que podem ser visualizados na Figura 5.6. Os sinais de carrier e colisão foram aterrados para a implementação do Link, considerando que esses sinais são utilizados no modo half-duplex. Para interligação ponto a ponto de MIIs, os dados de transmissão são conectados aos dados de recepção, o sinal que habilitada transmissão conecta ao sinal dado válido, os sinais de erro conectados um aos outros, e os sinais Tx_CLK e Rx_CLK das interfaces receberam um sinal de clock de uma fonte externa. Para manter o sincronismo nas operações de leitura e escrita dos dados, esse sinal foi gerado a partir do sinal global do sistema. A Figura 5.6 apresenta sinais de duas MII conectados ponto a ponto.

Os sinais de erro (Tx_ER e Rx_ER) foram removidos da implementação do Link pois a porta do swtich não implementa esses sinais, como também não implementa os sinais CRS e COL. Portanto, os sinais utilizados para implementar o Link desse projeto foram: Tx EN, Tx_D[3:0], Rx_DV e Rx_D[3:0], representados pelas quatro setas internas do Link 


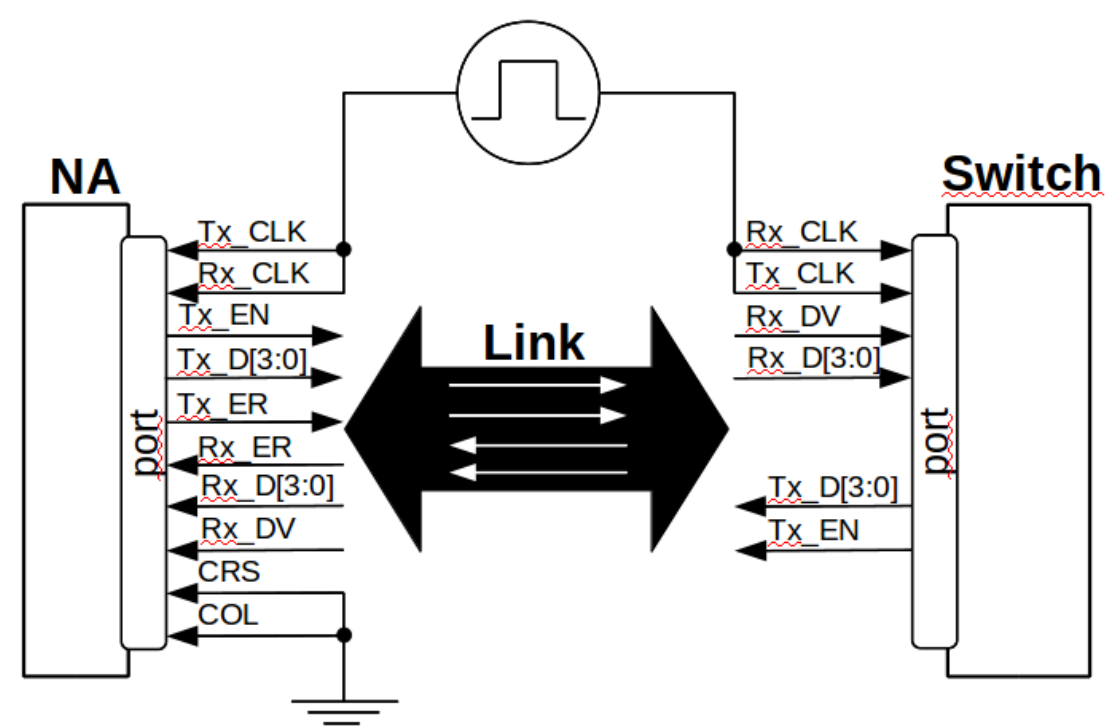

Figura 5.6: Sinais de interconexão entre uma NA e um switch

da Figura 5.6. Considerando que os sinais de dados são de 4-bits, então a largura do phit da NoC é de 10-bits.

Por conta da definição do padrão da MII, o parâmetro link speed pode possuir duas opções de velocidade, a $10 \mathrm{Mb} / \mathrm{s}$ e a $100 \mathrm{Mb} / \mathrm{s}$. Porém, a implementação desse parâmetro não foi concluída, mantendo a velocidade de transmissão fixa em $100 \mathrm{Mb} / \mathrm{s}$. O aumento dessa taxa de transmissão para $1 \mathrm{~Gb} / \mathrm{s}$ ou $10 \mathrm{~Gb} / \mathrm{s}$ pode ser alcançados com as interfaces GMII e XGMII, respectivamente.

\subsubsection{Switch}

Como apresentado na Figura 5.1, o Switch é dividido em cinco módulos internos. O PLU é responsável pela interface com a rede. O IBA pode ser considerado como o buffer desse Switch, que deve armazenar os pacotes durante o roteamento. O DCP e o DPQ juntos fazem a parte do controle, responsável por realizar o roteamento do pacote. Por fim, o XBAR é o crossbar do Switch que, baseado na decisão de roteamento, direciona o pacote para a porta de saída correta. Todos os módulos são detalhados individualmente, apresentando suas estruturas internas e suas funcionalidades. Todos os blocos com suas fronteiras tracejadas possuem mais de uma instância, determinado pelo número de portas do Switch.

\subsubsection{PLU}

O PLU possui três funções, interfacear com a rede, decodificar o protocolo MII e converter a largura (bits) dos dados. Essa conversão se resume a sincronização e tradução dos nibbles (4-bits), que chegam por uma porta do Switch, para Bytes (8-bits) e esses Bytes para Words (32-bits). O processo inverso também é implementado e essa conversão é 
necessária, pois a lógica interna do Switch foi desenvolvida com uma largura de dados de 32-bits.

A principal preocupação no desenvolvimento do PLU foi o sincronismo dos dados de entrada e saída com os sinais de startfrm e endfrm. Esse sinais são utilizados para orientação dos módulos internos do Switch, indicando o início (startfrm) ou o fim (endfrm) de um quadro ethernet. A responsabilidade de geração correta desses sinais, quando relacionados a um quadro de recepção, é do módulo PLU. Eles são gerados no módulo interno responsável pela decodificação do protocolo MII, o rxethmac. Porém, durante os processos de conversão interna, os sinais startfrm e endfrm podem dessincronizar em relação ao dado, o que pode gerar um problema para os próximos módulos do Switch. Então, no desenvolvimento dos módulos internos do PLU, esses sinais foram tratados para estarem sincronizados com os dados convertidos.

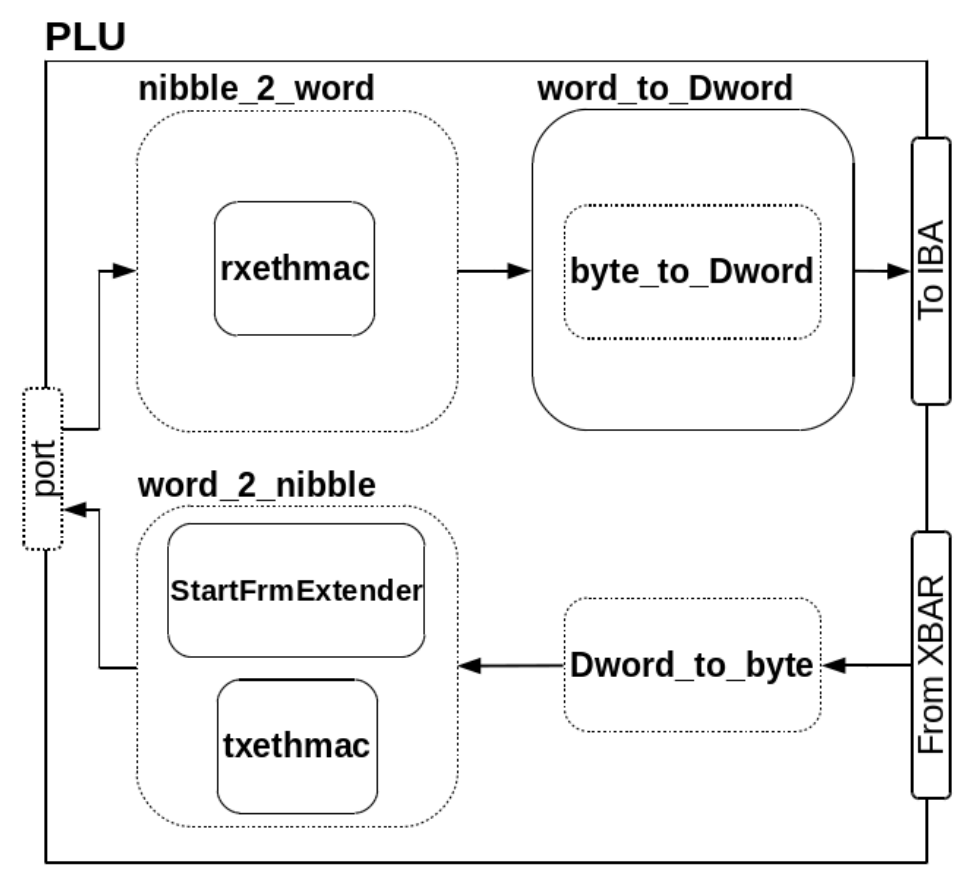

Figura 5.7: Estrutura interna do módulo PLU

A Figura 5.7 mostra a estrutura interna do PLU com seus módulos internos e as interconexões entre eles. O dado que ingressa pela porta do Switch é recebido pelo módulo interno nibble_2_word do PLU, que é responsável pela interface com a rede, decodificação do protocolo MII e conversão de nibbles para Bytes. Com o intuito de manter o padrão na implementação, as funcionalidades de interface com a rede e decodificação do protocolo MII foram reutilizadas da NA através dos módulos rxethmac e txethmac. As principais saídas do nibble_2_word são os dados em Byte e os sinais de início e término do quadro. A funcionalidade de converter os dados de 8-bits para dados de 32-bits pertence ao submódulo byte_to_Dword. Esse submódulo é instanciado pelo módulo word_to_Dword, que tem como responsabilidade converter os Bytes dos dados de entrada em dados de 32-bits mantendo o sincronismo dos sinais startfrm e endfrm. O dado convertido para 32-bits 
mais os sinais de sincronismo do quadro são as principais saídas do PLU em uma de suas saídas (parte de cima da Figura 5.7).

Na outra saída (parte de baixo da Figura 5.7), os dados de 32-bits que ingressam pela entrada do módulo Dword_to_Byte são convertidos para 8-bits. Além dos dados, também ingressam os sinais de sincronismos de início e fim do quadro ethernet, que são usados pelo Dword_to_byte para sincronizar a conversão e o envio dos dados para o próximo módulo. O word_2_nibble possui dois submódulos, o StartFrmExternder e o txethmac. O StartFrmExternder foi implementado para lidar com um atraso intrínseco inserido pela conversão, com a função de manter os sinais startfrm e endfrm sincronizados com os dados. As responsabilidades de codificação do protocolo MII e interface com a rede dos quadros de transmissão são do módulo txethmac. A saída do módulo word_2_nibble são os sinais MII, com os dados convertidos para nibble.

\subsubsection{IBA}

O segundo componente do Switch é o IBA, responsável pelo parser e armazenamento do quadro. Ele recebe os sinais do PLU referentes a um quadro de recepção e, baseado nos sinais de sincronismo armazena-os até que seu roteamento seja definido. Na função de parser, o módulo deve identificar o cabeçalho do quadro, separá-lo do restante do quadro e enviá-lo para uma das suas saídas. Mesmo assim, o cabeçalho é armazenado junto com o restante do quadro. As duas responsabilidades do IBA são realizadas pelo seu único módulo interno, o men_units.

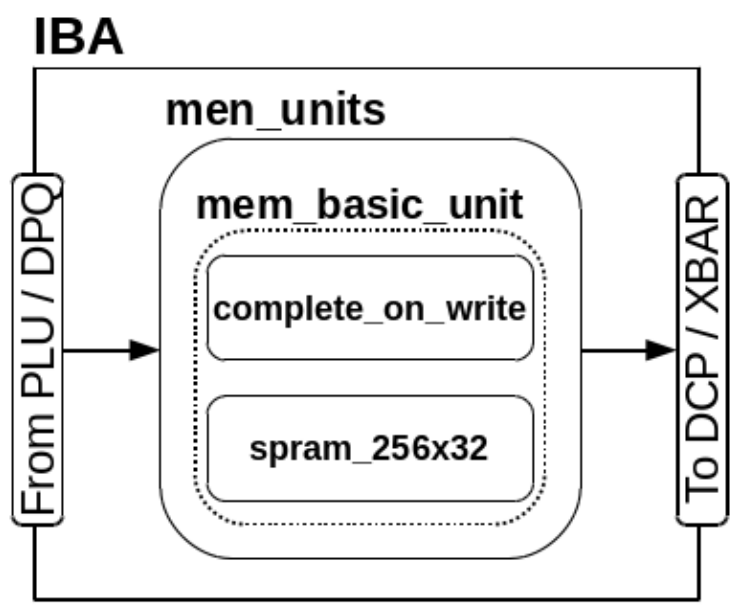

Figura 5.8: Estrutura interna do módulo IBA

Observando a Figura 5.8, percebe-se que o men_units possui um submódulo, o mem_ basic_unit. Esse submódulo contempla uma memória de armazenamento spram_256x32 e um controle adicional para gestão da memória, o complete_on_write. O bloco spram_256x32 é uma memória de 1 MByte. Os Bytes dos dados de 32-bits são armazenados em cada um dos quatro bancos internos de memória, com o intuito de acelerar os processos de gravação e de leitura. Esse bloco foi reutilizado do NA, onde ele implementa o armazenamento dos 
BDs. O complete_on_write foi implementado para lidar com a diferença de timing do processo de leitura. Ao realizar uma leitura na memória, o dado é obtido com um certo atraso, que deve ser corrigido conforme ilustrado na Figura 5.9. A integração desses blocos com a gestão do armazenamento do quadro na memória e o parser do cabeçalho também é implementada no submódulo mem_basic_unit.

Na Figura 5.9, o sinal $D w \_i b a \_i$ representa o dado obtido na operação de leitura da memória. Esse dado é um sinal de entrada do componente complete_on_write que insere a esse sinal um atraso de um ciclo e meio de clock. O sinal resultante dessa operação é o Completed ram_do, que tem um ciclo e meio de atraso comparado ao sinal de entrada, com um total de 60ns de diferença um para o outro. No exemplo simulado, esse atraso foi de um ciclo e meio. No entanto, esse atraso pode não ser fixo, que é sincronizado pelo complete_on_write independente do atraso.

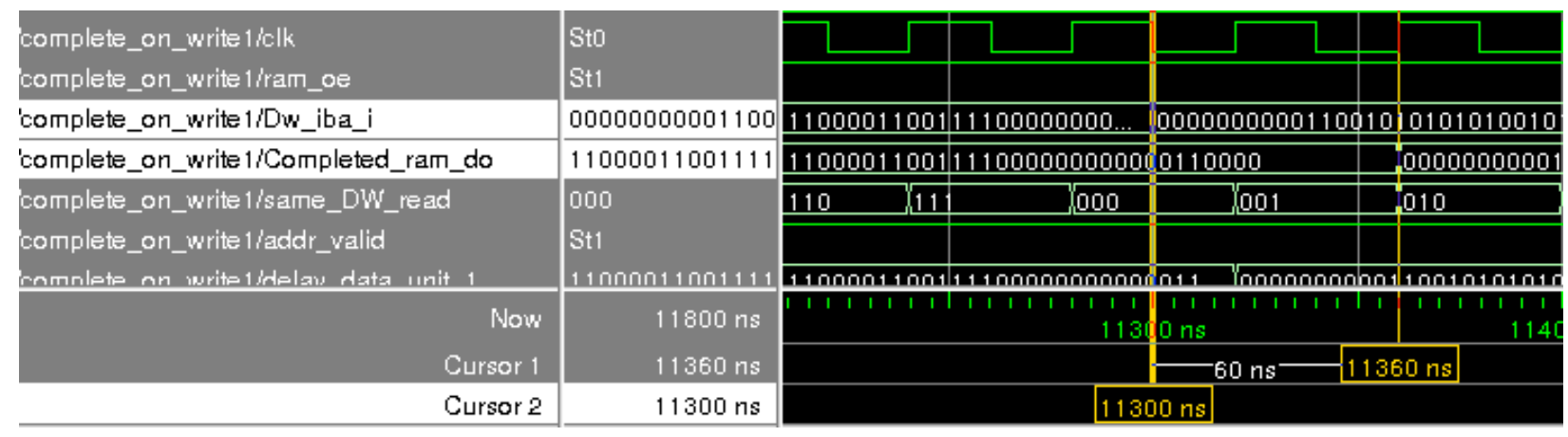

Figura 5.9: Sinal de dados com atraso, corrigido pelo complete_on_write

O processo inverso, ou seja, obtenção do quadro armazenado para transmissão, inicia com o sinal adr_valid. Esse sinal de entrada informa que o roteamento foi definido e que o pacote deve ser transmitido. A informação do quadro está contida no sinal de entrada start_lenth, que combina o offset do endereço de início e a quantidade de dados de 32-bits daquele quadro. Além do envio dos dados referentes ao quadro, é de responsabilidade do mem_basic_unit gerar os sinais relacionados com o início e o fim do quadro. O mesmo problema, relatado no desenvolvimento do PLU de geração dos sinais de sincronismo startfrm e endfrm foi enfrentado na implementação do IBA. O sinal de adr_valid foi utilizado como base para implementação do startfrm, incluindo pequenos ajustes de sincronismos. O sinal endfrm foi implementado utilizando o fim do envio do quadro como trigger, informação retirada do sinal start_lenth.

Dois parâmetros de configuração foram implementado no IBA, o flow-control e o buffer size. O parâmetro flow-control da NoC possui duas possibilidades de configuração: o store-and-forward e o wormhole. A opção wormhole é a configuração padrão, que foi implantada junto com a implementação do módulo IBA. Nessa configuração, o IBA opera armazenando o quadro completo, incluindo o CRC, e só libera o parser do cabeçalho quando o quadro tenha sido completamente armazenado. Para a implementação da outra opção, o store-and-forward, o submódulo mem_basic_unit teve duas alterações. A primeira 
foi a subtração de um na contagem do armazenamento do quadro, que representa quantos dados de 32-bits pertencem a aquele quadro. A outra alteração foi no trigger do envio do cabeçalho, ajustado para enviar assim que o cabeçalho tenha sido completamente identificado, independente do restante do quadro.

O IBA, que é o buffer do Swtich, possui sua capacidade de armazenamento variável, definida conforme o parâmetro buffer size do Switch. Esse parâmetro permite informar, para cada porta do Switch, a quantidade de blocos spram_256x32 que vão ser instanciados no submódulo mem_basic_unit. A implementação base contava apenas com um bloco spram_256x32 por mem_basic_unit. Para implementação desse segundo parâmetro de configuração, foram previamente instanciados mais três módulos do bloco spram_256x32 no mem_basic_unit. Esses módulos são ativados conforme alguns defines do arquivo de configuração. Uma lógica de troca do bloco de memória utilizado para armazenamento foi implementada, e também é integrada ao restante do sistema conforme os defines de sistema. Esses defines são detalhados na Seção 5.2.5.

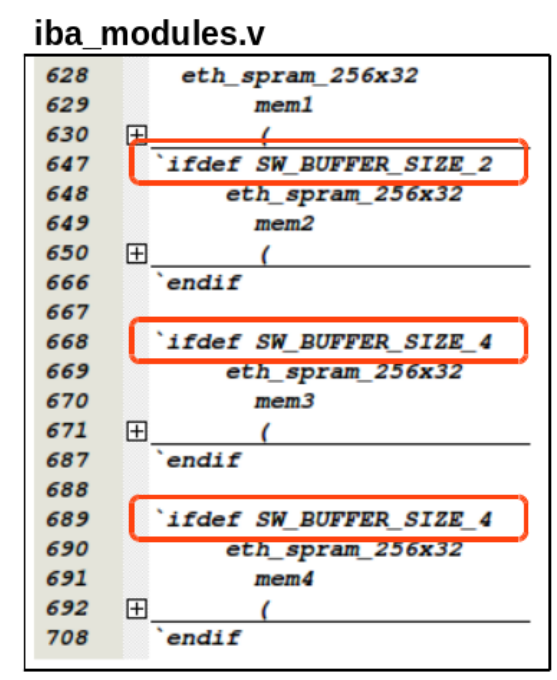

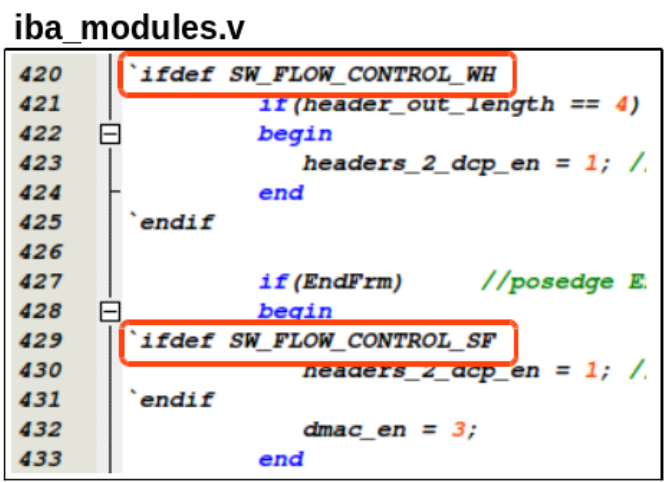

(b)

(a)

Figura 5.10: Os principais pontos da implementação dos parâmetros flow-control e buffer size

A Figura 5.10 apresenta os pontos chaves da implementação dos parâmetros flow control e o buffer size do Switch. O código ilustrado na parte (a), mostra quatro instâncias seguidas do bloco spram_256x32. A primeira delas é uma instancia normal, sem condição, e as outras três estão condicionadas pelas diretivas destacadas pelo círculo no código. Essas essas diretivas são ativadas apenas se a macro em questão tenha sido definida. O exemplo da Figura 5.10 mostra as instâncias mem3 e mem4 dependentes da macro $S W_{-} B U F F E R \_S I Z E_{-}$, que pode ser definida no arquivo de configuração apresentado na Seção 5.2.5. A parte (b) da figura mostra a variável header_2_dcp_en condicionada as duas macros destacas pelo círculo laranja, a $S W_{-} F L O W_{-} C O N T R O L_{-} S F$ e a $S W_{-} F L O W_{-} C O N T R O L_{-} W H$. Essa variável é responsável por ativar o envio do cabeçalho 
para parte de controle do roteamento no Switch. Na primeira parte, que ativa o controle de fluxo wormhole, essa variável é ativa quando a contagem do cabeçalho é igual a quatro. Já para o controle de fluxo store-and-forward, essa variável é ativa apenas com o sinal de fim do pacote (endfrm).

\subsubsection{DCP e DPQ}

Os módulos DCP e DPQ do Switch são responsáveis pelo roteamento dos quadros ethernet. As informações contidas no cabeçalho do quadro são necessárias para realizar esse roteamento, que foi dividido nas funcionalidades desses dois blocos. A primeira função é a de parser do cabeçalho, fornecida pelo DCP. Com as informações do cabeçalho divididas e organizadas, a próxima função é o roteamento propriamente dito, que utiliza o endereço de destino para determinar por qual porta de saída o quadro deve ser encaminhado. Essa função também é implementada no DCP. O DPQ possui a função de enfileirar os quadros de saída de uma porta para que uma transmissão não sobressaia a outra. Diferente dos módulos PLU e IBA, os DCP e DPQ possuem apenas um sentido de informação.

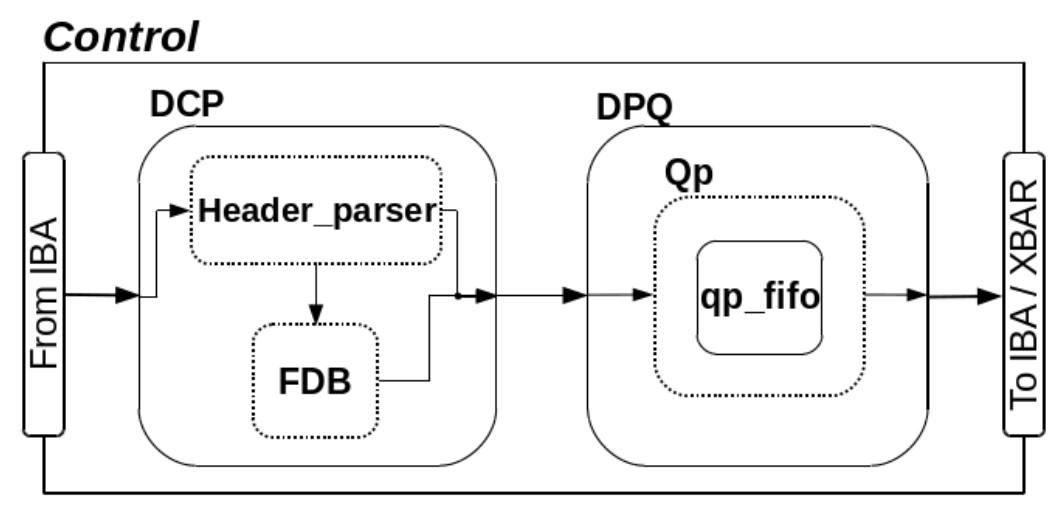

Figura 5.11: Estrutura interna dos módulos DCP e DPQ

O DCP possui dois módulos internos, o Header_paser e o FDB, ilustrados na Figura 5.11. O Header_paser é responsável pelo parser do cabeçalho que concatenado ao sinal start_lenth são as únicas informações de entrada desse módulo. Ele recebe o cabeçalho completo e deve separar os campos endereço de destino, endereço de origem e tamanho/tipo; informações que podem ser utilizadas no roteamento. Os endereços de destino e de origem são passados para o módulo interno FDB, que deve definir o roteamento do pacote. O FDB define o roteamento baseando em uma tabela que contem os endereços de destino possíveis daquele Switch vinculados a uma porta. Caso algum endereço de destino seja equivalente com algum dos endereços dessa tabela, o FDB deve executar três passos: informar qual a porta de saída que o quadro deve ser encaminhado, concatenar essa informação com o sinal start_lenth e repassá-la para o módulo DPQ.

Com apenas o módulo interno $Q p$, o módulo DPQ implementa uma FIFO dos quadros de saída. O $Q p$ possui uma instância do bloco $q p_{-} f i f o$, que é uma fila FIFO. Como o 
objetivo dessa fila é ordenar o envio dos quadros armazenados no IBA seu tamanho é calculado com base na capacidade de armazenamento do buffer da porta, considerando um tamanho mínimo do quadro (64 Bytes). Por exemplo, caso o IBA tenha apenas uma instância do bloco de memória, no caso 1 MByte de armazenamento, então a FIFO terá profundidade 16, pois 1 MByte dividido por 64 Bytes é igual a 16. Essa profundidade determina a quantidade de quadros que ela pode enfileirar. As saídas do módulo $Q p$ são a informação de roteamento para o XBAR e a informação de qual quadro para o IBA.

\subsubsection{XBAR}

O último módulo do Switch é o XBAR. Ele pode ser considerado um crossbar, que interliga todas as portas de entrada com as portas de saída. Esse módulo não tem nenhum submódulo e sua implementação equivalente a um case/swtich que, baseado na informação de roteamento, direciona o dado de entrada para uma porta de saída. Além dos dados, o XBAR também direciona os sinais do início e do fim do quadro em questão, sem lidar com o sincronismo. A Figura 5.12 mostra um trecho de código em Verilog da sua implementação.

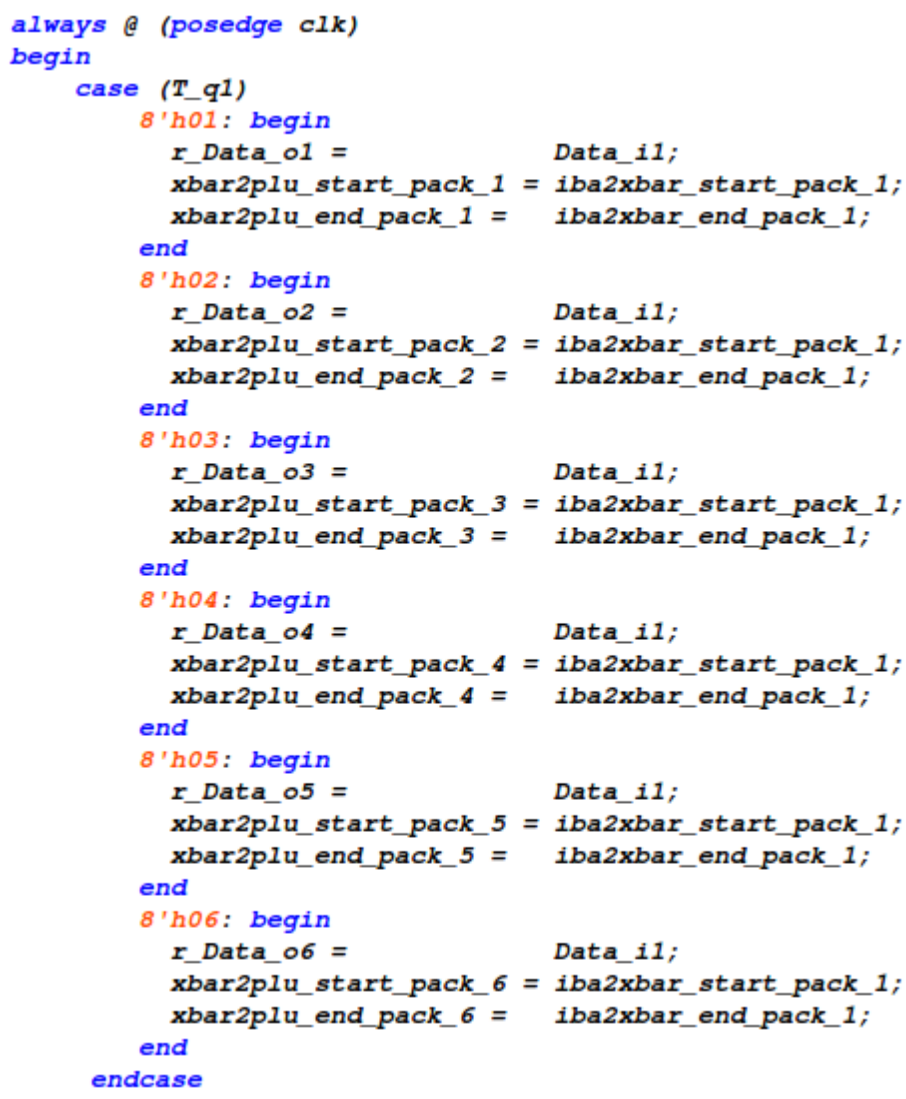

Figura 5.12: Trecho de código do direcionamento das informações da porta de entrada 1 para todas as portas de saída

Na Figura 5.12, o sinal $T_{-} q 1$ contem a decisão de roteamento para um quadro que ingressou pela porta 1 do Switch. Baseado nessa decisão, o conjunto de informações 
do quadro é redirecionado para porta de saída correta. Essas informações são os sinais Data_i1, representando os dados do quadro, iba2xbar_start_pack_1, que é o sinal de início do quadro, e iba2xbar_end_pack_1, que é o sinal de fim do quadro. A decisão só pode ser de um a seis devido a quantidade total de portas implementadas no Switch, nesse caso seis.

\subsubsection{Arquivo de configuração}

O arquivo de configuração (Verilog file configuration da Figura 5.1) foi o último elemento implementando da NoC. O objetivo da sua implementação foi permitir a configuração centralizada dos parâmetros disponíveis nos módulos da NoC. A distribuição desses parâmetros de configuração pelas instâncias dos elementos da NoC é realizada de forma manual. No entanto, uma vez distribuído, todas as configurações podem ser alteradas por este arquivo de configuração. Esse arquivo é composto de macros em Verilog (defines), que permitem a parametrização das configurações. O conteúdo do arquivo depende do tipo e da quantidade de instâncias de cada componente NoC da arquitetura, que pode conter CEs, NAs e Switches. No exemplo da Figura 5.13, os parâmetros listados são referentes a um NA, um CE e um Switch.

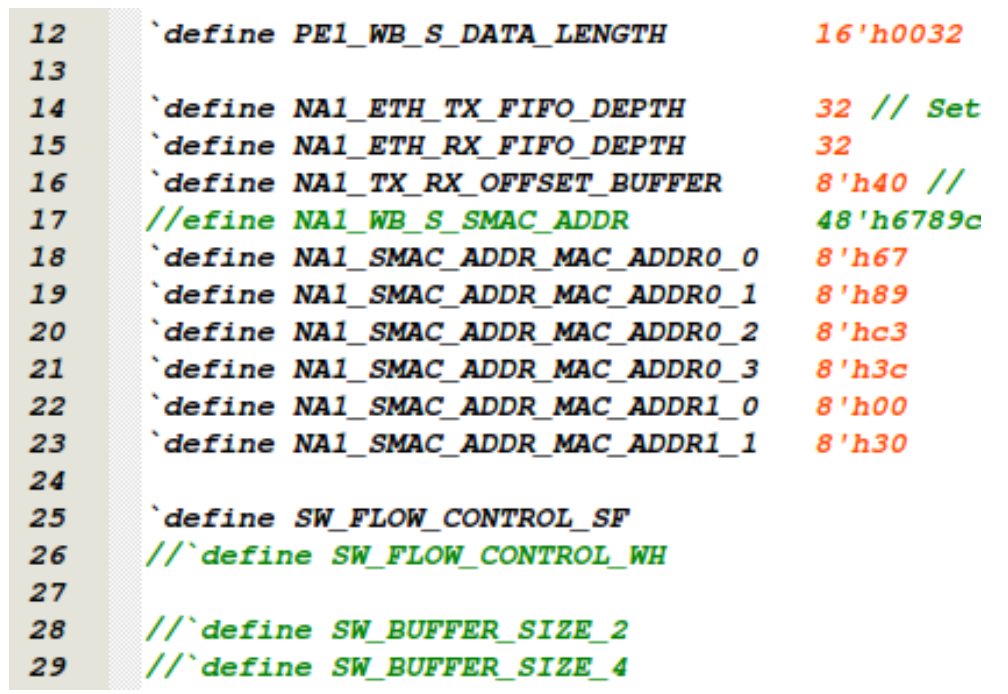

Figura 5.13: Exemplo do arquivo de configuração da NoC

No arquivo exemplificado pela Figura 5.13, a macro que define o parâmetro data_length do elementos de processamento é a CE1_WB_S_DATA_LENGTH, que contem o valor 0x32. Esse valor indica que os quadros transmitidos tem tamanho (dados + FCS) de 50 Bytes, sendo que os quatro últimos Bytes são reservados para o FCS. Todas as macros exemplificadas nesse arquivo iniciam com o prefixo de qual componente ele pertence, como no exemplo, o CE1 indica que o parâmetro data_length é do elemento de controle número um. Esse mesmo prefixo é utilizado para os parâmetros da NA, que são o TX/RX FIFO depth, o TX/RX buffer offset e o MAC source address. No NA exemplificado, o tamanho 
das FIFOs de recepção e transmissão são iguais, com o valor 32. Esse valor significa que cada FIFO tem capacidade de armazenar 32 identificadores de quadro. O próximo parâmetro, o TX/RX buffer offset, para ambas as instancias de NA são configurados para 0x40, que divide o buffer de armazenamento dos BDs em partes iguais para a transmissão e a recepção. A última configuração relacionada com o NA é seu endereço de origem, representado pelas seis macros SMAC_ADDR_MAC_ADDR relacionadas com os registradores MAC_ADDR_0 e MAC_ADDR_1 (Seção 5.2.1.1). Os Bytes do endereço de destino de uma NA são distribuídos nessas macros, com a ordem definida na Tabela 5.2.

Os defines do arquivo de configuração referentes ao Swtich, exemplificado na Figura 5.13, não possuem valores definidos, que os diferenciam das macros do NA e do CE. Eles são utilizados no código com as primitivas 'ifdef, 'ifndef e 'endif, que permitem habilitar ou desabilitar um bloco de código em tempo de síntese. No exemplo, a macro referente ao parâmetro fluxo de controle store-and-forward do Switch (SW_FLOW_CONTROL_SF) está declarada. No entato, as outras referente ao fluxo de controle wormhole (SW_FLOW_ CONTROL_WH), ao tamanho do buffer igual a 2 (SW_BUFFER_SIZE_2) e ao tamanho do buffer igual a 4 (SW_BUFFER_SIZE_4) estão comentadas. O parâmetro tamanho do buffer está configurado para sua opção padrão, utilizando um BD_RAMs de 1 MByte para todas as interfaces. Caso seja definido uma das opções disponíveis, SW_BUFFER_SIZE_2 ou SW_BUFFER_SIZE_4, os Switches utilizam dois ou quadro BD_RAMs de 1 MByte para cada interface, respectivamente. Os valores padrões dos parâmetros e suas opções implementadas são apresentadas na Tabela 5.3. As implementações dos parâmetros do Switch são exemplificadas na Seção 5.2.4.2.

A Figura 5.14 apresenta um exemplo de como um dos parâmetros da NA foi adaptado e implementado na NoC. O primeiro passo foi implementar o arquivo de configuração, definindo o padrão de nome a ser utilizado na macro do parâmetro TX/RX buffer offset. Com esse nome definido e seu valor devidamente preenchido, foi adicionado o include do arquivo de configuração no cabeçalho do arquivo top level do projeto (noc_mac_etherenet.v) da NoC. Ainda nesse arquivo, na instância do NA, foi configurado a passagem do parâmetro para o seu correspondente de implementação. No próximo arquivo do ciclo, o ethmac.v, foi instanciado um tipo de dados parameter para receber o valor passado por parâmetro. No exemplo, esse parâmetro recebe o valor padrão, que é definido no arquivo de configuração (configuration_file.v). Esses dois últimos passos, o de informar o parâmetro na instância do componente e o de instanciar um dado do tipo parameter, são repetidos nos arquivos ethmac.v e eth_registers.v, respectivamente, não ilustrados no exemplo da figura. O último passo destacado no arquivo eth_registers.v da Figura 5.14 demonstra o uso do valor informado no arquivo de configuração no componente eth_register. 


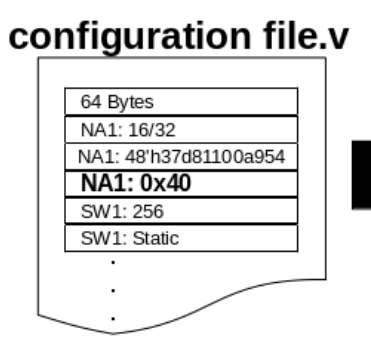

ethmac.v noc mac ethernet.v

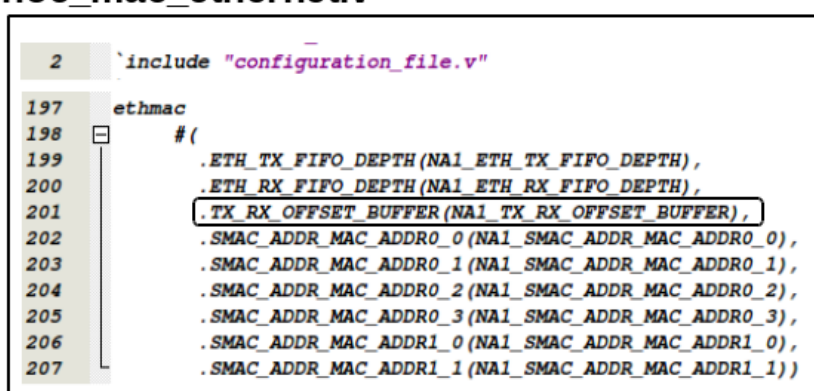

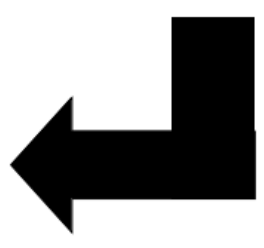
parameter SMAC ADDR MAC ADDR1 $O=$ SMAC ADDR MAC ADDR1 O DEFAULI; parameter SMAC_ADDR_MAC_ADDR1_1 = SMAC_ADDR_MAC_ADDR1_1_DEFAULT;

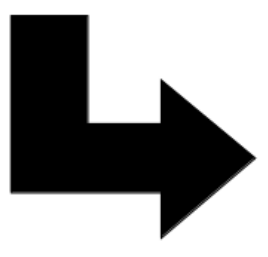

eth_registers.v

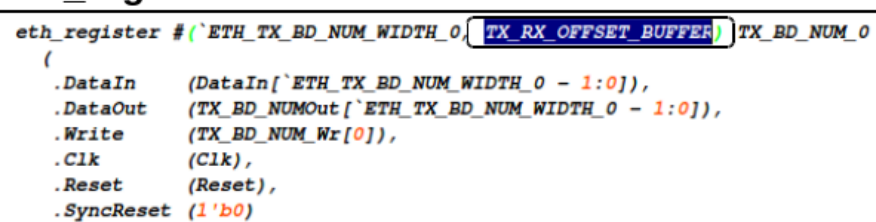

Figura 5.14: Exemplo do caminho da configuração buffer offset de uma NA

\subsection{Rede ethernet on chip parametrizável: característi- cas e parâmetros}

Conforme discutido no Capítulo 2, existem várias classificações possíveis das características de uma NoC. A desenvolvida nesse projeto pode ser classificada como uma NoC ethernet packet-based switch, com a arquitetura indireta e topologia irregular. O Link possui velocidade de transmissão fixa de $100 \mathrm{Mb} / \mathrm{s}$, com tamanho de phit igual a 5-bits e o de flit igual a 32-bits. No NA, o pacote é divido em cabeçalho (14 Bytes), payload e tail (CRC de 4 Bytes), com o tamanho do payload flexível limitado de 64 Bytes até 1536 Bytes. O Switch de seis portas tem uma arquitetura BE com buffers nas portas de entrada de tamanho variável e com duas opções para o controle de fluxo, store-and-forward ou wormhole. O número de portas é fixo, possui roteamento estático e não implementa canais virtuais.

No início desse Capítulo, a Figura 5.1 apresenta a proposta inicial de implementação da NoC. No entanto, alguns dos componentes propostos não foram implementados e são destacados em amarelo na Figura 5.15. Esses componentes não implementados são a topologia (Topology), que é um parâmetro da NoC como um todo, a velocidade do link (Link speed), pertencente ao módulo Link, e os parâmetros roteamento (Routing) e número de portas (Ports number), que são do Switch. A codificação do parâmetro 
topologia pode ser possível com o uso de scripts para gerar o arquivo de instância dos componentes da NoC (noc_mac_etherenet.v) de forma controlada onde suas interligações obedeçam a uma topologia escolhida. Para implementação do routing, pode ser construída uma tabela (lookup table) no módulo DCP, tornando possível o roteamento dinâmico. O ports number do Switch pode ser desenvolvido com as primitivas de pré síntese comentadas na Seção 5.2.5. Como o número de portas é determinado pelas instâncias dos módulos internos no swtich, isso pode ser parametrizável e controlado com o uso dessas primitivas. A implementação do Link speed é discutida na Seção 5.2.3.

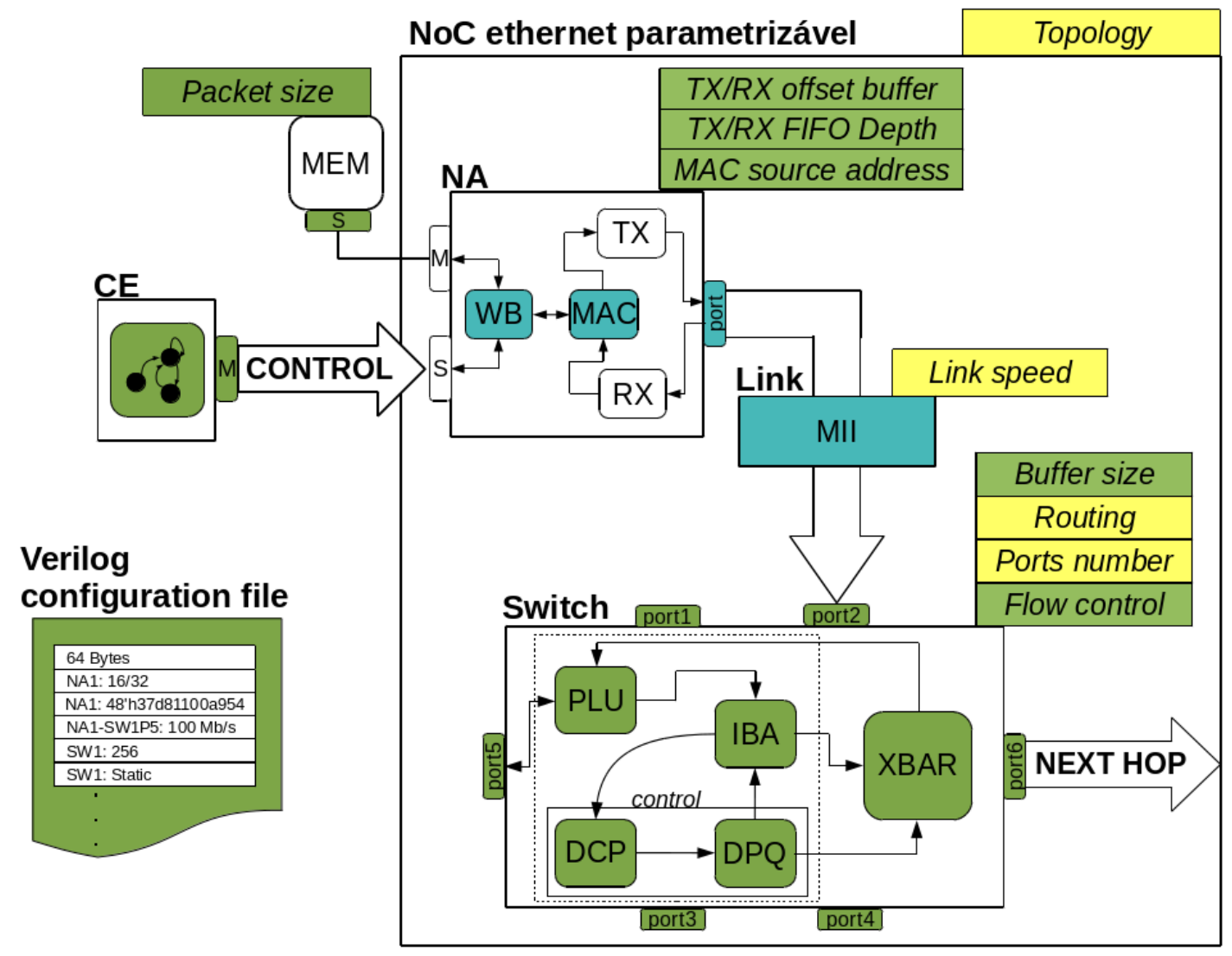

Figura 5.15: Componentes da NoC implementados (verde), modificados (azul) e não implementados (amarelo)

Os blocos da Figura 5.15 pintados na cor verde são os componentes que foram totalmente implementados neste trabalho e que estão concluídos, e os destacados na cor azul também são componentes concluídos que foram adaptados de outros projetos para a implementação da NoC e dos seus parâmetros. A definição do parâmetro Packet size em verde na Figura 5.15 é de responsabilidade do core, que é um componente (externo) fornecido pelo usuário da NoC. Mas, como o módulo CE criado para testes nesse projeto o implementa, esse parâmetro pode ser considerado como concluído. O mesmo acontece para o arquivo de configuração (configuration file) que possui uma codificação incremental de acordo com a adição de novas características e parâmetros na NoC, e é considerado como concluído atendendo todos os parâmetros com a implementação concluída. 
A escolha das configurações que foram implementadas e parametrizadas levaram em consideração as características de aplicações DSP estudas e apresentadas no Capítulo 4. Por exemplo, o parâmetro control flow do Switch teve sua opção wormhole desenvolvida para suportar a transferência de stream de dados com menos atraso. A opção TX/RX buffer offset foi desenvolvida especialmente para aplicações DSP. A configuração desse parâmetro permite dedicar a memória de BDs somente para um tipo de operação, transmissão ou recepção. Isso é conveniente em aplicações DSP, pois, em uma transferência de stream de dados, normalmente, um core apenas transmite enquanto o outro core só recebe. Nesse caso aumenta-se a capacidade de armazenamento de dados na NA e reduz o disperdício de memória. Um outro parâmetro disponível voltado para aplicações DSP é o packet size. Como algumas aplicações exigem uma sincronismos maior na recepção dos dados, a opção de um quadro pequeno pode ser interessante. No entanto, para aplicações DSP, o overhead de controle existente na comunicação com quadros pequenos não é desejável. Então, a tolerância a perda de algum dado transferido permite o uso de quadros maiores para aplicações DSP que fazem stream de dados.

Os valores padrão dos parâmetros implementados são listados na Tabela 5.3, com suas possíveis configurações/opções.

Tabela 5.3: Parâmetros da NoC

\begin{tabular}{l|c|c|c}
\hline Parâmetro & Valor padrão & $\begin{array}{c}\text { Opções e valores } \\
\text { permitidos }\end{array}$ & Módulo pertencente \\
\hline \hline Packet size & 0x32 (50) & 0x32-0x5F2 (1522) & CE \\
TX/RX buffer offset & $0 \times 40$ & 0x0 - 0x80 & NA \\
TX/RX FIFO detph & 32 & $2-256$ & NA \\
MAC source address & 0x452301EF03E8 & Hexadecimal de 48-bits & NA \\
Buffer size & 1 & 1,2 ou 4 & Switch \\
Flow control & $\mathrm{SF}$ & SF ou WH & Switch \\
\hline
\end{tabular}

\subsection{Resultados}

\subsubsection{Métricas de desempenho}

Como apresentado no survey de NoC de Salminen et al. (2008), uma rede on-chip pode ser avaliada pelo tempo de execução da aplicação, área em silício, consumo de energia e atraso. Os resultados apresentados neste trabalho considera duas dessas métricas de desempenho: a área em silício e o atraso da NoC. 


\subsubsection{Experimentos}

Foram realizados cinco experimento, com o objetivo de apresentar as diferenças da utilização de recursos lógicos da FPGA conforme a adição de componentes na arquitetura da NoC e do tempo gasto para transmissão de um quadro ethernet alterando alguns dos parâmetros propostos. Os três primeiros experimentos apresentam resultados em configurações diferentes de arquitetura. Os dois últimos experimentos utilizam a mesma configuração de arquitetura apresentada no experimento 3, contudo, recebem alterações no arquivo de configuração dos parâmetros.

O primeiro experimento apresenta o teste de funcionalidade do NA interconectado a um CE, com a NA configurada em modo promiscuous e loopback. A configuração desse experimento pode ser visualizada na Figura 5.3. Os parâmetro referentes ao NA e ao CE mantiveram os seus valores padrão, definidos na Tabela 5.3. A Figura 5.16 apresenta os sinais de funcionamento utilizados para a validação. A transmissão completa de um quadro ethernet desse experimento executado no FPGA demorou 223 ciclos de clock, com frequência de 50 MHz. Os recursos lógicos utilizados no FPGA são listados na Tabela 5.4.

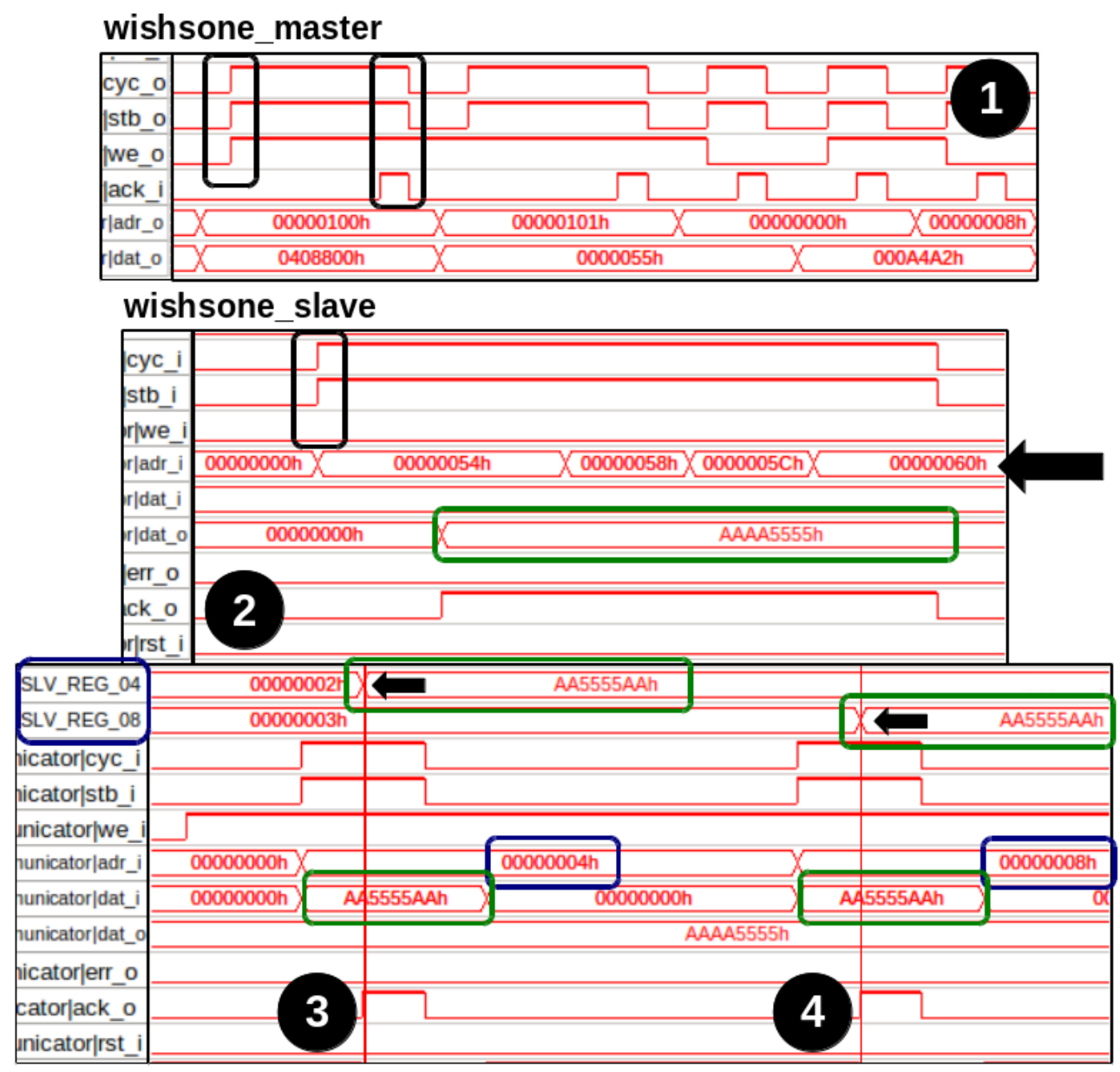

Figura 5.16: Formas de onda capturadas no SinalTap da execução do experimento 1 
Os círculos pretos na Figura 5.16 representam momentos diferentes do teste realizado. No primeiro momento são analisados os sinais da interface master do CE. No início do ciclo de comunicação os sinais cyc_o, stb_o e we_o são ativados, com os dois primeiros sinais indicando o inicio do ciclo e o we_o indicando que é uma operação de escrita. Observa-se que o campo adr_o está preenchido com 0x100 e o valor que deseja escrever é 0x408800 (primeiros 32-bits do Tx_BD). No próximo ciclo, ainda no momento 1, a segunda parte do Tx_BD é transferida com endereço (adr_o) 0x101 e valor (dat_o) 0x55 (ponteiro para os dados na memória). O próximo ciclo é de leitura para adquirir o valor do registrador MODER no endereço (adr_o) 0x0. O valor retornado 0xA4A0 é utilizado para ativar o TXEN no MODER através do próximo ciclo de escrita que tem endereço (adr_o) 0x0 e valor (dat_o) 0xA4A2.

O momento 2 da Figura 5.16 ilustra sinais da interface slave do CE. Nota-se que o CE recebe uma solicitação da NA com o início do ciclo de rajada incremental, que é destacado na mesma figura. A seta nessa figura indica o valor do endereço sendo alterado de 0x54 até 0x60 e o destaque em verde o valor do dado para cada endereço. Nesse exemplo, para os quatro endereços solicitados durante o ciclo o valor do dado é o mesmo, 0xAAAA5555.

Os momentos 3 e 4 da Figura 5.16 também são referentes aos sinais da interface slave. Nesse momento, o CE recebe um ciclo de escrita da NA, que quer repassar os dados do quadro recebido. O endereço (adr_i) de memória 0x4, destacados em azul no momento 3, recebem o valor (dat_i) 0xAAAA5555 destacado em verde. Indicado pela seta preta, isso pode ser verificado no registrador (SLV_REG_04) referente aquela posição de memória, que troca seu valor pelo recebido. O mesmo acontece no momento 4, só que para a posição de memória endereçada em 0x8 (adr_i) e o para registrador SLV_REG_08.

No segundo experimento, o objetivo foi validar o componente Link da NoC. Para esse experimento são utilizados dois NAs e dois CEs, com os NAs interconectados ponto-a-ponto utilizando o Link definido nesse projeto. Os parâmetros dos módulos utilizados no teste estão com seus valores padrão. A configuração desse experimento utilizou 4677 elemento lógicos do FPGA e o dado consegue alcançar o seu destino em 237 ciclos, considerando uma frequência de clock de $50 \mathrm{MHz}$.

Com a adição da interconexão ponto-a-ponto utilizando o módulo Link do experimento 2 a diferença do tempo de transmissão de um quadro ethernet comparada ao do experimento 1 é de 14 ciclos.

O terceiro experimento também envolve dois CEs e dois NAs. Porém, a interconexão entre as NAs é intermediada por um Switch. A Figura 5.17 apresenta a configuração desse experimento. Todos os parâmetros do NA, do CE e do Switch estão com valores padrão. Nesse experimento, a quantidade total de elementos lógicos utilizado pelos módulos da NoC é de 7310. O quadro gasta 337 ciclos para atravessar o Switch completo, e 422 ciclos para chegar no seu destino final, a uma frequência de $50 \mathrm{MHz}$. 


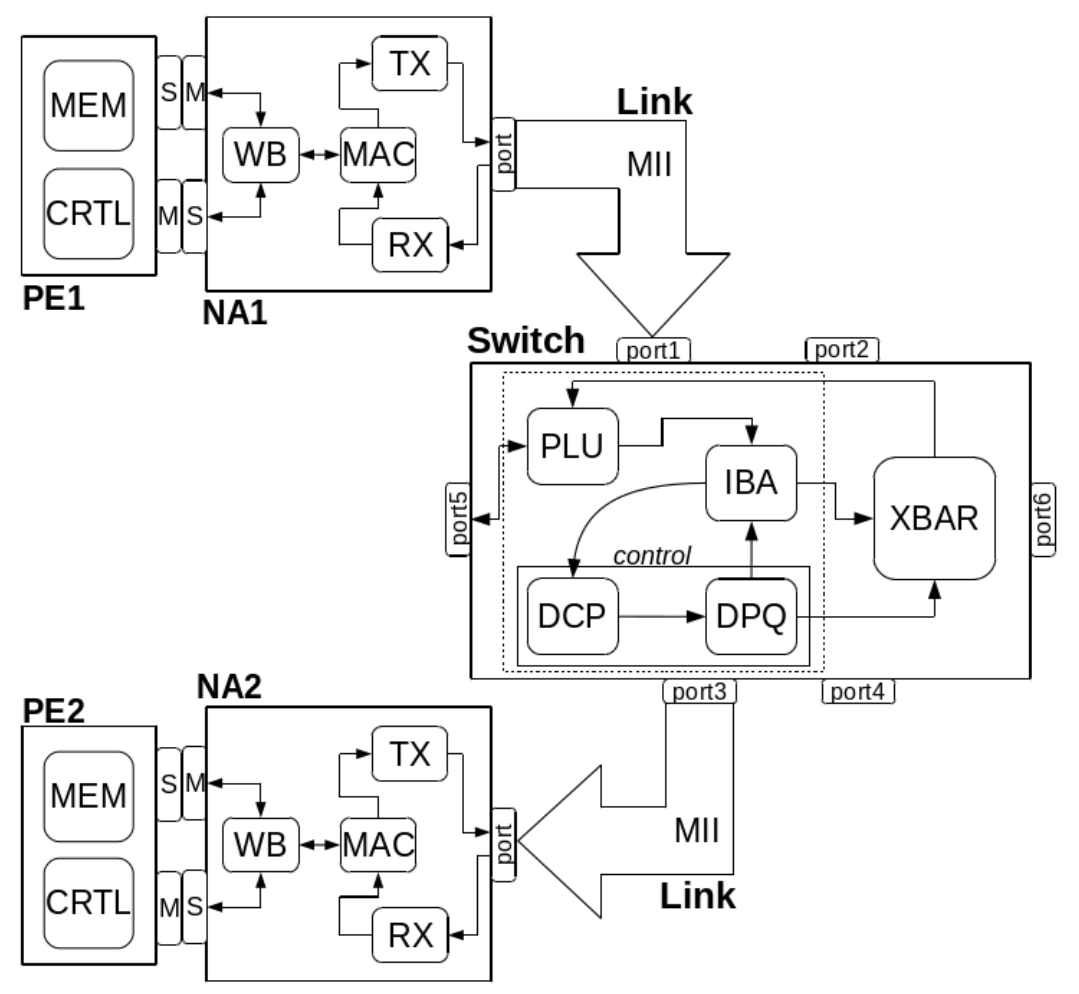

Figura 5.17: Configuração dos experimentos 3, 4 e 5

Os dois próximos experimentos mantêm a configuração de ligação e instância dos módulos apresentadas no terceiro experimento, ilustrado pela Figura 5.17. No entanto, alguns dos parâmetros dos módulos relacionados com esse experimento são modificados, variando seus valores respeitando as possíveis configurações apresentada na Tabela 5.3.

No quarto experimento, com dois CEs, dois NAs e um Switch, o tamanho do buffer do Swtich foi alterado de '1' para '2'. O resultado dessa modificação no valor do parâmetro, observando os recursos lógicos do FPGA, é o aumento de bits de memória total do bloco. Esse recurso, que utilizou 879.456 bits no experimento 3, subiu para 895.840 bits de memória total do bloco no experimento 4. Uma diferença de 16.384 bits, que pode ser relacionada com os BD_RAM adicionados por porta do Switch. Considerando que o Switch tem seis portas, pode-se dizer que o custo de cada BD_RAM adicionado é de aproximadamente 2730 bits. Então, para a configuração do parâmetro com quatro BD_RAMs por porta, o total de bits de memória utilizado no FPGA deve ser de 928.608 bits, considerando 32.768 bits a mais para suportar os dois blocos adicionados. A mudança dos outros recursos lógicos foi insignificante e foram desconsiderados para a avaliação desse experimento.

O quinto experimento manteve o tamanho do buffer no valor padrão e alterou o parâmetro referente ao fluxo de controle do Switch. Diferente do experimento 4, o experimento 5 utiliza o atraso como métrica de desempenho. O atraso para o parâmetro configurado em store-and-forward é detalhado no experimento 3, que precisou de 337 ciclos de clock para o quadro ethernet atravessar o Switch. Com o parâmetro configurado 
para wormhole esse atraso é de 229 ciclos de clock que são necessários para um quadro, que ingresse por uma porta do swtich, seja completamente transmitido. Uma diferença de aproximadamente 108 ciclos, considerando o tamanho mínimo do quadro (64 Bytes). Com o aumento do tamanho do quadro, essa diferença de atraso das duas opções do flow-control deve aumentar, pois esse parâmetro define se o Swtich vai armazenar o quadro completo antes de decidir o roteamento ou apenas o cabeçalho. Na opção wormhole, esse resultado deve-se manter fixo nos 229 ciclos de clock. No entanto, na opção store-and-forward esse atraso deve aumentar conforme o tamanho do quadro.

\subsubsection{Análise dos resultados}

A Tabela 5.4 apresenta detalhadamente os recursos lógicos desses cinco experimentos. Como pode-se observar o experimento 1 utilizou 2118 ALUTs do FPGA. Considerando que esse experimento tinha um $\mathrm{CE}$ e um NA, pode-se considerar que dois CEs mais dois NAs da NoC gastam juntos 4236 ALUTs. Então, se subtraído a quantidade de ALUTs gasta pelos dois CEs e os dois NAs do experimento 2, consegue-se o custo de recursos lógicos necessário para implementado do Link, que é de 441 ALUTs. Observando os recursos lógicos do experimento 3, foi necessário 7310 ALUTs para sintetizar dois CEs, dois NAs, dois Links e um Switch. Baseado nas suposições e nos resultados anteriores, pode-se afirmar que um Switch deve gastar 2192 ALUTs dos recursos lógicos do FPGA para ser implementado. Essas análises não se estendem para os experimentos 4 e 5 pois, utilizam a mesma configuração de arquitetura do experimento 3.

Tabela 5.4: Recursos lógicos utilizados nos experimentos 1, 2, 3, 4 e 5

\begin{tabular}{|c|c|c|c|c|c|}
\hline Experimento & 1 & 2 & 3 & 4 & 5 \\
\hline $\begin{array}{l}\text { Top-level Entity Name } \\
\text { Family } \\
\text { Device } \\
\text { Timing Models } \\
\text { Logic utilization } \\
\text { Combinational ALUTS } \\
\text { Memory ALUTS } \\
\text { Dedicated logic registers } \\
\text { Total registers } \\
\text { Total pins } \\
\text { Total virtual pins } \\
\text { Total block memory bits }\end{array}$ & \begin{tabular}{|l} 
noc_mac_ethemet \\
Stratix IV \\
EP4SGX230KF40C2ES \\
Final \\
$1 \%$ \\
$2,118 / 182,400(1 \%)$ \\
$0 / 91,200(0 \%)$ \\
$1,251 / 182,400(<1 \%)$ \\
1251 \\
$40 / 888(5 \%)$ \\
0 \\
$9,216 / 14,625,792(<1 \%)$ \\
\end{tabular} & \begin{tabular}{|l} 
noc_mac_ethemet \\
Stratix IV \\
EP4SGX230KF40C2ES \\
Final \\
$4 \%$ \\
$4,677 / 182,400$ ( $3 \%$ ) \\
$0 / 91,200$ ( $0 \%$ ) \\
$4,169 / 182,400(2 \%)$ \\
4169 \\
$36 / 888$ ( $4 \%$ ) \\
0 \\
$862,208$ / 14,625,792 ( $6 \%)$ \\
\end{tabular} & \begin{tabular}{|l|} 
noc_mac_ethemet \\
Stratix IV \\
EP4SGX230KF40C2ES \\
Final \\
$6 \%$ \\
$7,310 / 182,400(4 \%)$ \\
$0 / 91,200$ ( $0 \%)$ \\
$5,498 / 182,400(3 \%)$ \\
5498 \\
$36 / 888$ ( $4 \%$ ) \\
0 \\
$879,456 / 14,625,792$ ( $6 \%)$ \\
\end{tabular} & $\begin{array}{l}\text { noc_mac_ethernet } \\
\text { Stratix IV } \\
\text { EP4SGX230KF40C2ES } \\
\text { Final } \\
6 \% \\
7,319 / 182,400 \text { ( } 4 \% \text { ) } \\
0 / 91,200(0 \%) \\
5,504 / 182,400 \text { ( 3 \% ) } \\
5504 \\
36 / 888 \text { ( } 4 \% \text { ) } \\
0 \\
895,840 \text { / } 14,625,792 \text { ( } 6 \%\end{array}$ & \begin{tabular}{|l} 
noc_mac_ethernet \\
Stratix IV \\
EP4SGX230KF40C2ES \\
Final \\
$6 \%$ \\
$7,318 / 182,400(4 \%)$ \\
$0 / 91,200(0 \%)$ \\
$5,502 / 182,400(3 \%)$ \\
5502 \\
$36 / 888$ ( $4 \%)$ \\
0 \\
$879,456 / 14,625,792$ ( $6 \%$ \\
\end{tabular} \\
\hline
\end{tabular}

A Tabela 5.5 demonstra uma comparação entre os três últimos experimentos, os quais são versões completas de uma NoC com variações em alguns parâmetros.

Os resultados apresentados na Tabela 5.5 mostram a influência dos parâmetros nas métricas de desempenho adotadas. Observa-se que o número de ALUTs (Altera LookUp Tables) utilizado é similares para os três experimentos apresentados. O mesmo acontece para os registradores, que sofrem pouca alteração entre os experimentos. Contudo, para 
Tabela 5.5: Resultados dos experimentos 3,4 e 5

\begin{tabular}{l|c|c|c|c|c|c|c}
\hline \multicolumn{2}{l|}{ Métrica de desempenho } & \multicolumn{3}{c|}{ Área em silício } & \multicolumn{2}{c}{ Atraso } \\
\hline Exp & $\begin{array}{c}\text { Parâmetro } \\
\text { alterado }\end{array}$ & Opção & ALUTs & Registradores & $\begin{array}{c}\text { Bits de } \\
\text { memória }\end{array}$ & $\begin{array}{c}\text { Ciclos } \\
\text { port-port }\end{array}$ & $\begin{array}{c}\text { Ciclos } \\
\text { fim a fim }\end{array}$ \\
\hline \hline 3 & nenhum & padrão & 7310 & 5498 & 879.456 & 337 & 422 \\
4 & buffer size & 2 & 7319 & 5504 & $\mathbf{8 9 5 . 8 4 0}$ & 340 & 425 \\
5 & flow control & WH & 7318 & 5502 & 879.456 & $\mathbf{2 2 9}$ & 314 \\
\hline
\end{tabular}

a última métrica que considera a área em silício, os valores são diferentes comparando os resultados das síntese do experimento 4 aos do 3 e 5. Isso devido a adição de componentes que necessitam de mais bits de memória. Observando os resultados relacionados com a métrica atraso, os valores são próximos para os experimentos 3 e 4 . No entanto, no experimento 5 esse valor diminui para as duas métricas analisadas. A métrica Ciclos port-port, que representa quantos ciclos um quadro gasta para atravessar de uma porta para outra no Switch, tem o resultado do experimento 5 em destaque, o qual apresenta o menor atraso quando o controle de fluxo optado é wormhole. Isso também é observado no Ciclos fim a fim, que é o atraso de transmissão de dados da sua origem até seu destino.

O experimento 3, que contém uma NoC completa com um Swtich, dois NAs e dois CEs, utiliza 7310 elementos lógicos da Stratix IV, o que da aproximadamente 4\% da sua capacidade total. Considerando a Stratix X como a plataforma atual, a configuração do experimento 3 ocuparia $0,18275 \%$ da sua capacidade total, que é aproximadamente de 4.000.000 de elementos lógicos. Isso mostra que os recursos lógicos necessários para o uso do padrão ethernet no desenvolvimento de NoCs nos FPGAs modernos é factível. 
O objetivo do trabalho foi desenvolver e disponibilizar uma NoC no padrão Ethernet que tivesse suas configurações facilmente parametrizáveis. Os componentes implementados possibilitam a criação de inúmeras arquiteturas de NoC, com suas características específicas para a aplicação. No entanto, antes de partir para o objetivo principal foi necessário realizar a avaliação de hipóteses para o desenvolvimento dos componentes. Para o desenvolvimento do NA, foram avaliados dois cores, o ethmac do OpenCores e o greth da Gaisler. O componente da Gaisler, descrito em VHDL, não sintetizava separado do processador Leon, o que fez com que o ethmac fosse escolhido. A ideia inicial para a implementação do Switch era encontrar um core pronto que pudesse ser feita as modificações necessárias para a implementação dos parâmetros de configuração. No entanto, não foi encontrado nenhum que fosse livre e descrito em HDL, o que levou a sua implementação.

A escolha de um padrão para implementação dos módulos e funcionamento da NoC é contestada, pois, segundo alguns autores, o custo de adoção de um padrão é desnecessário, justificado pela falta de customização e aumento da área em silício ocupada. No entanto, os resultados apontam que mesmo adotando um padrão, a NoC pode ser implementada utilizando um percentual de recursos de hardware reduzido. Além disso, o uso de FPGAs possibilita definir parâmetros para configuração em tempo de instância, o que permite a customização da NoC para uma determinada aplicação. Nessa situação de reconfigurabilidade o uso de um padrão torna-se ainda mais importante. Então, com um pouco a mais de recursos em relação as não padronizadas, o projeto de NoC pode atingir aspectos, como o aumento da confiabilidade do sistema, a facilidade na manutenção e a simplicidade na adição de novas características. O uso de um padrão como o Ethernet, permite 
alcançar esses aspectos, porque é um padrão testado, utilizado em muitos ambientes de comunicação e difundido na área da computação.

Por fim, implementar uma NoC no padrão Ethernet não é uma tarefa trivial, pois o padrão é complexo por definir todos os detalhes internos do comportamento da comunicação para seus diversos modos de operação. No entanto, com a constante expansão da capacidade de recursos lógicos dos chips e com a tendência do aumento da quantidade de cores numa única pastilha, esse esforço extra para prover um meio de comunicação robusto pode ser a solução mais adequada para viabilizar a implementação e manutenção de sistemas computacionais embarcados modernos.

Espera-se que este seja o pontapé inicial de novas pesquisas visando contribuir com o surgimento de novas tecnologias para a comunicação em SoC.

\subsection{Trabalhos futuros}

Para os trabalhos futuros é possível sugerir uma grande quantidade de ideias. Uma vez que o problema em questão constitui um amplo tema de pesquisa, a gama de variações sobre o mesmo tema e as técnicas existentes para abordá-las também são muito extensa.

Inicialmente sugere-se a finalização da implementação de todos os parâmetros propostos, que têm como objetivo a customização da NoC. Com a realização dessa implementação, os novos parâmetros poderiam proporcionar uma maior variedade de configurações da NoC.

Outro tópico que merece uma maior atenção é a realização de testes de carga da NoC no FPGA. Além de possibilitar a avaliação dos outros parâmetros implementados, os resultados desses testes poderiam indicar a confiabilidade e disponibilidade do sistema de comunicação utilizando a NoC.

Uma outra avaliação nos módulos básico da NoC poderia ser feita com o objetivo de identificar possíveis novos parâmetros de configuração, respeitando o padrão ethernet. Além de uma reavaliação nos limiares e valores permitidos dos parâmetros implementados, o que pode proporcionar uma maior flexibilidade na configuração atual.

Uma última sugestão seria a criação de scripts para gerar o arquivo top level do sistema, com o intuito de automatizar o processo de instância dos elementos da NoC. Além de contribuir para a implementação do parâmetro topology, isso poderia acarretar uma maior facilidade na especificação da arquitetura. 


\section{Referências}

ALLIANCE, V. 2 ed Virtual component interface standard Version. 2000.

Altera Stratix iv gx fpga development board: Reference manual. Altera Corporation, San Jose, 2012.

Amory, A.; Lubaszewski, M.; Moraes, F.; Moren, E. Test time reduction reusing multiple processors in a network-on-chip based architecture. In: Design, Automation and Test in Europe, 2005. Proceedings, 2005, p. 62-63 Vol. 1.

Asanovic, K.; Bodik, R.; Catanzaro, B. C.; Gebis, J. J.; Husbands, P.; Keutzer, K.; Patterson, D. A.; Plishker, W. L.; Shalf, J.; Williams, S. W.; Yelick, K. A. The Landscape of Parallel Computing Research: A View from Berkeley. , n. UCB/EECS-2006-183, 2006.

Benini, L.; Bertozzi, D. Network-on-chip architectures and design methods. Computers and Digital Techniques, IEE Proceedings -, v. 152, n. 2, p. 261-272, 2005.

Benini, L.; De Micheli, G. Networks on chips: a new SoC paradigm. Computer, v. 35, n. 1, p. $70-78,2002$.

Bjerregaard, T.; Mahadevan, S. A Survey of Research and Practices of Network-on-chip. ACM Comput. Surv., v. 38, n. 1, 2006.

Disponível em http://doi.acm.org/10.1145/1132952.1132953

Dall'Osso, M.; Biccari, G.; Giovannini, L.; Bertozzi, D.; Benini, L. Xpipes: A latency insensitive parameterized network-on-chip architecture for multi-processor SoCs. In: Computer Design (ICCD), 2012 IEEE 30th International Conference on, 2012, p. 45-48.

Daphal, S.; Jagtap, S. DSP based improved Speech Recognition system. In: Communication, Information Computing Technology (ICCICT), 2012 International Conference on, 2012, p. 1-6. 
Derbel, A.; Ghorbel, M.; Samet, M.; Ben Hamida, A. Implementation of strategy based on auditory model based wavelet transform speech processing on DSP dedicated to cochlear prosthesis. In: Computational Intelligence and Intelligent Informatics, 2009. ISCIII '09. 4th International Symposium on, 2009, p. 143-148.

Diniz, P. S. R.; da Silva, E. A. B.; Neto, S. L. Processamento digital de sinais: Projeto e análise de sistemas. Bookman, 2004.

Dorta, T.; Jimenez, J.; Martin, J.; Bidarte, U.; Astarloa, A. Overview of FPGA-Based Multiprocessor Systems. In: Reconfigurable Computing and FPGAs, 2009. ReConFig '09. International Conference on, 2009, p. 273-278.

Freescale, S. I. MSC8156 Product Brief: Broadband Wireless Access DSP. Freescale Semiconductor, Inc., 2011.

Disponível em http://www.freescale.com/webapp/sps/site/prod_summary.jsp? code=MSC8156\&nodeId=0127950E5F5699

Glossner, J.; Iancu, D.; Moudgill, M.; Nacer, G.; Jinturkar, S.; Schulte, M. The sandbridge SB3011 SDR platform. In: Mobile Future, 2006 and the Symposium on Trends in Communications. SympoTIC '06. Joint IST Workshop on, 2006, p. ii-v.

Guzma, V.; Bhattacharyya, S.; Kellomaki, P.; Takala, J. An integrated ASIP design flow for digital signal processing applications. In: Applied Sciences on Biomedical and Communication Technologies, 2008. ISABEL '08. First International Symposium on, 2008, p. 1-5.

Herveille, R. WISHBONE System-on-Chip (SoC) Interconnection Architecture for Portable IP Cores. 3 edOpenCores Organization, 2002.

Intel A Platform 2015 Workload Model Recognition, Mining and Synthesis Moves Computers to the Era of Tera. Intel Corporation, 2005.

JAFRI, S. M. A. H.; GUANG, L.; JANTSCH, A.; PAUL, K.; HEMANI, A.; TENHUNEN, H. Self-adaptive NoC Power Manegement with Dual-level Agents: Arhitecture and Implementation. Royal Institute of Technology, 2009.

Karam, L.; AlKamal, I.; Gatherer, A.; Frantz, G.; Anderson, D.; Evans, B. Trends in multicore DSP platforms. Signal Processing Magazine, IEEE, v. 26, n. 6, p. 38-49, 2009.

Karuri, K.; Leupers, R. Application Analysis Tools for ASIP Design: Application Profiling and Instruction-set Customization. 2011.

Meyer-Baese, U. Digital Signal Processing with Field Programmable Gate Arrays. 2007. 
Mitra, S. Digital Signal Processing: A Computer-Based Approach. 2 ed. The McGraw-Hill Companies, Inc., 1998.

Mohor, I. Ethernet ip core design document. OpenCores Organization, 2002.

Murillo, J. J. HW-SW Components for Parallel Embedded Computing on NoC-Based MPSoCs. Tese de Doutoramento, U NIVERSITAT A UTON OMA DE B ARCELONA, Bellaterra, 2009.

OCPIP 3 edOpen Core Protocol (OCP) Specification. 2009.

OpenCores Ethernet mac 10/100 mbps :: Overview. 2013.

Disponível em http://opencores.org/project, ethmac

OpenCores $100 \mathrm{mb} / \mathrm{s}$ ethernet mac layer switch :: Overview. 2014.

Disponível em http://opencores.org/project,mac_layer_switch

Oppenheim, A. V.; Schafer, R. W. Digital Signal Processing. 1975.

OSI ISO/IEC 7498-1:Information technology - Open Systems Interconnection - Basic Reference Model: The Basic Model. International, Organization for Standardization, 2 edSuiça, 1996.

Ost, L.; Mello, A.; Palma, J.; Moraes, F.; Calazans, N. MAIA - a framework for networks on chip generation and verification. In: Design Automation Conference, 2005. Proceedings of the ASP-DAC 2005. Asia and South Pacific, 2005, p. 49-52 Vol. 1.

Papamichalis, P. Digital Signal Processing Applications with the TMS320 Family: Theory, Algorithms, and Implementations. Texas Instruments Inc, 1990.

Papamichalis, P. Introduction to the TMS320 Family of Digital Signal Processors. Texas Instruments, 1999.

Peyravi, H. Medium access control protocols performance in satellite communications. Communications Magazine, IEEE, v. 37, n. 3, p. 62-71, 1999.

Picochip PC205 Multi-Core SDP for Wireless Infrastructure. Mindspeed Technologies Inc, 2012.

Proakis, J. G.; Manolakis, D. G. Digital Signal Processing: Principles, Algorithms, and Applications. 3 ed. 1996.

Rabiner, L. R.; Gold, B. Theory and Application of Digital Signal Processing. 1975. 
Salminen, E.; Kulmala, A.; Hamalainen, T. D. H. Survey of Network-on-chip Proposals. OCP-IP, 2008.

da Silva Cardozo, R. Redes-em-Chip de Baixo Custo. Dissertação de Mestrado, Universidade Federal do Rio Grande do Sul, Porto Alegre, 2005.

Sparsoe, J. Asynchronous design of networks-on-chip. In: Norchip, 2007, 2007, p. 1-4.

Texas, I. I. TNETV3020 Carrier Infrastructure Platform: Telogy Software ${ }^{T M}$ products integrated with TI's DSP-based high-density communications processor. Texas Instruments Incorporated, 2008.

Disponível em http://focus.ti.com/lit/ml/spat174a/spat174a.pdf

The Dini Group, I. The dini group - leader in high performace fpga boards. 2014.

Disponível em http://www.dinigroup.com/new/index.php

The Institute of Electrical and Electronics Engineers, I. IEEE Standard for Ethernet. The Institute of Electrical and Electronics Engineers, Inc., 2012.

Tilera, C. TILE64 Processor: Product Brief. Tilera Corporation, 2008.

Truong, D.; Cheng, W.; Mohsenin, T.; Yu, Z.; Jacobson, A.; Landge, G.; Meeuwsen, M.; Watnik, C.; Tran, A.; Xiao, Z.; Work, E.; Webb, J.; Mejia, P.; Baas, B. A 167-Processor Computational Platform in $65 \mathrm{~nm}$ CMOS. Solid-State Circuits, IEEE Journal of, v. 44, n. 4, p. 1130-1144, 2009.

Tsai, W.-C.; Lan, Y.-C.; Hu, Y.-H.; Chen, S.-J. Networks on Chips: Structure and Design Methodologies. Journal of Electrical and Computer Engineering, 2012.

Xu, J.; Sotudeh, R.; Josephs, M. Asynchronous Packet-Switching for Networks-on-Chip. In: Application of Concurrency to System Design, 2006. ACSD 2006. Sixth International Conference on, 2006, p. 201-207.

Zeferino, C.; Susin, A. SoCIN: a parametric and scalable network-on-chip. In: Integrated Circuits and Systems Design, 2003. SBCCI 2003. Proceedings. 16th Symposium on, 2003, p. 169-174.

Zeferino, C. A.; Santo, F. G. M. E.; Susin, A. A. ParIS: A Parameterizable Interconnect Switch for Networks-on-chip. In: Proceedings of the 17th Symposium on Integrated Circuits and System Design, SBCCI '04, New York, NY, USA: ACM, 2004, p. 204-209 $\left(S B C C I{ }^{\prime} 04\right.$, ).

Disponível em http://doi.acm.org/10.1145/1016568.1016624 
Zhang, Y.; He, H.; Zhou, Z.; Yang, X.; Sun, Y. A Scaleable DSP System for ASIP Design. In: Solid-State Circuits Conference, 2006. ASSCC 2006. IEEE Asian, 2006, p. $215-218$. 


\section{A.1 Protocolo Wishbone}

O Wishbone é um protocolo de interconexão de projetos SoC para IPs portáteis. A ideia é prover um protocolo de comunicação livre que seja utilizado em projetos de SoC, com o intuído de aliviar problemas de integração, melhorar a portabilidade e a confiança do sistema e criar uma interface comum entre os nós IPs. Uma das principais características do Wishbone é o reuso intrínseco na sua implementação, resultando em um rápido time-to-maket de projetos (Herveille, 2002). Outras características desse protocolo podem ser destacadas, como por exemplo: ser compacto, pois provê uma interface simples de hardware para IP que necessita de poucos recursos lógicos; ser independente de tecnologia de hardware e de ferramenta de síntese/teste; suportar métodos de interconexão como ponto a ponto, barramento compartilhado, comutação crossbar e switched fabric; possui arquitetura mestre / escravo; e tem tamanho flexível do barramento de dados, tamanho dos operando e a largura dos endereços.

\section{A.1.1 Sinais do protocolo Wishbone}

Os sinais do protocolo Wishbone são similares para os módulos master e slave, que são classificados em quatro tipos: os sinais do módulo SYSCON, sinais em comum das interfaces master e slave, sinais do master e sinais do slave. Alguns desses sinais são opcionais e outros podem não serem necessários, dependendo do tipo de ciclo da transmissão. A Figura A.1 lista os sinais presentes em cada módulo do protocolo Wishbone. 


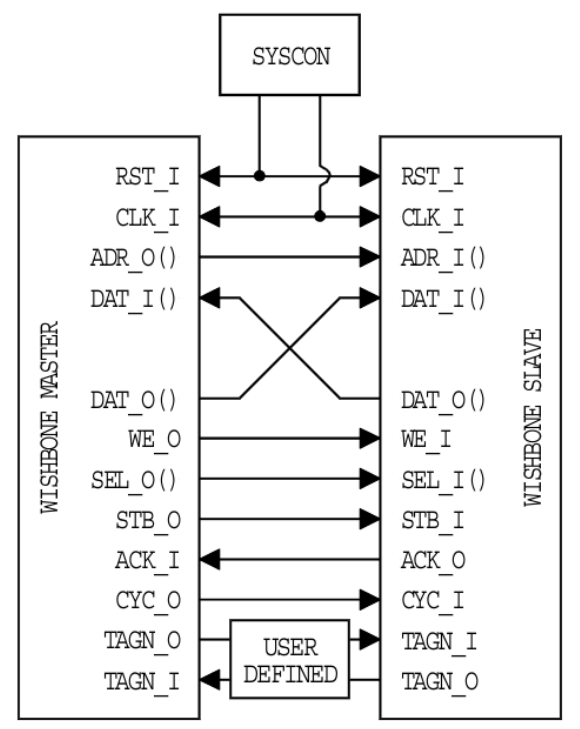

Figura A.1: Sinais básicos dos módulos master e slave interconectados ponto a ponto

Na descrição dos sinais, a palavra 'ativo' indica nível logíco '1' e a 'não ativo' nível logico '0'. Os sinais possuem sufixo '_I' para indicar uma entrada e '_O' para indicar uma saída. Os parênteses significam que o sinal é um vetor.

\section{A.1.1.1 Sinais do modulo SYSCON}

O módulo SYSCON da Figura A.1 representa o sistema global, que deve fornecer para os módulos Wishbone os sinais de clock e de reset.

- CLK_O: a saída de clock do sistema é gerada pelo módulo SYSCON. Ele coordena todas as atividade da lógica interna do protocolo Wishbone;

- RST_O: sinal de reset do sistema. Ele força todas as interconexão do Wishbone reiniciarem. As máquinas de estado vão para o estado inicial.

\section{A.1.1.2 Sinais comuns das interfaces master e slave}

Os sinais que as interfaces dos módulos master e slave possuem em comum são:

- CLK_I: entrada de clock que controla a lógica interna dos módulos Wishbone. Todos os sinais de saída são registrados na borda de subida desse sinal. Todos os sinais de entrada são estáveis antes da borda de subida desse sinal;

- DAT_I(): um vetor de dados de entrada, usado para passar os dados binários. Os limites do vetor são determinados pelo tamanho da porta, que pode possuir tamanho máximo de 64-bits;

- DAT_O(): um vetor de dados de saída, usado para trafegar dados binários. Como no sinal DAT_I(), o tamanho do vetor pode assumir no máximo 64-bits e é determinado na implementação; 
- RST_I: entrada do sinal de reset. Esse sinal reinicia apenas a lógica interna dos módulos Wishbone, incluindo as máquinas de estado. Os IPs conectados através dela não são reinicializados;

- TGD_I() / TGD_O(): os "tipo de tag dos dados", representados pelos sinais TAGN da Figura A.1, são sinais opcionais que podem ser implementados com o intuito de transmitir uma informação customizada do sistema. Ele é um vetor associado ao sinal DAT_I/DAT_O e é quantificado pelo sinal STB_I. Exemplos do seu uso são: proteção de paridade, correção de erro e informação de timestamp;

- CTI_I/O(): saída do master para entrada do slave. O identificador do tipo de ciclo provê uma informação adicional para slave, indicando que tipo de ciclo está em progresso. Esse sinal possui tamanho fixo de 3-bits. A Tabela A.1 lista os possíveis tipos de ciclos.

Tabela A.1: Tipos de ciclo do Wishbone

\begin{tabular}{c|c}
\hline CTI_O(2:0) & Descrição \\
\hline \hline '000' & Ciclo clássico \\
'001' & Ciclo de rajada com endereço constante \\
'010' & Ciclo de rajada incremental \\
'111' & Fim da rajada \\
\hline
\end{tabular}

\section{A.1.1.3 Sinais do master}

Os sinais que apenas a interface do modulo master possui. Os sinais TGA_O() e TGC_O() não são detalhados, por serem sinais opcionais relacionados com o endereço e o ciclo respectivamente, não implementados no trabalho, representados pelo sinal TAGN na Figura A.1.

- ACK_I: saída do sinal de reconhecimento que, quando ativo, indica o fim normal (com sucesso) de um ciclo;

- ADR_O(): um vetor de saída de endereço. Os limites do vetor são determinados de duas formas: o limite alto conforme a largura de endereço do nó e o limite baixo determinado pelo tamanho da porta de dados e sua granularidade (definida pela divisão por octetos);

- CYC_O: saída de ciclo que, quando ativo, indica o início de um ciclo válido. Ele permanece ativo durante todo o progresso do ciclo;

- ERR_I: entrada de erro que, quando ativo, indica o fim anormal (com erro) de um ciclo; 
- SEL_O(): um vetor de saída de tamanho variado que indica onde o dado válido é esperado no sinal DAT_I() durante ciclos de READ, e no DAT_O() para WRITE. Seu tamanho é calculado baseado na granularidade da porta (entrada e saída de dados), no caso sua quantidade de octetos. Exemplo: porta com 32-bits: tamanho do vetor SEL_O() é de 4-bits;

- STB_O: saída que indica um ciclo de transferência de dados válidos;

- WE_O: saída que indica qual a operação do ciclo atual. Escrita quando está ativo, e leitura quando não ativo.

O sinal LOCK_O só possui utilidade em sistemas com mais de um master e por esse motivo não será detalhado. O sinal RTY_I também não é tratado, pois não foi utilizado na implementação.

\section{A.1.1.4 Sinais do slave}

Os sinais pertencentes apenas a interface do módulo slave.

- ACK_O: saída de reconhecimento que indica o fim de um ciclo com sucesso;

- ADR_I(): vetor de entrada de endereço que contém o endereço de acesso desejado pelo ciclo atual e possuiu tamanho igual ao ADR_O();

- CYC_I: entrada que indica o início de um ciclo válido. Esse sinal permanece ativo durante a transferência do primeiro até o ultimo dado;

- ERR_O: saída de reconhecimento que indica o fim de um ciclo com erro;

- SEL_I(): informa a posição do dado válido nos vetores DAT_I/O() para executar a operação desejada;

- STB_I: indica que o master iniciou um ciclo válido com esse slave e aguarda uma reposta. Esse resposta pode ser atendida pelos sinais ACK_O ou ERR_O;

- WE_I: informa a operação desejada no ciclo atual. Ativo para escrita e não ativo para leitura.

Os sinais LOCK_I e RTY_O também não são discutidos, pelo mesmo motivo dos sinais LOCK_O e RTY_I do módulo master. 


\section{A.1.2 Ciclos do Wishbone}

As operações de transferência de dados no Wishbone são realizadas por ciclos. Existe mais de um tipo de ciclo possível, que estão listados na Tabela A.1. Dentre esses ciclos, o ciclo clássico realiza operações de leitura e escrita simples e deve ser suportado por todos os módulos Wishbone. Pelo fato do protocolo Wishbone possuir uma arquitetura mestre/escravo, o módulo master sempre inicia o ciclo de operação. Os exemplos utilizados para demonstrar o funcionamento dos ciclos de operação consideram apenas ciclos de sucesso, sem desvios ou tratamento de erro.

\section{A.1.2.1 Ciclo clássico: leitura}

O ciclo clássico de leitura transfere apenas uma unidade de dado por vez e o seu tamanho depende da largura do canal de dados. O exemplo de funcionamento do protocolo, ilustrado na Figura A.2, considera o sinal CYC_O sempre ativo.

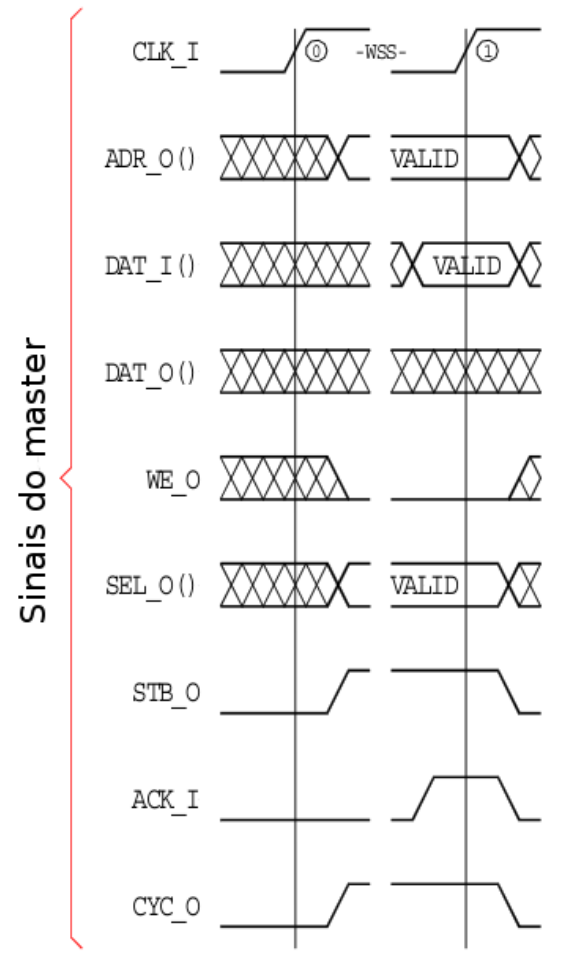

Figura A.2: Sinais de um ciclo clássico de leitura (Herveille, 2002)

No instante '0', ilustrado na Figura A.2, o master preenche um endereço válido no sinal ADR_O(). Em seguida, ele nega (nível logico '0') o sinal WE_O para indicar uma leitura. O master ainda deve preencher o campo SEL_O() com '1' no bit correspondente ao octeto válido do dado. Caso seja mais de um octeto válido, ele deve preencher todos os bits correspondentes. E por fim, para informar o início do ciclo, o master ativa o sinal CYC_O e, para indicar o início da fase, ele ativa o STB_O. O slave deve decodificar a entrada com '1' no sinal ACK_I. Ao mesmo tempo, ele preenche o sinal DAT_I com um 
dado válido, obedecendo os campos ADR_O() e o campo SEL_O(), e caso o sinal STB_O ainda esteja ativo, mantem '1' no sinal ACK_I.

No instante seguinte, o '1' da Figura A.2, o master trata o sinal DAT_I para adquirir o dado da leitura e nega os sinais STB_O e CYC_O para indicar o fim do ciclo. O slave, que monitorava o sinal STB_O, nega o ACK_I em resposta ao fim do ciclo. Isso finaliza a leitura de um único dado utilizando o ciclo clássico.

\section{A.1.2.2 Ciclo clássico: escrita}

O ciclo clássico de escrita, como no de leitura, transfere apenas uma unidade de dado por vez, e possuiu a mesma característica referente ao tamanho do dado. O exemplo ilustrado na Figura A.3, também considera o sinal CYC_O sempre ativo. O procedimento de escrita é ligeiramente mais simples, considerando que o master não espera um dado como resposta do slave, apenas um sinal confirmação.

No instante '0', conforme a Figura A.3, o master preenche um endereço válido no sinal ADR_O() e um dado válido no DAT_O(). Em seguida, ele ativa (nível logico '1') o sinal WE_O para indicar uma escrita. Depois, o master configura o campo SEL_O() com '1' no bit correspondente ao octeto válido do dado. Caso seja mais de um octeto válido, ele deve preencher todos os bits correspondentes. Para iniciar o ciclo de transmissão, o master ativa o sinal CYC_O. No próximo passo, o master ativa o sinal STB_O indicando o início da fase. O slave, ao receber o sinal CYC_O e STB_O, percebe o início do ciclo. Ao verificar que se trata de um ciclo de escrita, o slave verifica o campo DAT_O() para adquirir o dado. Assim que ele terminar a obtenção dado, ele responde para o master a escrita com sucesso, ativando o sinal ACK_I.

No próximo instante, o '1', o master que monitora o sinal ACK_I, recebe o sinal do slave indicando o sucesso da operação e finaliza a mesma através da negação dos sinais STB_O e CYC_O. O slave, que mantinha o sinalo ACK_I ativado, percebe a negação do sinal STB_O e em reposta, nega o sinal ACK_I.

\section{A.1.2.3 Ciclo Rajada incremental: leitura e escrita}

O ciclo de rajada incremental implementa uma operação que transmite mais de um dado por ciclo. Essa operação é controlada com a ajuda do sinal CTI_O() definido na Seção A.1.1.2. Além dos sinais de início de ciclo (CYC_O) e início de fase (STB_O) para controle da operação, o sinal CTI_O informa o tipo de ciclo atual e o seu fim, para o caso de ciclo de rajada incremental. A Figura A.4 mostra um exemplo do funcionamento desse tipo de ciclo para leitura, considerando um dado com tamanho de 32-bits.

No primeiro instante '0', o master preenche o sinal ADR_O() com o primeiro endereço válido 'N' e o sinal CTI_O() com '010', indicando um ciclo de rajada incremental. Como próximo passo, o master nega o sinal WE_O que representa uma operação de leitura. 


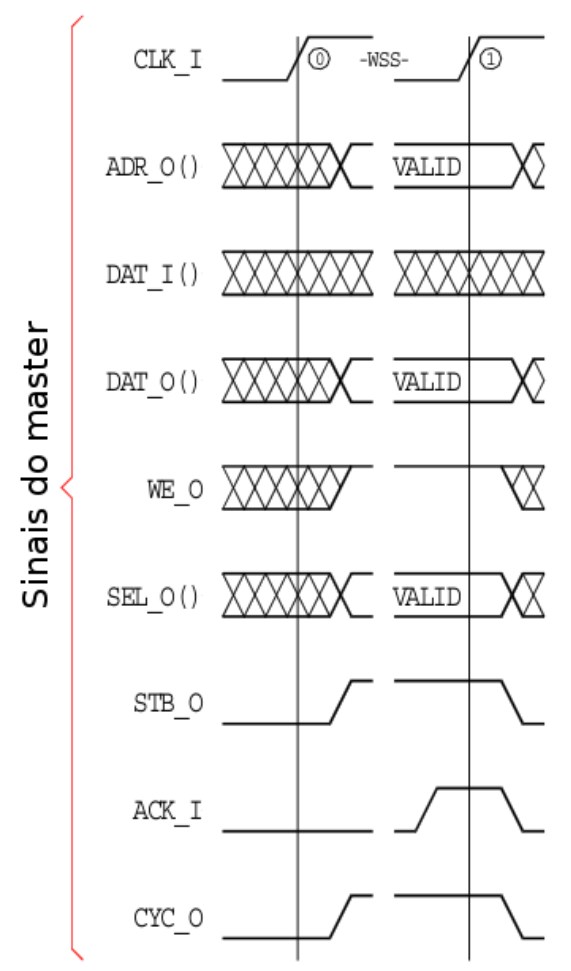

Figura A.3: Sinais de um ciclo clássico de escrita (Herveille, 2002)

Depois, no sinal SEL_O(), o master coloca '1' no bit correspondente ao octeto válido do dado. Caso seja mais de um octeto válido, ele deve preencher todos os bits correspondentes. E como os dois últimos passos do primeiro ciclo de clock, o master ativa os sinais CYC_O e STB_O.

O instante '1' começa com o slave detectando o início de um ciclo de rajada incremental. Com o master monitorando o sinal ACK_I, o slave ativa esse sinal e apresenta um dado válido, correspondente ao endereço do ADR_O() e o octeto do SEL_O(), no sinal DAT_I () .

O instante '2', tem o master validando e adquirindo o dado do sinal DAT_I(). Além disso, ele preenche o campo ADR_O() com o novo endereço ' $\mathrm{N}+4$ '. O slave preenche o dado no sinal DAT_I(), respondendo ao novo endereço apresentado, e mantêm o sinal ACK_I ativado, até que o sinal CTI_O() indique o final do ciclo.

O instantes '3' repete as mesmas instruções dos instantes '2', com a única diferença no sinal ADR_O(), que é preenchido com o endereço ' $\mathrm{N}+8$ '.

No instante '4', o master obtêm o novo dado do sinal DAT_I() e apresenta um novo endereço para o sinal ADR_O(), no caso o 'N + C'. Para indicar o final do ciclo de rajada incremental, o master preenche o sinal CTI_O com '111', que significa end-of-burst. O slave, ainda sem saber do final do ciclo de rajada, preenche o DAT_I() com o dado referente ao ultimo endereço requisitado e mantêm o ACK_I ativo.

No último instante do procedimento, o '5', o master verifica e adquire o dado do sinal DAT_I(), e nega os sinais CYC_O e STB_O, declarando o fim do ciclo. Ao mesmo tempo, 
o slave que possuiu o conhecimento do end-of-burst, nega o sinal ACK_I, finalizando o ciclo com sucesso.

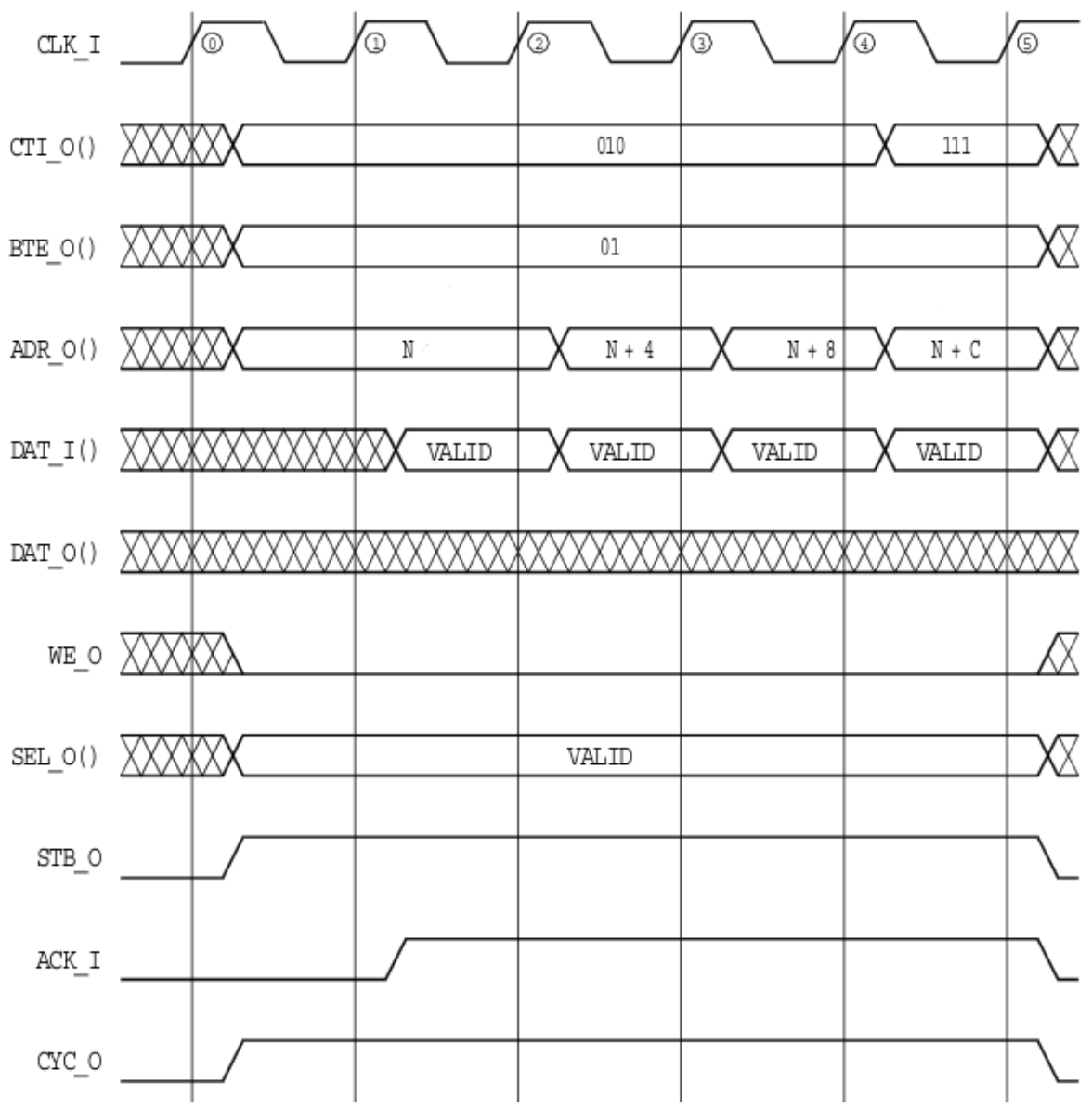

Figura A.4: Sinais de um módulo master realizando uma operação de leitura com ciclo de rajada incremental (Herveille, 2002)

A operação de escrita utilizando um ciclo de rajada incremental pode ser comparada com a operação de leitura exemplificada na Figura A.4. Com a mesma característica de uso do sinal CTI_O(), uma diferença é que o sinal WE_O deve conter nível lógico '1', para indicar uma escrita. Outra diferença é que o master deve informar o dado, que será escrito, no sinal DAT_O() seguindo o mesmo sincronismo do ADR_O(). 